GUSTAVO RUSSO BLAZEK

ESTUDO DA BLENDA POLI(3-HIDROXIBUTIRATO) / POLI(ETILENO GLICOL) 


\section{ESTUDO DA BLENDA POLI(3-HIDROXIBUTIRATO) / POLI(ETILENO GLICOL)}

Dissertação de Mestrado apresentada ao Departamento de Engenharia Metalúrgica e de Materiais da Escola Politécnica da Universidade de São Paulo.

Áreas de Concentração:

ENGENHARIA DE MATERIAIS

Orientador: Profa. Dra. Wang Shu Hui 

Este exemplar foi revisado e alterado em relação à versão original, sob responsabilidade única do autor e com a anuência de seu orientador.

São Paulo 14 de fevereiro de 2012

Assinatura do autor

Assinatura do orientador

FICHA CATALOGRÁFICA

Blazek, Gustavo Russo

Estudo da blenda Poli(3-hidroxibutirato) / Poli(etileno glicol) -- São Paulo, 2012.

$78 \mathrm{p}$.

Dissertação de Mestrado - Escola Politécnica da Universidade de São Paulo. Departamento de Engenharia Metalúrgica e de Materiais

1.Poli(3-hidroxibutirato) 2.Polímeros biodegradáveis 3.Blendas Poliméricas I. Universidade de São Paulo. Escola Politécnica. Departamento de Engenharia Metalúrgica e de Materiais 


\section{AGRADECIMENTOS}

Ao meu pai, Adalbert Victor Blazek (in memoriam), e à minha mãe, Maria Alice Russo Blazek (in memoriam), pela formação que me deram e que me foi e será fundamental durante todas as fases da minha vida.

Aos meus irmãos, Ricardo, Mônica, Renata e Marta, pelo apoio familiar e incentivo que me deram durante as etapas mais difíceis da minha vida.

À professora Wang Shu Hui, primeiramente pela oportunidade, pelo tempo disponibilizado e também pela orientação e persistente ajuda e encorajamento em diversos aspectos e em todos os passos do curso de mestrado.

Ao caro amigo José Manuel Pena Coto, pela excelente impressão e encadernação deste trabalho.

Aos meus amigos, Gabriel Augusto da Matta Ribeiro, Pierre Briquet Caradec, Conrado Cristoph Rössger, Rafael Bechelli Paviato, Henrique Strobl Costa, Nicholas "Teves" Piccoli Zané, Pedro "Jacaré" Garcia Lins, Henrique Carlo Farina, entre outros tantos companheiros de estudos, trabalhos e risadas que me ajudaram a cumprir todas as etapas deste curso, culminando nesta dissertação.

A todos aqueles que contribuíram direta ou indiretamente para a realização deste trabalho. 


\section{RESUMO}

Esse projeto visa a melhoria das propriedades mecânicas e de processabilidade do Poli(3-hidroxibutirato) (PHB) para futuras aplicações.

Foram preparados filmes de blendas de PHB por dissolução em clorofórmio. Poli(etileno glicol), com massa molar de 300 (PEG) ou $4.000 .000 \mathrm{~g} \mathrm{~mol}^{-1}$ (PEO), foi misturado em proporções de 5 a $30 \%$ em massa e análises termogravimétricas (TG), de calorimetria diferencial exploratória (DSC) e ensaios dinâmico-mecânicos (DMTA) foram realizadas para avaliar a miscibilidade da blenda.

Foram também analisados filmes recém-preparados e filmes envelhecidos, para avaliar o avanço da cristalização e consequente alteração das propriedades dos filmes com o passar do tempo. Para isso foram feitas comparações visuais de imagens microscópicas da morfologia das blendas, obtidas através de microscopia eletrônica de varredura (MEV).

As blendas foram analisadas quanto ao grau de cristalinidade através de análise calorimétrica (DSC) e de difratometria de raio-X.

As curvas de DSC mostram uma redução da $T_{m}$ do PHB com a adição de $P E G$ e PEO, o que indica uma forte interação entre os polímeros.

As análises de TG mostram uma etapa principal de degradação, evidenciando a miscibilidade entre os polímeros. A TG também mostra uma sensível redução na temperatura de degradação do PHB para concentrações acima de 10 \% em PEG, o que é indesejável.

Através do MEV nota-se que existe também uma segregação de fases que aumenta com o tempo de estocagem do material, levando à recristalização do PHB e sua consequente fragilização.

A difração de raios-X nos mostra que a adição de PEG e PEO ao PHB traz uma redução considerável para a cristalinidade do sistema, e que o aumento de $5 \%$ para $30 \%$ no teor de PEG é responsável por apenas uma pequena redução na cristalinidade, mas uma considerável redução na recristalização sofrida pela blenda com o tempo de estocagem.

As análises de DMTA mostram que as blendas possuem módulo de armazenamento similar ao de polímeros flexíveis, evidenciando uma efetiva tenacificação do PHB. Amostras utilizando PEO apresentam maior rigidez do que as amostras contendo PEG. 


\section{ABSTRACT}

This project aims the enhancement of both processability and mechanical properties of poly(3-hydroxybutyrate) (PHB) for future applications.

Films of blends of PHB and poly(ethylene oxide) were prepared by chloroform solution casting and evaporation. Poly(ethylene oxide) having molar mass of $4,000,000$ (PEO) or 300 g.mol ${ }^{-1}$ (PEG) was blended in proportion of 5 to $30 \mathrm{wt} \%$, Thermogravimetric Analysis (TG), Differential Scanning Calorimetry (DSC) and Dynamic-Mechanic Analysis (DMTA) were performed in order to evaluate the miscibility of the blends.

As-cast and aged films were also compared in order to analyze the crystallization progress and the consequent changes in the blends properties due to the aging process. For this, visual comparison was drawn between microscopy pictures obtained through scanning electron microscopy (SEM).

The blends have their crystallinity degree determined by analyzing their X-ray diffraction curves.

The DSC curves show a reduction at the PHB's $T_{m}$ as the mass percentage of $P E G$ increases, indicating a strong interaction in between the polymers.

The TG and DTG analyses reveal a single main degradation step, what denotes miscibility in between the polymers. The TG also shows a considerable reduction of the PHB's degrading temperature for PEG concentrations over $10 \%$, which is undesirable.

Through SEM one can note a phase segregation that increases with storaging time, leading to further crystallization of PHB and its subsequent enbrittlement.

The X-ray diffraction curves show that the PEG and PEO bring a considerable crystallinity reduction to the system, and that the increasing of PEG content from 5 to $30 \%$ has only a minor effect per se, though also a considerable reduction of the perfection undergone by the system with storage time.

The DMTA shows that the blends have a storage modulus similar to the one of flexible polimers, hence showing an effective PHB toughening. Samples containing $\mathrm{PEO}$ are more rigid than those containing PEG. 


\section{Sumário}

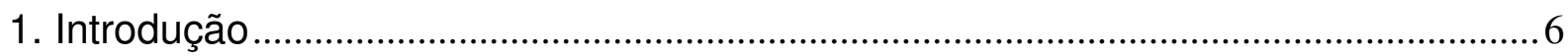

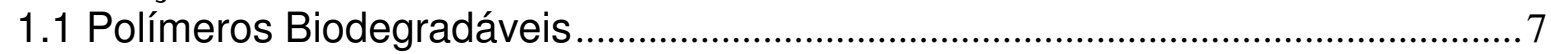

1.1.1 Polímeros biodegradáveis sintéticos ..............................................................

1.1.2 Polímeros biodegradáveis naturais...................................................................

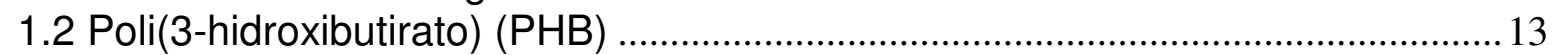

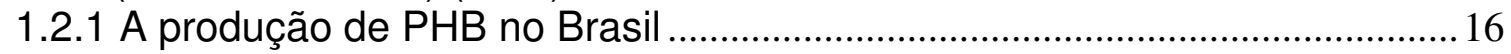

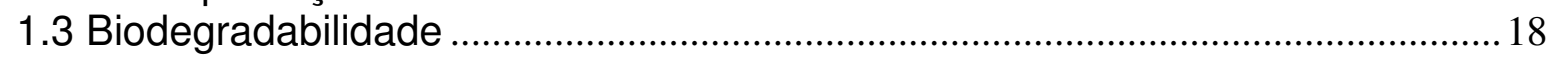

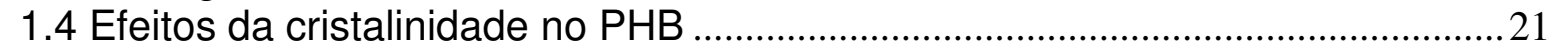

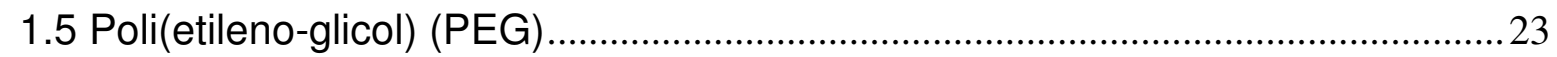

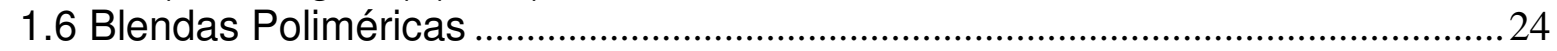

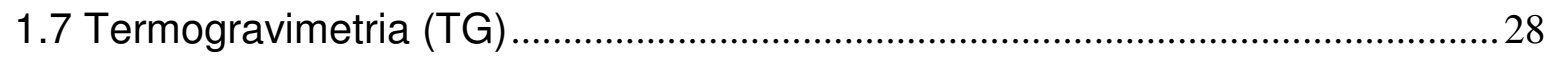

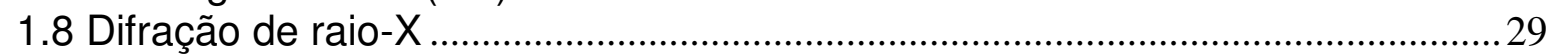

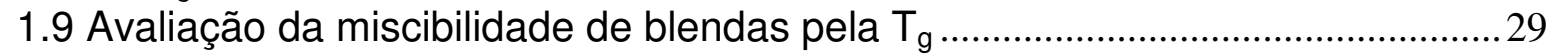

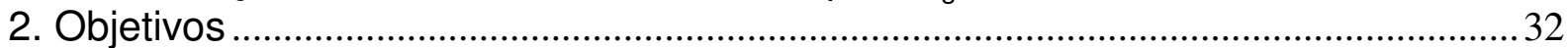

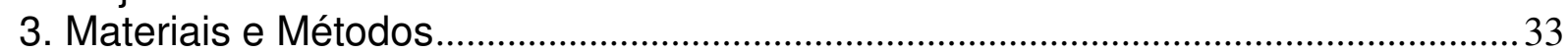

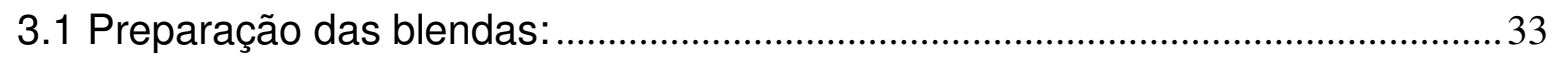

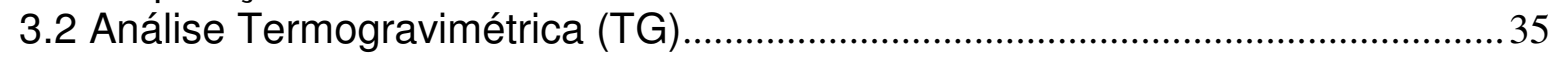

3.3 Microscopia Eletrônica de Varredura (MEV) ………………………........................36

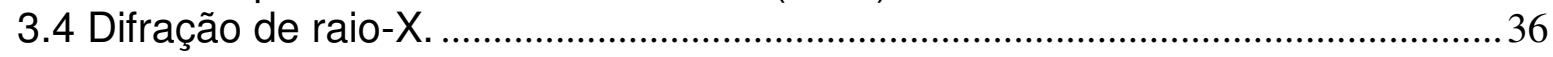

3.5 Calorimetria Diferencial Exploratória (DSC) ……………………………................ 37

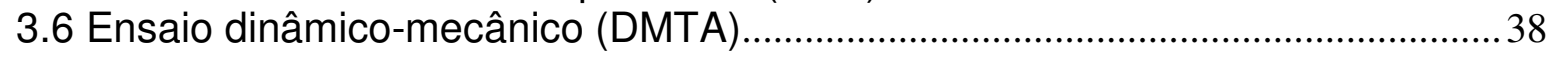

4. Resultados e Discussão ........................................................................................ 38

4.1 Análise termogravimétrica (TG) e Termogravimetria diferencial (DTG): ............38

4.2 Microscopia Eletrônica de Varredura (MEV) ………………………......................4 44

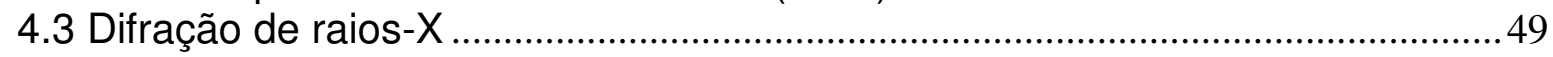

4.4 Calorimetria diferencial exploratória (DSC) ………….......................................5

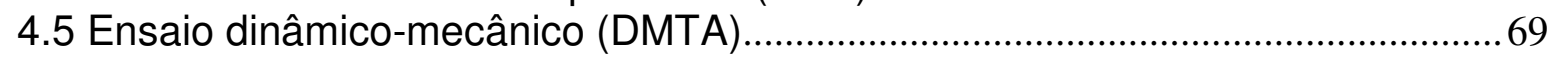

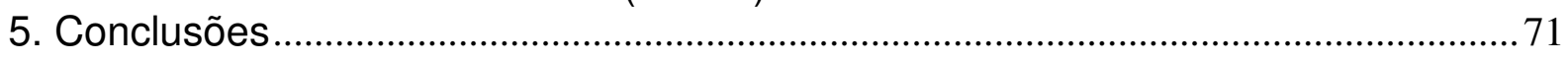

6. Referências Bibliográficas ……………………………………………………….... 74 


\section{Introdução}

Os plásticos têm um papel fundamental na vida moderna. Devido ao fato de serem resistentes, leves, baratos, facilmente processáveis e eficientes energeticamente ${ }^{1}$, os plásticos são utilizados em uma enorme gama de aplicações, incluindo desde aplicações cotidianas (vestuário, bijuterias, embalagens) até aplicações de alta tecnologia (microencapsulamentos, próteses).

Isso faz com que a produção de plásticos cresça cada vez mais e, uma vez que a grande maioria dos plásticos é resistente à degradação biológica, cresça irreversivelmente o volume de resíduos plásticos acumulados em aterros, rios, lagos ou mar, aumentando os custos mundiais para a eliminação dos resíduos e para a preservação do meio ambiente. Esta resistência à degradação biológica se dá porque os microorganismos não possuem enzimas capazes de degradar ou utilizar como insumo a maioria dos polímeros sintéticos, soma-se a isso a pequena área superficial e a inerente alta massa molecular, além da característica hidrofóbica dos plásticos, que inibe a atividade de enzimas ${ }^{1}$.

Nos últimos anos, os polímeros biodegradáveis têm despertado interesse ${ }^{1,2}$, uma vez que geram resíduos que perduram por um tempo bem menor em aterros e compostagens e causam menores danos ao meio ambiente. Atualmente, encontrase em produção vários tipos de polímeros biodegradáveis. Podemos ver descritos na Tabela 1 alguns dos polímeros biodegradáveis disponíveis comercialmente ${ }^{1}$ :

Tabela 1: Polímeros biodegradáveis disponíveis comercialmente ${ }^{1}$

\begin{tabular}{|c|c|c|c|c|}
\hline Base & Polímero & Marca & Fornecedor & Origem \\
\hline Amido & $\begin{array}{l}\text { Blenda Amido - } \\
\text { Poli( } \varepsilon \text { - } \\
\text { caprolactona) } \\
\text { (PCL) }\end{array}$ & $\begin{array}{ll}\text { - } & \text { Mater-Bi TM } \\
\text { - } & \text { Bioflex TM }\end{array}$ & $\begin{array}{ll}\text { - } & \text { Novamont } \\
\text { - } & \text { Biotech }\end{array}$ & $\begin{array}{ll}\text { - } & \text { Itália } \\
\text { - } & \text { Alemanha }\end{array}$ \\
\hline Amido & $\begin{array}{l}\text { Blenda Amido - } \\
\text { Poli(álcool } \\
\text { vinílico) (PVOH) }\end{array}$ & $\begin{array}{ll}\text { - } & \text { Noven }^{\mathrm{TM}} \\
\text { - } & \text { Novon }{ }^{\mathrm{TM}} \\
\text { - } & \text { Mater-Bi }{ }^{\mathrm{TM}}\end{array}$ & $\begin{array}{ll}\text { - } & \text { Chisso Corp } \\
\text { - } & \text { Warner Lambert } \\
\text { - } & \text { Novamont }\end{array}$ & $\begin{array}{ll}\text { - } & \text { Japão } \\
\text { - } & \text { EUA } \\
\text { - } & \text { Itália }\end{array}$ \\
\hline Amido & $\begin{array}{l}\text { Polilactídeo } \\
\text { (PLA) }\end{array}$ & $\begin{array}{ll}\text { - } & \text { Lacea } \\
\text { - } & \text { Lucty } \\
\text { - } & \text { Nature }\end{array}$ & $\begin{array}{ll}\text { - } & \text { Mitsui Toatsu } \\
\text { - } & \text { Shimazu } \\
\text { - } & \text { Cargil-Dow }\end{array}$ & $\begin{array}{ll} & \text { Japão } \\
\text { - } & \text { Japão } \\
\text { - } & \text { EUA }\end{array}$ \\
\hline
\end{tabular}




\begin{tabular}{|c|c|c|c|c|}
\hline & & Works & & \\
\hline Amido & $\begin{array}{l}\text { Poli( } \varepsilon- \\
\text { caprolactona) } \\
(\mathrm{PCL})\end{array}$ & $\begin{array}{ll}- & \text { Tone } \\
\text { - } & \text { CAPA } \\
\text { - } & \text { Placeel }\end{array}$ & $\begin{array}{ll}\text { - } & \text { Union Carbide } \\
\text { - } & \text { Solvay } \\
\text { - } & \text { Diacel Chemical }\end{array}$ & $\begin{array}{ll}\text { - } & \text { EUA } \\
\text { - } & \text { Bélgica } \\
\text { - } & \text { Japão }\end{array}$ \\
\hline $\begin{array}{l}\text { Poliéstere } \\
\text { s Alifáticos }\end{array}$ & PBS-PBS-A & $\begin{array}{ll} & \text { Bionelle } \\
\text { - } & \text { Skygreen } \\
\text { BDP }\end{array}$ & $\begin{array}{ll}\text { - } & \text { Showa } \\
\text { Highpolymer } \\
\text { - } & \text { SK Polymer }\end{array}$ & $\begin{array}{l}\text { - Japão } \\
\text { - } \quad \text { Coréia }\end{array}$ \\
\hline $\begin{array}{l}\text { Poliéstere } \\
\text { s Alifáticos }\end{array}$ & $\begin{array}{l}\text { Copolímero } \\
\text { (hidroxibutirato- } \\
\text { co- } \\
\text { hidroxihexanoat } \\
\text { o) }\end{array}$ & - $\quad$ Nodax ${ }^{\mathrm{TM}}$ & $\begin{array}{ll} & \text { Procter \& } \\
\text { Gamble e } \\
\text { Kaneka Corp }\end{array}$ & 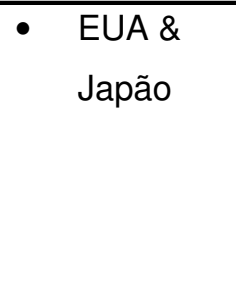 \\
\hline $\begin{array}{l}\text { Poliéstere } \\
\text { s Alifáticos }\end{array}$ & $\begin{array}{l}\text { Poli(3- } \\
\text { hidroxibutirato) }\end{array}$ & - Biocycle & - $\mathrm{PHB}$ Industrial & - $\quad$ Brasil \\
\hline $\begin{array}{l}\text { Poliéstere } \\
\text { s Alifáticos }\end{array}$ & PHB/PHBV & $\begin{array}{ll}- & \text { Mirel } \\
\text { - } & \text { Enmat } \\
\text { - } & \text { Biomer L }\end{array}$ & $\begin{array}{ll}\text { - } & \text { Metabolix/ADM } \\
\text { - } & \text { Tianan } \\
\text { - } & \text { Biomer }\end{array}$ & $\begin{array}{ll}- & \text { EUA } \\
\text { - } & \text { China } \\
\text { - } & \text { Alemanha }\end{array}$ \\
\hline
\end{tabular}

\subsection{Polímeros Biodegradáveis}

Estes polímeros são materiais degradáveis, nos quais a degradação resulta da ação de microrganismos, tais como fungos, bactérias e algas de ocorrência natural, gerando $\mathrm{CO}_{2}, \mathrm{CH}_{4}$, componentes celulares e outros produtos, segundo estabelecido pela "American Standard for Testing and Methods" (ASTM-D-833) $\mathrm{Ou}$ de outro modo, são materiais que se degradam em $\mathrm{CO}_{2}, \mathrm{H}_{2} \mathrm{O}$ e biomassa, como resultado da ação de organismos vivos ou enzimas ${ }^{5}$.

Descobertos há cerca de 20 anos, os plásticos biodegradáveis, também denominados plásticos biológicos ou bioplásticos ${ }^{6}$, hoje ainda têm uma participação mínima no mercado internacional ${ }^{7}$.

Apesar da vantagem de sua aplicação quanto à preservação do meio ambiente, os plásticos biológicos são mais caros, e têm aplicações mais limitadas que os sintéticos, por serem menos flexíveis ${ }^{8}$.

Em meados da década de 90, iniciou-se no Brasil o desenvolvimento de uma tecnologia para produção de plásticos biodegradáveis empregando como matériaprima derivados da cana-de-açúcar, a partir de um projeto cooperativo desenvolvido pelo IPT, Copersucar e Universidade de São Paulo. Desta parceria, iniciou-se um 
estudo, com os polímeros da família dos poli(hidroxialcanoatos) (PHAs), que podem ser produzidos por bactérias em biorreatores a partir de açúcares.

Tais polímeros possuem propriedades semelhantes às dos plásticos petroquímicos, com a vantagem de poderem ser biodegradados por microrganismos presentes no meio ambiente, em curto espaço de tempo, após o descarte ${ }^{8}$. 0 principal representante dos PHAs é o poli(3-hidroxibutirato) (PHB), semelhante ao polímero sintético, polipropileno (PP), em propriedades físicas e mecânicas ${ }^{8}$.

O interesse por estes polímeros tem crescido muito nos últimos tempos, no mundo todo. Apesar disto, o alto custo de sua produção ainda é uma grande desvantagem em relação aos polímeros convencionais, basta comparar o custo de produção do PHB estimado a US\$2,65/kg para uma planta de 100.000 t/ano, com uso de sacarose como substrato, com o valor do polipropileno US\$1,00/ $\mathrm{kg}^{3,9}$. Outras estimativas preliminares apresentam um custo de produção de US $\$ 5,85 / \mathrm{kg}$ para uma planta de 30.000 t/ano ${ }^{10,11}$. O custo dos PHAs, utilizando $A$. eutrophus é de US\$ $16 / \mathrm{kg}$, isto é 18 vezes mais que o polipropileno ${ }^{6}$. Com E. coli o preço pode ser reduzido a US $\$ 4 / \mathrm{kg}$, um custo semelhante a materiais plásticos biodegradáveis, tais como o poli(ácido lático) (PLA) e a poli(ع-caprolactona) (PCL).

A produção de PHB demanda $3 \mathrm{~kg}$ de sacarose $/ \mathrm{kg}$ do produto final, sendo que o preço do açúcar representa $29 \%$ do custo final do produto (sem considerar taxas) ${ }^{9}$, portanto, o custo médio de produção do PHB varia em função do tipo de açúcar empregado, do preço do açúcar, do microrganismo utilizado e da planta de produção ${ }^{9}$.

Os polímeros biodegradáveis podem ser agrupados em duas classes principais $^{8}$ : naturais e sintéticos

\subsubsection{Polímeros biodegradáveis sintéticos}

Esta classe de polímeros tem sido muito empregada em usos biomédicos, tais como cápsulas de liberação controlada de droga em organismos vivos, fixadores em cirurgias (suturas, clips, pinos para ossos) e para embalagens especiais. Os polímeros mais usados têm sido poli(ácido láctico) (PLA), poli(ácido glicólico) (PGA), poli(ácido glicólico-ácido láctico) (PGLA), poli( $\varepsilon$-caprolactona) (PCL) (Figura 1) ${ }^{12,8}$. 


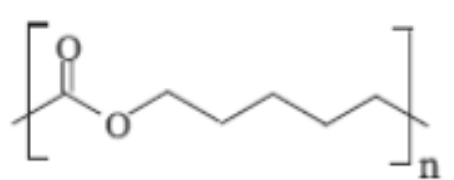

(a)

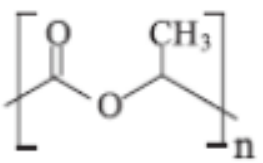

(b)

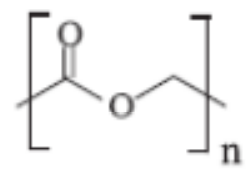

(c)

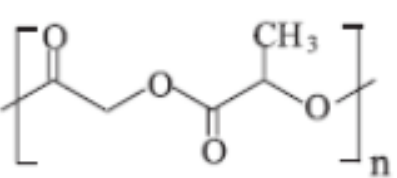

(d)

Figura 1 - Estrutura química de: a) poli(ع-caprolactona) (PCL); b) poli(ácido láctico) (PLA); c) poli(ácido glicólico) (PGA) e, d) poli(ácido glicólico-láctico) (PGLA)

Estes polímeros são ésteres alifáticos biodegradáveis, por possuírem cadeias carbônicas hidrolisáveis. Se a biodegradação se der por meio da ação de enzimas, a cadeia polimérica deve se ajustar aos sítios ativos das enzimas, e isto é favorecido pela flexibilidade das cadeias poliméricas alifáticas, o que não ocorre com os poliésteres aromáticos. PLA, PGA e PGLA são poliésteres muito utilizados em suturas absorvíveis dentro de um sistema vivo, sendo que uma grande vantagem é a sua biodegradabilidade por hidrólise simples da cadeia de éster em meio aquoso, ou seja, nos fluidos corporais ${ }^{8}$. PCL foi muito estudado como substrato para biodegradação e como matriz para liberação controlada de drogas. PCL é biodegradado através da hidrólise enzimática, por fungos ${ }^{8}$.

\subsubsection{Polímeros biodegradáveis naturais}

Polímeros formados durante o ciclo de crescimento de organismos vivos são, então, denominados polímeros naturais. Sua síntese envolve, geralmente, reações catalisadas por enzimas e reações de crescimento de cadeia a partir de monômeros ativados, que são formados dentro das células por processos metabólicos complexos. 


\subsubsection{Polissacarídeos}

Os principais polissacarídeos de interesse comercial são celulose (Fig. 2) e amido, havendo uma atenção especial aos carboidratos mais complexos: quitosanas, quitinas e xantanas ${ }^{8}$. Comparando-se as estruturas de alguns destes polímeros, verifica-se que são formados por unidades básicas de glicose, ligadas como anéis de grupos acetais (aldeído e álcool) (Fig. 2) e, portanto, com grande quantidade de grupos hidroxilas (alta hidrofilicidade). A celulose é um polissacarídeo formado de unidades de glicose, presente em madeira, papel e algodão.

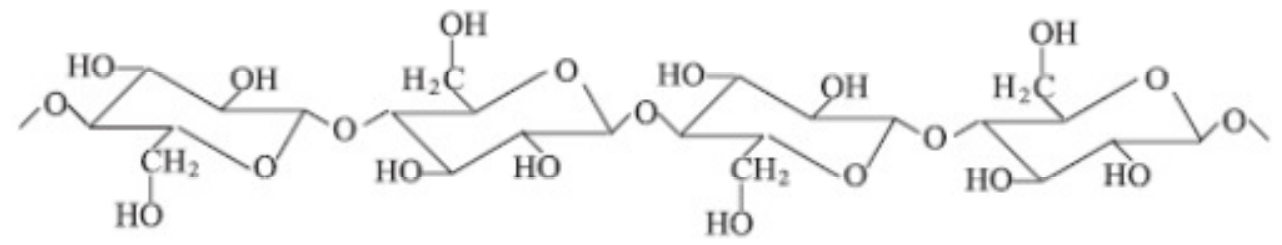

Figura 2 - Estrutura da celulose

Os outros polissacarídeos têm estrutura semelhante à da celulose. A quitina é uma molécula complexa encontrada nos crustáceos: caranguejos, siris, lagostas, camarões. Também está presente em insetos, fungos, cogumelos e minhocas. A quitosana é um polímero derivado da quitina, utilizado em aplicações médicas e em dietas de perda de peso. Possui uma significativa compatibilidade com tecidos vivos e melhora a cicatrização de ferimentos. A xantana, por sua vez, é polímero comercial hidrofílico, muito utilizado como espessante e estabilizante, em cosméticos e alimentos e como cápsulas para liberação controlada de drogas ${ }^{13,14}$.

Estes polímeros naturais são degradados na natureza por fungos, que podem secretar enzimas, que catalisam reações de oxidação da celulose e do amido. As bactérias podem secretar endo e exoenzimas para degradar este tipo de macromolécula. Além disso, uma mistura de fungos e bactérias pode agir cooperativamente, isto é, microrganismos específicos degradam a celulose à glicose que, por sua vez, chega aos produtos finais da degradação $\mathrm{CO}_{2}$ e água ${ }^{8}$.

O amido, outro polissacarídeo, tem sido utilizado disperso em uma matriz polimérica não-biodegradável, usualmente, polietileno (PE), para facilitar a acessibilidade dos microrganismos ao polímero sintético ${ }^{8,15}$. O amido é adicionado como aditivo, sendo degradado facilmente por microrganismos, provocando a 
degradação parcial da matriz ${ }^{15}$. Amido de batata adicionado a filmes de polietileno de baixa densidade (PEBD) melhorou a biodegradabilidade destes filmes ${ }^{16}$. A adição de amido a resinas de isocianatos reduziu o custo de produção e melhorou sua resistência à solventes ${ }^{8}$. A adição de amido a amostras semi-cristalinas de poli(álcool vinílico) (PVA) levou ao consumo de algumas estruturas amorfas do PVA, juntamente com o amido, durante a biodegradação ${ }^{17}$.

\subsubsection{2 Ácidos algínicos}

Estes ácidos são formados de monômeros de ácidos manurônico e gulurônico. São solúveis em água e tornam-se insolúveis na presença de cátions, como cálcio, berílio, alumínio e ferro, formando géis, que podem servir para liberação controlada de drogas em sistemas vivos, bem como para encapsulamento de herbicidas, microrganismos e células $^{8}$. Estes ácidos estão representados na Figura 3.

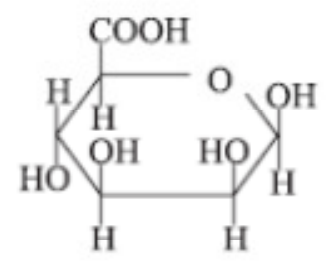

(a)

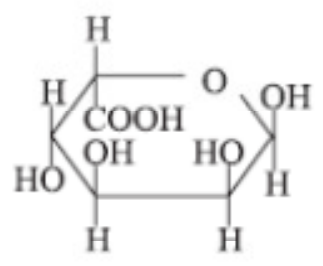

(b)

Figura 3 - Estrutura química de ácidos algínicos: a) ácido manurônico, b) ácido gulurônico

\subsubsection{Polipeptídeos naturais}

As gelatinas são polímeros biodegradáveis, constituído por proteínas do tipo animal, com grande aplicação industrial, farmacêutica e biomédica, empregados como coberturas e microencapsulação de drogas e no preparo de hidrogéis ${ }^{8}$. Na conformação $\beta$, as proteínas apresentam a cadeia polipeptídica estendida em uma estrutura em zigue-zague, denominada de folha $\beta^{18}$, mantida por ligações de hidrogênio, como ilustrado na Figura 4. 


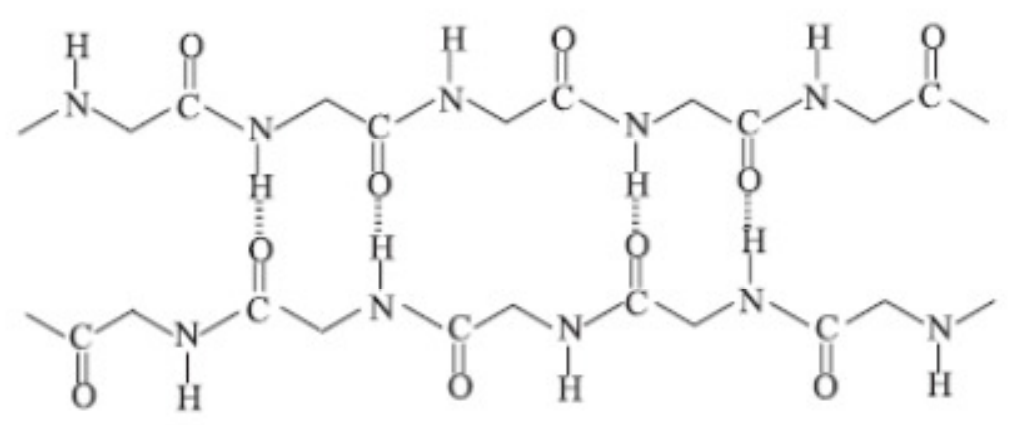

Figura 4 - Conformação $\beta$ das cadeias polipeptídicas

\subsubsection{Poliésteres bacterianos}

Poliésteres naturais, que são produzidos por uma grande variedade de bactérias, como materiais de reserva intracelular, têm sido alvo de muita atenção para aplicações comerciais, como polímeros biodegradáveis, vantajosamente produzidos por fontes renováveis.

Esta classe de poliésteres alifáticos, a qual pertencem os poli(hidroxialcanoato)s (PHAs), também denominados biopolímeros ou bioplásticos, mostra uma grande variação em suas propriedades, isto é, de materiais rígidos e quebradiços a plásticos com boas propriedades de impacto ou até elastômeros resistentes, dependendo do tamanho dos grupos alquilas laterais e da composição do polímero ${ }^{6,8}$. Os poli(hidroxialcanoato)s mais conhecidos são poli(3-hidroxibutirato) (PHB), poli(3-hidroxivalerato)(PHV) e poli(hidroxibutirato-co-valerato) (PHB-V), sendo este último conhecido comercialmente como Biopol. Suas estruturas químicas podem ser vistas na Figura 5.

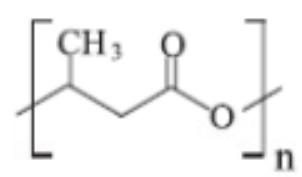

(a)

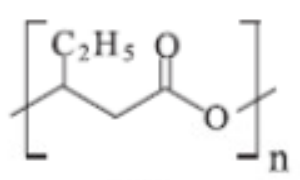

(b)

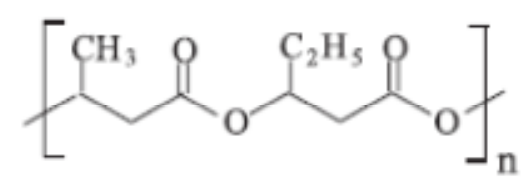

(c)

Figura 5 - Estrutura química dos poli(hidroxialcanoato)s (PHAs): a) poli(3-hidroxibutirato); b) poli(3hidroxivalerato) e, c) poli(3-hidroxibutirato-co-valerato) 
Estes poliésteres têm sido sintetizados por vários tipos de microrganismos, tais como Alcaligenes eutrophus ${ }^{19}$, Ralstonia eutropha ${ }^{20}$, Alcaligenes lótus, Comamonas acidvorans ${ }^{12}$ e Pseudomonas putida ${ }^{21}$ em meios apropriados, como material de reserva de energia e têm como principais vantagens sua biocompatibilidade e biodegradabilidade ${ }^{22}$.

PHB é um polímero muito cristalino com alta temperatura de fusão $\left(T_{m}=177^{\circ}\right.$ C) e temperatura de transição vítrea $\left(T_{g}\right)$ de cerca de $5{ }^{\circ} \mathrm{C}$. Isto torna os filmes de PHB muito quebradiços, o que pode ser melhorado utilizando-se o copolímero PHBV (Biopol). Este copolímero foi sintetizado pela primeira vez pela ICI (UK) em 1983 e, em 1990, garrafas deste material foram produzidas na Alemanha, para embalar shampoo ${ }^{12}$.

O preço corrente do Biopol na Inglaterra é de £8000/t, comparado com £500/t de outros polímeros comuns como poli(cloreto de vinila) (PVC) e polipropileno (PP) e $£ 600 / t$ para polietileno de alta densidade (PEAD) e poliestireno (PS) ${ }^{12}$. Poliésteres microbianos são relativamente resistentes à hidrólise química, mas são suscetíveis ao ataque bacteriológico, o que restringe o seu uso para embalar alimentos. Entretanto, o PHBV tem excelentes propriedades de barreira contra gás e pode ser usado associado com camadas de gelatinas metacrílicas, que conferem ao produto uma baixa permeabilidade a oxigênio, alta resistência à água em ebulição e boa capacidade de adesão ${ }^{12}$.

\subsection{Poli(3-hidroxibutirato) (PHB)}

Dentre os polímeros biodegradáveis, o poli(3-hidroxibutirato) se destaca por apresentar um grande potencial em aplicações como plástico biodegradável e biocompatível $^{23}$, na área médica (implantes) ${ }^{24,25}$, farmacêutica (micro encapsulamentos) $^{26}$, copos e garrafas descartáveis ${ }^{27}$, tintas, têxteis e, principalmente, na área de filmes para embalagens de alimentos ${ }^{28}$.

O poli(3-hidroxibutirato) - PHB ou $\mathrm{P}(3 \mathrm{HB})$ pertence à família dos poliésteres alifáticos e pode ser produzido por uma variedade de algas e microorganismos, através da fermentação bacteriana ${ }^{1}$. É um poliéster termoplástico duro e quebradiço, com propriedades físicas comparáveis ao polipropileno, por possuir ponto de fusão, grau de cristalinidade e temperatura de transição vítrea similares ${ }^{29}$. 
Lemoigne do instituto Pasteur (1925) foi o primeiro a descrever o isolamento de um poliéster alifático - poli(3-hidroxibutirato) (PHB), do citoplasma de bactérias Alcaligenes eutrophus. O polímero é produzido como reserva de energia ${ }^{1}$.

O PHB e outros PHAs são acumulados em grânulos esféricos discretos no citoplasma celular e a proporção mássica, entre o peso do polímero e o peso total da bactéria seca, pode atingir $90 \% 1$.

A Fig. 6, retirada do site da biocycle, traz o fluxograma do processo de produção do PHB.

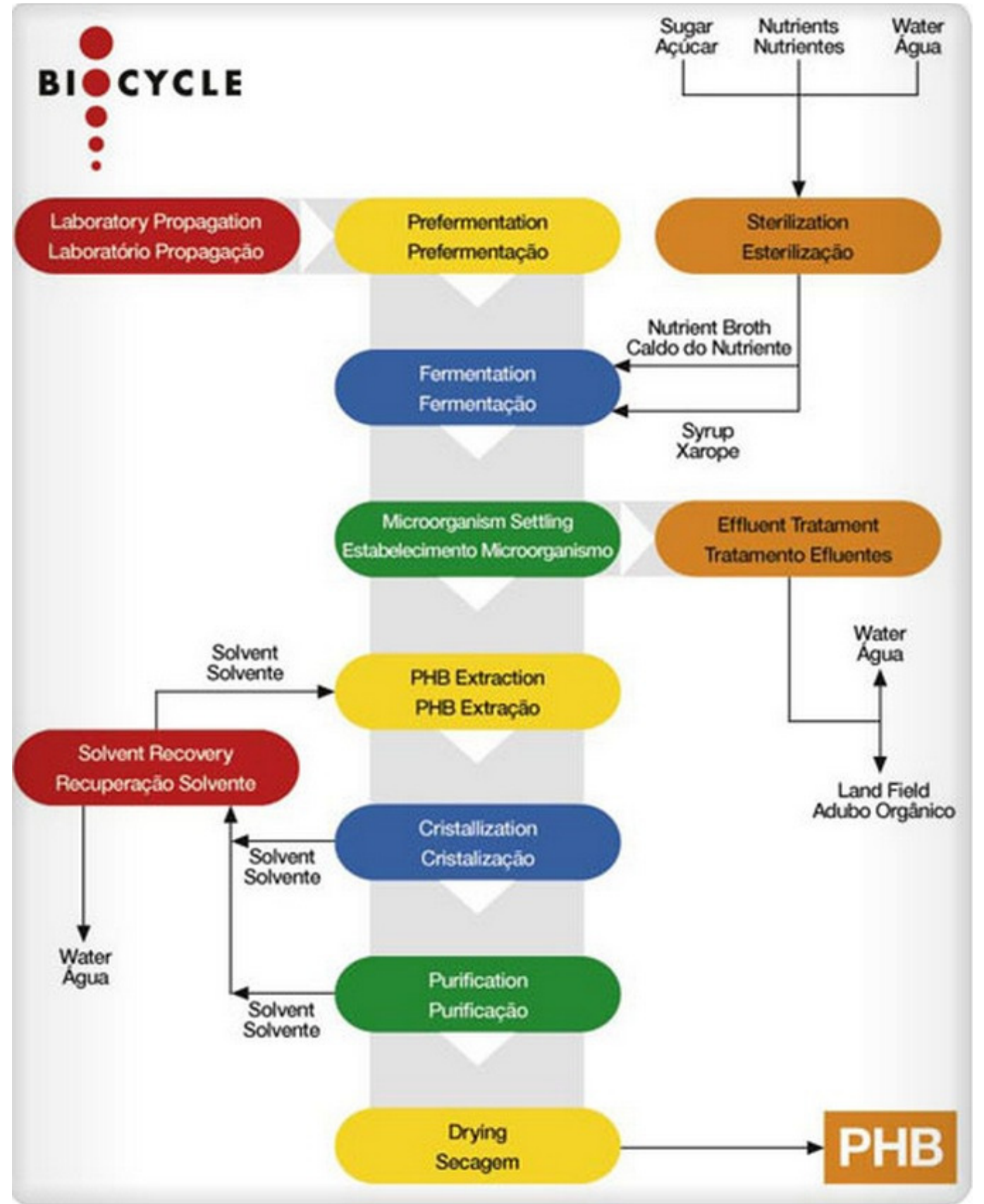

Figura 6: Fluxograma de produção do $\mathrm{PHB}^{30}$ 
O PHB é $100 \%$ isotático e similar ao polipropileno isotático, sua massa molecular varia entre 10.000 e $3.000 .000 \mathrm{~g} / \mathrm{mol}$, sendo sua massa molar crítica, valor inferior ao qual o material apresenta perda acentuada de propriedades, considerada em torno de $160.000 \mathrm{~g} / \mathrm{mol}$. Possui um grupo metila pendente fixado na cadeia principal numa configuração unitária, como mostra a Fig. $7^{1}$. Apresenta uma configuração em hélice estabilizada pela interação dos grupos metila e carboxila, representando uma das poucas exceções da natureza que não dependem da ligação de hidrogênio para sua formação e estabilidade. ${ }^{1}$<smiles>CC(O)CC(=O)O</smiles>

Figura 7: Estrutura química do $\mathrm{PHB}^{1}$

Este polímero possui características que, se melhoradas, podem torná-lo um polímero com ampla aplicação tecnológica ${ }^{1}$, os filmes de PHB apresentam baixa permeabilidade ao $\mathrm{O}_{2}$, vapor d'água e ao $\mathrm{CO}_{2}$, características altamente desejáveis para filmes de embalagens de alimentos. Suas propriedades físicas e mecânicas são comparáveis às do polipropileno, além disso, o PHB não é solúvel em água, porém é $100 \%$ biodegradável. Entre as características que dificultam a sua utilização estão a fragilidade na aplicação em embalagens e filmes (quebradiço e duro) ${ }^{1}$, reflexo de sua alta cristalinidade (acima de $60 \%$ ), que aumenta ainda mais quando estocado a temperatura ambiente, e também a sua limitada janela de processabilidade ${ }^{1}$, que dificulta a sua conformação.

O processamento do PHB é limitado pela temperatura de fusão cristalina, aproximadamente $177^{\circ} \mathrm{C}$, o qual requer uma temperatura da ordem de $190^{\circ} \mathrm{C}$. Sob estas condições a massa molar do PHB diminui rapidamente devido à sua degradação. Assim é necessário reduzir ao máximo o tempo de residência e a temperatura de exposição do material, sendo recomendado menos de 3 minutos a $170{ }^{\circ} \mathrm{C}^{1}$.

O desenvolvimento de blendas de polímeros biodegradáveis com um balanço ótimo de propriedades físicas e biodegradabilidade, num custo próximo dos polímeros convencionais é o fator chave para a resolução de problemas ambientais decorrentes dos resíduos gerados de plásticos não-biodegradáveis. 
A técnica de mistura com outros polímeros vem sendo muito estudadas, por exemplo, blendas de PHB com poli(óxido de etileno), poli(fluoreto de vinila), poli(acetato de vinila), poli(álcool vinílico), poli(metacrilato de metila) entre outros, visando a flexibilização do PHB, foram estudados por Ghaffar ${ }^{31}$, An et al $^{32}$ e Rosa et $\mathrm{al}^{33}$. Estes componentes não biodegradáveis limitam a biodegradabilidade da blenda. Poliésteres sintéticos alifáticos, como poliglicóis, poli(L-lactídeo), poli(Dlactídeo) e poli(ع-caprolactona) podem ser usados como elementos de blenda com PHB sem afetar sua degradabilidade.

\subsubsection{A produção de PHB no Brasil}

O PHB é produzido no Brasil pela PHB Industrial S.A. (PHBISA), na Usina da Pedra, sob a marca BIOCYCLE $^{\circledR}$, utilizando uma tecnologia desenvolvida, patenteada e licenciada pelo Instituto de Pesquisas Tecnológicas (IPT). O modelo de integração da produção de PHB tem uma grande importância para o setor sucroalcooleiro no Brasil, incluindo disponibilidade de energia (elétrica e térmica) de fontes renováveis, gerenciamento efetivo de resíduos e efluentes, disponibilidade de açúcar em grande quantidade e a preços baixos. O diagrama abaixo ilustra esta integração.

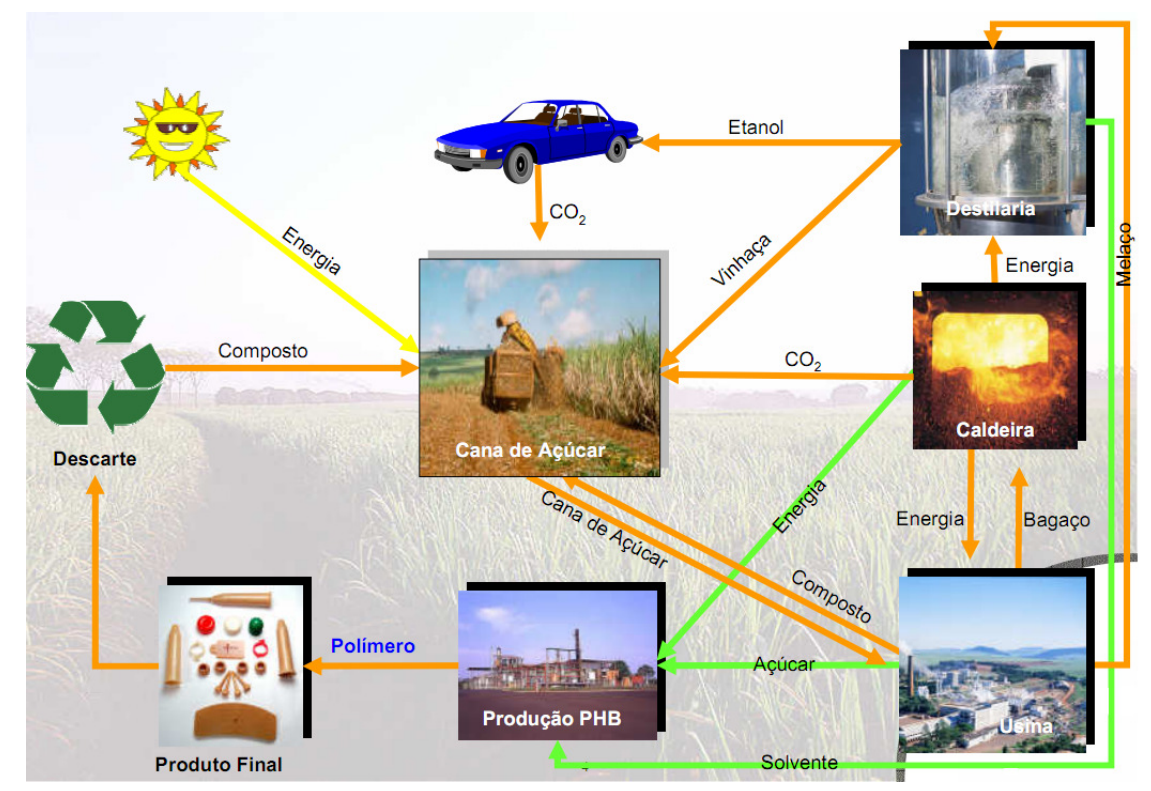

Figura 8: Integração do processo sucro-alcooleiro. ${ }^{34}$

Esta integração no processo de produção traz não somente vantagens econômicas mas torna o PHB um polímero ainda mais ambientalmente correto, uma vez que, para cada tonelada de PHB produzido, são resgatadas cerca de 4,4 
toneladas de $\mathrm{CO}_{2}{ }^{34}$. Quando comparada com a produção de outros polímeros, a produção de PHB neste modelo integrado consome, por exemplo, apenas $10 \%$ da energia não renovável consumida na produção de polipropileno ${ }^{34}$.

Outro interessante aspecto da integração da produção de PHB na produção de açúcar e álcool é, como ilustrado na Figura 8, a disponibilidade de solvente natural para a purificação do $\mathrm{PHB}$, subproduto da fermentação do etanol ${ }^{35}$.

Em 2008, a PHBISA previa o início de operação de uma nova planta para produzir 10 mil toneladas/ano de plástico biodegradável derivado de açúcar, o que acabou não se concretizando ${ }^{35}$.

A marca BIOCYCLE ${ }^{\circledR}$ produz PHB em quatro gradações diferentes, visando diferentes processamentos ${ }^{30}$ :

- Biocycle 189D-1, exclusiva para processo de injeção;

- Biocycle 189C-1, para injeção e extrusão de chapas;

- Biocycle 18BC-1, para injeção, extrusão e termoformagem; e

- Biocycle 1000, voltado para a substituição de Poliuretanos.

Em esforços conjuntos com diversas empresas que atuam no cenário nacional, a PHBISA já produziu diversos produtos tendo PHB como material-base em escala pré-comercial. A tabela abaixo traz uma breve descrição dos processamentos e aplicações já realizadas:

Tabela 2: Produtos baseados em $\mathrm{PHB}^{34}$

\begin{tabular}{|c|c|c|}
\hline Polímero substituído & Processo & Produtos \\
\hline - Polipropileno & $\begin{array}{ll}\text { - } & \text { Extrusão } \\
\text { - } & \text { Termoformagem } \\
\text { - } & \text { Injeção }\end{array}$ & $\begin{array}{l}\text { - } \text { Tubetes } \\
\text { - Peças automotivas } \\
\text { - Peças para crescimento } \\
\text { monitorado } \\
\text { - Brinquedos } \\
\text { - Embalagens }\end{array}$ \\
\hline - Poliestireno & - $\quad$ Termoformagem & $\begin{array}{l}\text { - } \text { Bandejas para plantas } \\
\text { - } \quad \text { Talheres descartáveis }\end{array}$ \\
\hline - Poliuretano & $\begin{array}{ll}\text { - } & \text { Injeção } \\
\text { - } & \text { Extrusão }\end{array}$ & $\begin{array}{l}\text { Elastômeros e espumas } \\
\text { - Isolantes (construção) } \\
\text { - Sapatos } \\
\text { - Peças automotivas }\end{array}$ \\
\hline - $\mathrm{ABS}$ & $\begin{array}{ll}\text { - } & \text { Extrusão } \\
\text { - } & \text { Termoformagem }\end{array}$ & $\begin{array}{l}\text { - Cartões (crédito, comercial, } \\
\text { telefônico) }\end{array}$ \\
\hline
\end{tabular}


Entre os produtos supracitados, dois bons exemplos de aplicação prática são os tubetes e braçadeiras para crescimento monitorado, voltados para programas de reflorestamento e para a indústria de papel e celulose, mostrados na Figura 9:

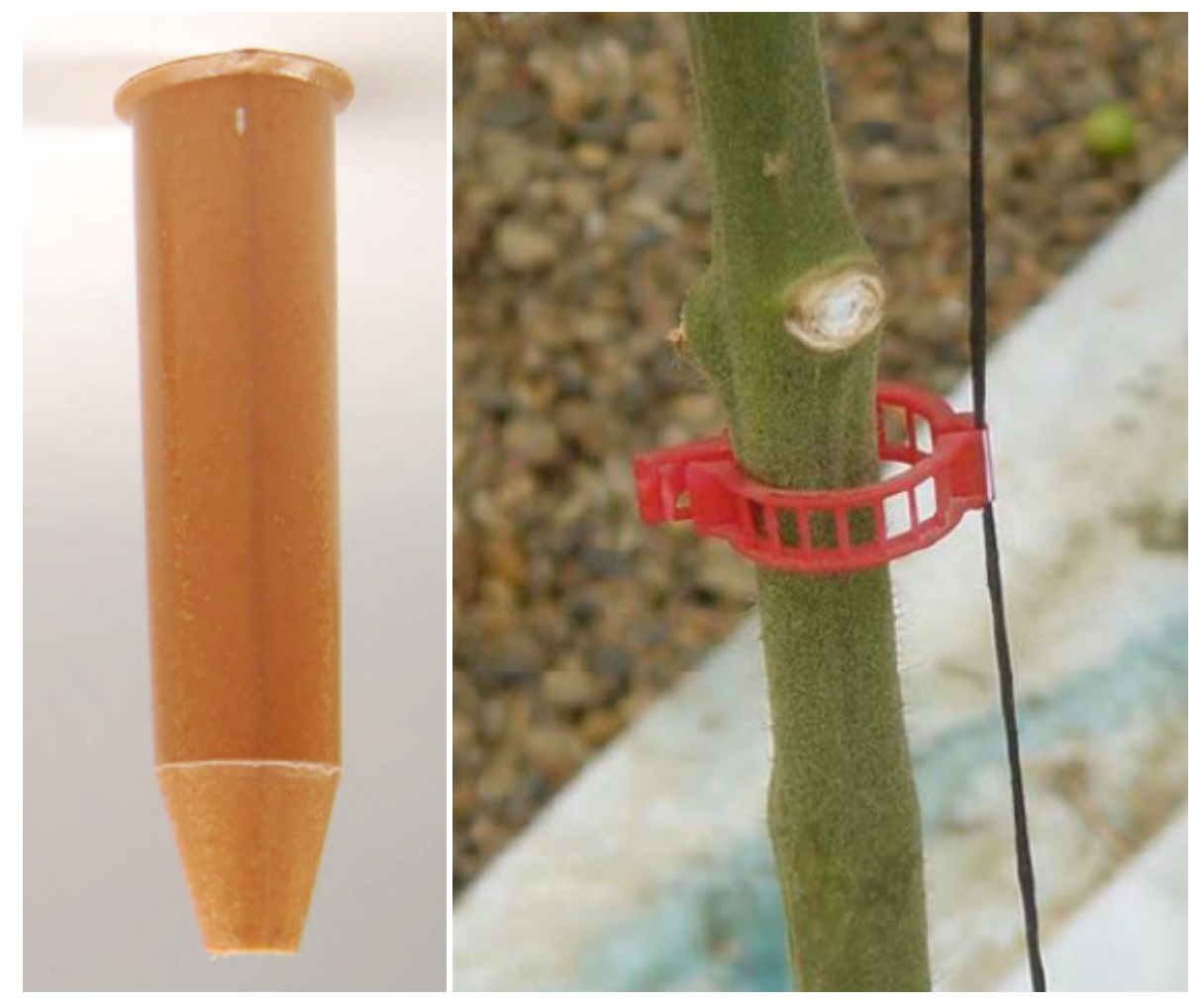

Figura 9: Tubete (a esquerda) e braçadeira para crescimento controlado (a direita), utilizados em programas de reflorestamento. ${ }^{34}$

De acordo com a PHB do Brasil, o PHB pode alcançar nos próximos anos algo entre $1 \%$ a $2 \%$ do mercado do polipropileno, que representa, atualmente, cerca de 200 milhões de toneladas por ano ${ }^{35}$.

\subsection{Biodegradabilidade}

Biodegradabilidade é um processo natural e irreversível, onde substâncias são convertidas em moléculas mais simples, e retornam aos ciclos elementares da natureza, como o ciclo do carbono, do enxofre e do nitrogênio ${ }^{1}$. A conversão pode ocorrer em diversos ambientes (solo, esgoto, rios, etc...), por ação de fungos e bactérias aeróbicas ou anaeróbicas. Mais especificamente, o termo é aplicado a polímeros rapidamente degradados em $\mathrm{CO}_{2}$, água e biomassa, via microorganismos aeróbicos ou anaeróbicos associados a nutrientes do ambiente, geralmente, o solo.

O processo global de biodegradação compreende duas etapas: 
1) Fragmentação (quebra em porções pequenas por fatores abióticos): 0 polímero é fragmentado em tamanho suficiente, aproximadamente $1000 \mathrm{Da}$ (equivalente a 6 moléculas de glucose), para que os microorganismos possam usálo como nutriente.

2) Mineralização: os fragmentos, $1000 \mathrm{~g} / \mathrm{mol}$, são digeridos por microorganismos produzindo $\mathrm{CO}_{2}$ e água sob condição aeróbica ou metano sob condição anaeróbica. Outros subprodutos são sais minerais e biomassa microbial.

Estudos de biodegradação, in vivo e in vitro, são importantes, tanto para minimizar os efeitos de resíduos plásticos sintéticos descartados no meio ambiente, como para ampliar a aplicação dos polímeros biodegradáveis nas áreas médica e de embalagens $^{36}$.

A biodegradação de polímeros ocorre, basicamente, por dois mecanismos distintos dependendo da natureza do polímero e do meio ${ }^{37}$ : hidrólise biológica e oxidação biológica

Hidrólise biológica: É a hidrólise catalisada por enzimas hidrolases. Certas enzimas proteolíticas (proteases) catalisam a hidrólise de ligações peptídicas e outras catalisam a hidrólise de ligações éster ${ }^{8}$. Este mecanismo é seguido pela oxidação biológica das cadeias poliméricas (catalisada pelas oxigenases), quebra das mesmas, gerando cadeias menores e bioassimilação destas pelos microrganismos. Este processo ocorre em polímeros contendo heteroátomos, tais como celulose, amido e poliésteres alifáticos, dos quais os PHAs são típicos ${ }^{3}$.

Os grupos ésteres destes polímeros são facilmente hidrolisáveis, pela ação enzimática das esterases de fungos ${ }^{8}$.

Oxidação biológica: É a reação de oxidação, na presença de oxigênio, com introdução de grupos peróxidos nas cadeias carbônicas, por ação das monooxigenases e dioxigenases, quebra das cadeias, seguida por bioassimilação de produtos de baixa massa molar, como ácidos carboxílicos, aldeídos, cetonas. Este mecanismo se aplica essencialmente a polímeros apenas de cadeias carbônicas. A degradação pode ser controlada pelo uso apropriado de antioxidantes.

A bioassimilação começa tão logo forem formados produtos de baixa massa molar no processo de peroxidação ${ }^{8,35}$.

Em geral, a velocidade de hidrólise dos polímeros é controlada por várias propriedades, incluindo estrutura, área superficial e morfologia. A susceptibilidade de polímeros à degradação enzimática é determinada pela relação entre propriedades e 
estrutura. Os microrganismos secretam enzimas que quebram o polímero em blocos moleculares menores, hidroxiácidos, que são utilizados como fonte de carbono para o crescimento destes microrganismos.

Neste sentido é conhecido, por exemplo, o desempenho das enzimas depolimerases de Penicillium funiculosum e Aspergillus fumigatus na biodegradação de poliésteres bacterianos. A incubação de filmes de PHB em lodos anaeróbios mostrou significativa degradação (perda de cerca de $23 \%$ em massa) em um tempo de 6 a 10 semanas, a $37^{\circ} \mathrm{C}$, monitorada por perda de massa dos filmes e formação de biogás ${ }^{38}$.

A biodegradação sob ação de enzimas pode ser monitorada por medidas de massa molar (Cromatografia de Permeação em Gel-GPC), da presença de grupos polares (Infravermelho com Transformada de Fourier - FTIR), de mudanças nas propriedades mecânicas (Análise Termo-Mecano-Dinâmica - DMTA), de mudanças de estrutura de microfase (Calorimetria Exploratória Diferencial - DSC) ou de estrutura de macrofase (Microscopia Eletrônica de Varredura - SEM) ${ }^{39}$. A biodegradação envolve não só a ação de enzimas como também outros mecanismos de interação entre os microrganismos e a superfície polimérica e pode ser chamada de biodeterioração ${ }^{40}$.

A biodeterioração é um processo interfacial, em que os microrganismos atacam e colonizam as superfícies poliméricas na forma de biofilmes, os quais são uma mistura de microrganismos, água, polissacarídeos e proteínas que, em contato com o polímero sintético, causam algumas modificações, entre elas ${ }^{40}$ : cobertura da superfície, mascarando suas propriedades superficiais e contaminando o meio adjacente; aumento da dessorção de aditivos e monômeros para fora da matriz; ataque ao polímero por enzimas; acúmulo de água e penetração na matriz com filamentos microbianos, causando intumescimento e aumento de condutividade e, excreção de pigmentos microbianos lipofílicos que colorem o polímero.

A biodeterioração é então um processo muito complexo, que depende das condições do meio, dos tipos de microrganismos e da estrutura do polímero propriamente dito. Se o polímero for biodegradável, isto é, com estrutura de cadeias alifáticas e grupos funcionais hidrolisáveis, o processo pode ocorrer, sob certas condições do meio ( $\mathrm{pH}$, umidade, oxigênio, etc), de maneira mais direta por ação de enzimas: hidrólise e subseqüente oxidação $^{12}$. Se o polímero não tiver grupos funcionais, como os ésteres, pode haver deterioração, mas não chegando à 
mineralização do polímero nos produtos finais: água e dióxido de carbono ou metano. A superfície polimérica pode ser inerte ao ataque microbiano, sendo apenas um suporte para o crescimento bacteriano ${ }^{40}$.

Os microrganismos podem agir de diferentes maneiras sobre a superfície polimérica: por deposição de material extracelular excretado por eles ("fouling"); por degradação de compostos extraídos (lixiviados) do polímero, tais como, aditivos e monômeros, por exemplo cortinas de PVC, usadas em boxes de banheiros, que perdem a flexibilidade, devido a perda de aditivos; por corrosão - isto é, pela ação do biofilme e de seu gradiente de $\mathrm{pH}$ e potencial de óxido-redução, que ajudam na deterioração do polímero. Corrosão deste tipo ocorreu em isolantes elétricos a base de poliuretanos, usados em vários equipamentos do aeroporto de Zurique, entre 1967 e 1969, que foram completamente deteriorados pela colonização e penetração de fungos nos equipamentos ${ }^{40}$.

Para quantificar a biodegradação/biodeterioração tem sido empregados vários métodos físico-quimícos, que ainda não estão totalmente padronizados, pois, em se tratando de interações entre microrganismos e superfícies poliméricas, que são processos complexos, é difícil a padronização dos métodos.

\subsection{Efeitos da cristalinidade no PHB}

As propriedades de blendas semicristalinas são determinadas não somente pela miscibilidade de seus componentes, mas dependem também em uma larga extensão da sua morfologia e superestrutura cristalina ${ }^{41}$. A adição de um componente polimérico amorfo afeta as propriedades da fase cristalina do componente semicristalino, incluindo o grau de cristalinidade, a morfologia, as dimensões dos esferulitos, e também a interface entre a fase amorfa e a fase cristalina. Por isso uma boa compreensão do processo de cristalização de blendas poliméricas traz uma grande contribuição para a análise de suas propriedades.

As condições em que a cristalização ocorre são o principal fator determinante da morfologia final do polímero e, portanto, das suas propriedades mecânicas. Por exemplo, um resfriamento rápido a partir do fundido leva a pequenos esferulitos, enquanto resfriamentos lentos (cristalização isotérmica) levam a esferulitos maiores e a formação de trincas entre os esferulitos. ${ }^{42}$ 
O PHB é um polímero duro e quebradiço, como citado anteriormente, apresentando uma elongação de ruptura de menos de $10 \%$, com módulo de elasticidade e tensão de ruptura por volta de 1,7 GPa e $35 \mathrm{MPa}$, respectivamente ${ }^{42}$.

$\mathrm{O}$ PHB, devido à sua baixa taxa de nucleação, é um polímero diferenciado ${ }^{43}$. Uma vez que o tamanho dos esferulitos é determinado pela competição entre as taxas de nucleação e de crescimento dos cristais ${ }^{44}$, o PHB tende a apresentar esferulitos relativamente grandes, com inúmeras fraturas inter-esferulíticas.

O processo de cristalização secundária, que ocorre com a reorganização das cadeias na fase amorfa do biopolímero e se propaga durante a estocagem em temperatura ambiente, é observado no PHB em diversos estudos ${ }^{45,46,47}$.

A cristalização secundária consiste na formação de esferulitos originados a partir da reorganização das cadeias no estado amorfo em cristais lamelares préexistentes. Esse processo promove o crescimento dos normalmente já grandes esferulitos do PHB e de áreas de tensão localizadas que favorecem o surgimento de trincas e rupturas circulares em torno do seu centro $42,48,49$.

Devido ao fato de possuir esferulitos grandes em uma estrutura bastante fina, com lamelas com espessuras de aproximadamente $30 \AA^{43}$, o PHB recém-preparado possui uma interface cristalina-amorfa por unidade de volume excepcionalmente grande. Qualquer processo envolvendo essa interface, tal como a cristalinização secundária (envelhecimento), terá um efeito mais pronunciado sobre o PHB do que em outros polímeros semi-cristalinos. ${ }^{43}$

As fraturas inter-esferulíticas, o envelhecimento que ocorre à temperatura de estocagem aliados à $T_{g}$ próxima da temperatura ambiente são os grandes responsáveis pela fragilidade apresentada pelo $\mathrm{PHB}^{42}$.

As desvantagens causadas pelo tamanho exagerado dos esferulitos podem ser evitadas através do controle da cinética de cristalização do PHB. A opção de blenda é uma boa alternativa, uma vez que o processo de cristalização de um polímero é afetado pela presença de um segundo componente. ${ }^{44}$

Koning et al. submeteram o PHB a um recozimento a $150 \stackrel{\circ}{\circ}$, obtendo uma elongação de ruptura de $30 \%$ contra $5 \%$ da amostra não recozida ${ }^{43}$. O autor atribuiu este resultado à geração de uma estrutura mais grosseira pelo recozimento, e portanto menos susceptível ao envelhecimento. O recozimento do PHB a temperaturas como a proposta por Koning é, no entanto, arriscado, uma vez que 
leva o polímero próximo à sua temperatura de degradação por um tempo relativamente longo, e pode trazer efeitos não desejados.

El Hadi et al. ${ }^{42}$ adicionaram diferentes lubrificantes e plastificantes em teores distintos à blendas de PHB contendo de 4 a $20 \%$ em massa de poli(acetato de vinila) (PVAc). As blendas também continham 0,5\% em massa de sacarina como agente nucleante. Os resultados mostram uma clara relação entre a cristalinidade, que foi reduzida a até $40 \%$, com propriedades mecânicas como resistência a impacto e elongação de ruptura, que sofreram aumentos de 3 para $43 \mathrm{~kJ} / \mathrm{mm}^{2}$ e de 10 para $600 \%$ respectivamente. Esta melhora é atribuida não somente à redução da cristalinidade mas também à redução no tamanho dos esferulitos presentes. El Hadi et al. ${ }^{42}$ também estudaram o efeito do tempo de estocagem da blenda sobre suas propriedades mecânicas.

\subsection{Poli(etileno-glicol) (PEG)}

O polietilenoglicol (PEG) é considerado um polímero atóxico, biocompatível com sangue e tecidos, largamente estudado em pesquisas biomédicas e com grande aplicação na indústria farmacêutica, principalmente na indústria de cosméticos*.

De acordo com o tamanho de cadeia, o PEG pode ser líquido ou sólido em temperatura ambiente, mantendo sempre, porém, sua natureza hidrofílica*. Convencionalmente, quando a massa molar do PEG é maior que 20.000 Da, este recebe o nome de Poli(óxido de etileno) (PEO).

O PEG é um candidato ideal para a formação de blendas com $\mathrm{PHB}^{+}$por ser um polímero flexível de boa solubilidade tanto em água como em solventes orgânicos, devido à sua estrutura molecular (Figura 10).

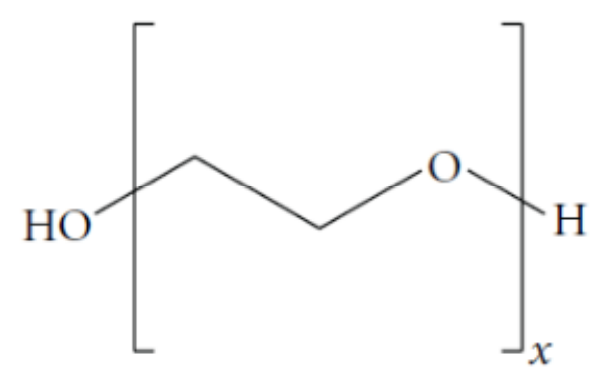

Figura 10: Estrutura química do Poli(etileno-glicol) / Poli(óxido de etileno) ${ }^{+}$ 
O PEG tem grande aplicação também na agricultura. Por não ser fitotóxico e nem metabolizado pelas sementes, é o agente osmótico mais utilizado para a hidratação controlada em sementes*.

\section{$\underline{1.6 \text { Blendas Poliméricas }}$}

Blenda polimérica é a mistura física de dois ou mais polímeros, de forma que entre as cadeias moleculares dos diferentes polímeros existam apenas interações moleculares secundárias sem um número significativo de ligação química entre as cadeias moleculares destes polímeros distintos.

Blendas podem ser miscíveis ou imiscíveis. As blendas miscíveis apresentam uma fase homogênea e blendas imiscíveis apresentam mais de uma fase. Em blendas miscíveis podemos notar mudanças em propriedades como $T_{m}, T_{g}$ e grau de cristalinidade em comparação com os homopolímeros, devido à interação entre estes $^{52}$.

A possibilidade de alterar as propriedades de um polímero através da simples adição mecânica de outros polímeros arcando com custos menores do que os de alterar o processo de polimerização, realizar reações químicas adicionais ou sintetizar um novo polímero, torna a blenda uma estratégia bastante atrativa para a indústria.

A termodinâmica de miscibilidade entre pares poliméricos é importante para entender porque alguns polímeros se misturam a nível molecular e outros não.

A miscibilidade de um par polimérico é determinada por fatores entálpicos e entrópicos. Uma aproximação clássica é a utilização da energia livre de Gibbs, onde a miscibilidade total só é alcançada quando:

$$
\Delta \mathrm{G}_{\mathrm{m}}=\Delta \mathrm{H}_{\mathrm{m}}-\mathrm{T} \Delta \mathrm{S}_{\mathrm{m}}<0 \quad \text { (Equação 1) }
$$

Onde $\Delta G_{m}, \Delta H_{m}$ e $\Delta S_{m}$ são, respectivamente, a energia livre de Gibbs, a entalpia e a entropia da mistura a uma temperatura $\mathrm{T}$.

Para um sistema unifásico estável, os critérios de estabilidade de fases em misturas binárias de composição $\varphi$ a uma temperatura T e pressão $p$ são ${ }^{53}$ : 


$$
\Delta \mathrm{G}_{\mathrm{m}}<0,\left(\frac{\partial^{2} \Delta \mathrm{G}_{\mathrm{m}}}{\partial \phi^{2}}\right)_{\mathrm{p}, \mathrm{T}}>0 \quad(\text { Equação 2) }
$$

Uma vez que a variação entrópica entre homopolímeros e mistura será sempre positiva, o valor de $\mathrm{T} \Delta \mathrm{S}_{\mathrm{m}}$ será, também, sempre positivo. Desta maneira, os valores de $\Delta G_{m}$ dependem da entalpia de mistura $\Delta H_{m}$. A miscibilidade do par polimérico deve ocorrer apenas quando a contribuição entrópica superar a contribuição entálpica:

$$
\Delta \mathrm{H}_{\mathrm{m}}<\mathrm{T} \Delta \mathrm{S}_{\mathrm{m}} \quad \text { (Equação 3) }
$$

Para a maioria das blendas poliméricas a miscibilidade aumenta com 0 aumento da pressão. Este efeito depende da magnitude da entalpia de mistura $\Delta \mathrm{H}_{\mathrm{m}}$. Para $\Delta \mathrm{H}_{\mathrm{m}}<0$ a miscibilidade é maior quando sob pressão, para $\Delta \mathrm{H}_{\mathrm{m}}>0$, a miscibilidade é reduzida.

A Fig. $10^{53}$ mostra um exemplo de diagrama de fases para blendas, com três diferentes regiões que representam diferentes graus de miscibilidade.

1. A região homogênea (miscibilidade) entre as duas curvas binodais;

2. As quatro regiões metaestáveis entre as curvas binodais e espinodais; e

3. As regiões heterogêneas (imiscibilidade), delimitadas pelas curvas espinodais.

O diagrama também mostra duas temperaturas de solubilidade críticas, uma mínima (LCST, da sigla em inglês) e uma máxima (UCST, da sigla em inglês). 0 exemplo mostra um diagrama para componentes de baixa massa molar, um diagrama de uma blenda polimérica apresenta normalmente apenas uma das temperaturas críticas, sendo a LCST a mais comum delas ${ }^{53}$. 


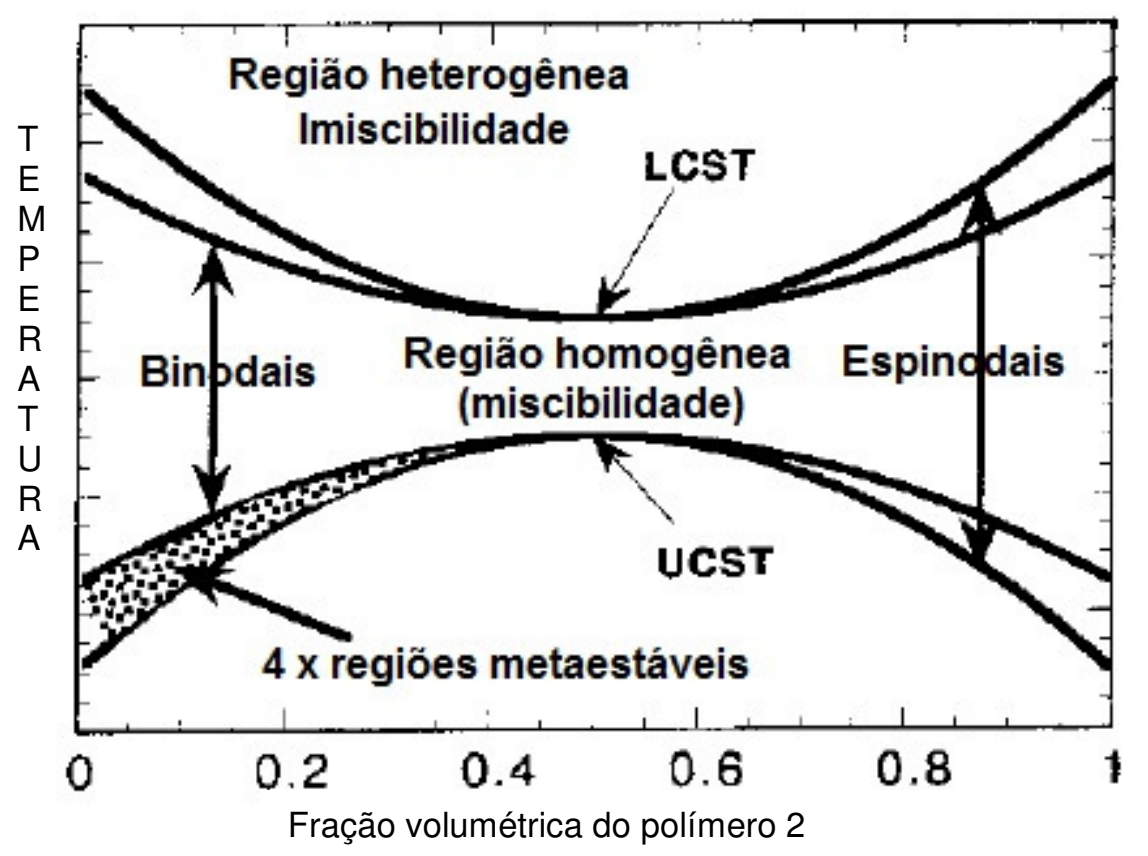

Figura 10: Diagrama de fases para misturas líquidas. ${ }^{53}$

As curvas binodais separam a região homogênea das regiões metaestáveis, enquanto as curvas espinodais separam as regiões metaestáveis das regiões heterogêneas. As condições termodinâmicas para a separação de fases são dadas por $^{53}$ :

Espinodal: $\quad\left(\frac{\partial^{2} \Delta \mathrm{G}_{\mathrm{m}}}{\partial \phi^{2}}\right)_{\mathrm{p}, \mathrm{T}}=0 \quad$ (Equação 4)
Pontos críticos: $\quad\left(\frac{\partial^{2} \Delta \mathrm{G}_{\mathrm{m}}}{\partial \phi^{2}}\right)_{\mathrm{p}, \mathrm{T}}=\left(\frac{\partial^{3} \Delta \mathrm{G}_{\mathrm{m}}}{\partial \phi^{3}}\right)_{\mathrm{p}, \mathrm{T}}=0 \quad$ (Equação 5)

Flory e Huggins extenderam o conceito de soluções líquidas para soluções poliméricas. Considerando-se um modelo incompressível (sem variação de volume durante a mistura), mistura aleatória e as interações entre as diferentes cadeias poliméricas, chegamos aos termos entrópico $\left(\Delta \mathrm{S}_{\mathrm{m}}\right)$ e entálpico $\left(\Delta \mathrm{H}_{\mathrm{m}}\right)$ da teoria de Flory Huggins:

$$
\Delta \mathrm{S}_{\mathrm{m}}=-\mathrm{R}\left[\frac{\phi_{1}}{\mathrm{r}_{1}} \ln \phi_{1}+\frac{\phi_{2}}{\mathrm{r}_{2}} \ln \phi_{2}\right] \quad \text { (Equação 6) }
$$


Onde $\varphi_{i}$ é a fração volumétrica do componente i e $r_{i}$ é o número de segmentos poliméricos (proporcional ao grau de polimerização), $R$ é a constante universal dos gases.

$$
\Delta \mathrm{H}_{\mathrm{m}}=\mathrm{RT} \chi \varphi_{1} \varphi_{2} \quad \text { (Equação 7) }
$$

Onde $X$ é o parâmetro de interação de Flory-Huggins.

Para sistemas binários, a equação de Flory-Huggins pode ser escrita da seguinte forma:

$$
\Delta \mathrm{G}_{\mathrm{m}}=\mathrm{RT}\left[\frac{\phi_{1}}{\mathrm{r}_{1}} \ln \phi_{1}+\frac{\phi_{2}}{\mathrm{r}_{2}} \ln \phi_{2}+\chi \phi_{1} \phi_{2}\right] \quad \text { (Equação 8) }
$$

Se considerarmos polímeros com massa molar infinita ( $r_{i}$ infinito), veremos que a contribuição entrópica (Eq. 6) se torna desprezível e a miscibilidade do sistema passa a depender apenas do valor da entalpia de mistura (Eq. 7). A miscibilidade pode ser somente atingida, então, para valores negativos de $X$.

O termo 'parâmetro' é utilizado para descrever $X$, mas este seria melhor definido como uma 'função', uma vez que depende de diversos fatores como temperatura, pressão, concentração, massa molar, entre outros ${ }^{53}$.

Podemos então calcular um valor de $X$ crítico $\left(X_{c r}\right)$, abaixo do qual a miscibilidade ocorre. Para tal, consideramos a definição de ponto crítico (Figura 10) e a equação 8 , obtendo ${ }^{53}$ :

$$
\chi_{\mathrm{cr}}=\frac{1}{2}\left(\frac{1}{\sqrt{\mathrm{r}_{1}}}+\frac{1}{\sqrt{\mathrm{r}_{2}}}\right)^{2}
$$

Nas equações 8 e 9, assumimos que $x$ não é função da composição, sendo assim $X_{c r}$ torna-se apenas função da massa molar dos polímeros.

Como foi citado anteriormente, haverá miscibilidade entre os polímeros quando:

$$
X<X_{c r} \quad \text { (Equação 10) }
$$


Polímeros miscíveis podem ser classificados em três grandes grupos:

- Polímeros quase idênticos quimicamente.

- Misturas que apresentam alguma interação específica, como ligação de hidrogênio, interações iônicas ou de dipolo, interações de elétrons $\pi$, etc.

- Sistemas em que as interações entre as cadeias de diferentes espécies não são muito favoráveis, mas ainda assim são maiores que as interações entre os componentes iguais. Geralmente é o caso de misturas entre um homopolímero e um copolímero ${ }^{52}$.

\section{$\underline{1.7 \text { Termogravimetria (TG) }}$}

A termogravimetria (TG) é uma das técnicas de análise térmica em que as variações de massa da amostra (ganho ou perda) são monitoradas como uma função da temperatura e/ou tempo, enquanto a substância é submetida a um programa controlado de temperatura, sob uma atmosfera especificada.

Os fatores que podem ser controlados para desenvolver um método analítico são taxa de aquecimento, atmosfera do forno, composição e volume do portaamostra e a massa da amostra.

A atmosfera utilizada é extremamente importante nesta análise, uma vez que a degradação de um polímero é significativamente afetada pelo meio em que a degradação ocorre. A taxa de aquecimento não deve ser muito alta, pois isso pode causar deslocamentos e imprecisões na curva final. O porta-amostra deve ser de um material que não reaja com a amostra, e deve permitir a liberação de gases, provenientes da degradação da amostra.

Analisando-se a temperatura de degradação da blenda é possível analisar a miscibilidade desta, caso ocorra alteração na temperatura de degradação da blenda em relação às temperaturas de degradação dos homopolímeros puros, pode-se dizer que existem fortes indícios de compatibilidade da blenda. Caso a blenda apresente temperaturas de degradação distintas e semelhantes às dos homopolímeros, então a blenda não é miscível. 


\section{$\underline{1.8 \text { Difração de raio-X }}$}

A principal aplicação da análise de curvas de difração de raio-X refere-se à identificação de compostos cristalinos, sejam eles inorgânicos ou orgânicos.

Os raios- $X$ ao atingirem um material podem ser espalhados elasticamente, sem perda de energia pelos elétrons de um átomo (dispersão ou espalhamento coerente). O fóton de raio-X após a colisão com o elétron muda sua trajetória, mantendo, porém, a mesma fase e energia do fóton incidente. Sob o ponto de vista da física ondulatória, pode-se dizer que a onda eletromagnética é instantaneamente absorvida pelo elétron e reemitida; cada elétron atua, portanto, como centro de emissão de raios- $X$.

Se os átomos que geram este espalhamento estiverem arranjados de maneira sistemática, como em uma estrutura cristalina, apresentando entre eles distâncias próximas ao do comprimento de onda da radiação incidente, pode-se verificar que as relações de fase entre os espalhamentos tornam-se periódicas e que efeitos de difração do raio-X podem ser observados em vários ângulos.

No caso de polímeros, cada um possui curvas de difração características, o que possibilita a comparação das curvas dos materiais desconhecidos com aqueles de referência, proporcionando, portanto, a identificação da presença de cada componente nas amostras. A determinação da fração cristalina segue uma relação simples entre as áreas dos picos cristalinos e o amorfo de uma curva de difração de raio-X.

\subsection{Avaliação da miscibilidade de blendas pela $T_{g}$}

A miscibilidade em um sistema pode ser avaliada pela medida de uma propriedade e analisando o seu comportamento de uma fase ou de duas fases. Uma das propriedades mais distintivas e mais empregadas é a temperatura de transição vítrea $\left(\mathrm{T}_{\mathrm{g}}\right)^{54}$.

Em baixas temperaturas, os polímeros se encontram no estado vítreo, ou seja, suas moléculas não têm energia interna suficiente para realizarem movimentos em grande escala, apenas movimentos locais, fazendo com que o material apresente comportamento frágil e duro. Aumentando a temperatura, as moléculas da fase amorfa adquirem mobilidade e isso ocasiona um aumento de volume livre, 
juntamente com uma alteração na capacidade calorífica do polímero, fazendo com que o polímero adquira comportamento elastomérico. A faixa de temperatura em que este fenômeno ocorre dá-se o nome de temperatura de transição vítrea $\left(T_{g}\right)$. Para se determinar a miscibilidade de blendas a partir de medições da $T_{g}$, compara-se a $T_{g}$ apresentada pela blenda com a $T_{g}$ dos componentes puros. Uma blenda miscível irá mostrar uma única $T_{g}$ entre as $T_{g}$ 's dos constituintes puros e ela deve ser tão nítida quanto a de seus componentes. Uma blenda imiscível irá mostrar duas $T_{g}$ 's nas mesmas temperaturas e tão nítidas quanto aquela dos componentes puros da mistura. A miscibilidade parcial é indicada por um dos seguintes resultados:

- aparecimento de uma única $T_{g}$ entre a dos constituintes puros, porém com o alargamento considerável da faixa de temperatura.

- a presença de duas $T_{g}$ 's, mas mais largas e/ou mais próximas do que aquelas dos componentes da mistura.

Todos os casos estão esquematizados na Figura 11, para as análises DSC (curvas à esquerda) e DMTA (curvas de módulo de armazenamento vs. temperatura à direita $)^{54}$.
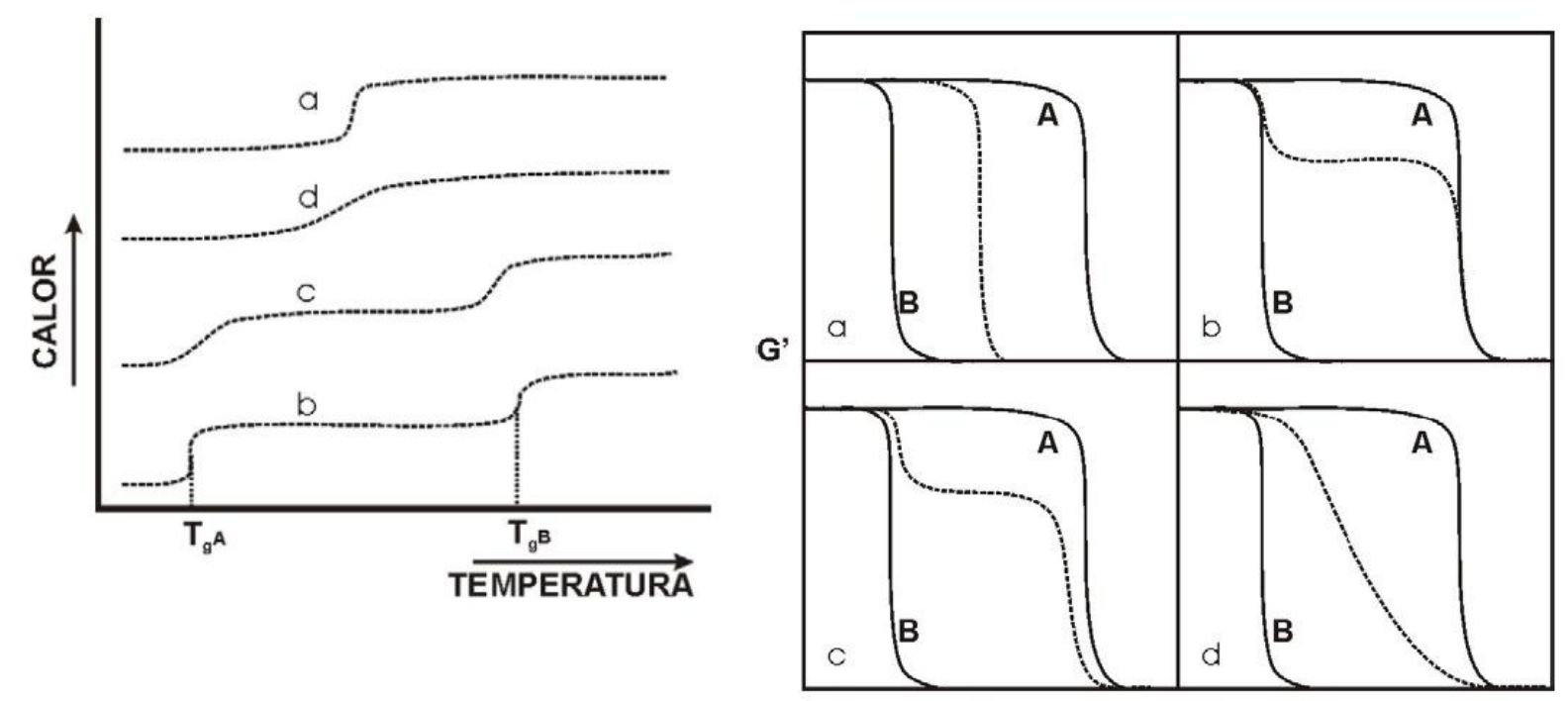

Figura 11: Representações esquemáticas da avaliação de miscibilidade de um par polimérico $A$ e $B$ baseado na medida da Tg. Caso (a): A e B são miscíveis; caso (b): A e B são imiscíveis; caso (c): A miscibilidade está limitada à baixa concentração de $A$ em $B$ e de $B$ em $A$ (parcialmente imiscível); caso (d): Blenda com fina dispersão (parcialmente miscível) ${ }^{54}$.

Como a transição vítrea é análoga a uma transição termodinâmica de segunda ordem, ela é caracterizada por uma variação do calor específico em função da temperatura naquele ponto, a qual pode ser explorada por técnicas 
calorimétricas, como a calorimetria diferencial de varredura (DSC). A principal vantagem do DSC é a facilidade e a velocidade com que as medidas são realizadas, necessitando de apenas alguns miligramas de amostra. Para que o DSC possa ser realizado, as $\mathrm{T}_{\mathrm{g}}$ 's dos componentes devem estar claramente separadas por uma faixa de temperatura, para que se possam distinguir os comportamentos de uma $T_{g}$ e de duas $\mathrm{T}_{\mathrm{g}}$ 's, além disso, as temperaturas de decomposição dos polímeros constituintes da mistura devem estar acima da $T_{g}$ mais alta ${ }^{54}$.

O ensaio dinâmico-mecânico (DMTA) é muito útil para determinar transições secundárias como a $T_{g}$. Nesta técnica uma deformação senoidal é aplicada a uma amostra de polímero (equação 11) que responde com uma variação de tensão (equação 12).

$\varepsilon=\varepsilon_{0} \operatorname{sen}(\omega t)$

Equação 11.

$\sigma=\sigma_{0}[\operatorname{sen}(\omega t)+\delta]$

Equação 12.

Aonde:

$\varepsilon=$ Deformação.

$\omega=$ Freqüência angular da deformação ondulatória.

$\delta=$ Ângulo de defasagem entre a deformação e a tensão máximas.

$\mathrm{t}=$ Tempo.

A defasagem entre as deformações cíclicas aplicadas e a resposta do corpo de prova permite analisar os rearranjos moleculares que o polímero sofre devido a pequenas deformações.

O módulo de armazenamento (E') mede a energia armazenada, representando a porção elástica, enquanto o módulo de perda (E’) mede a energia dissipada na forma de calor, representando a porção viscosa. Os módulos são definidos como:

$$
\begin{array}{ll}
E^{\prime}=\frac{\sigma_{0}}{\varepsilon_{0}} \cos \delta & \text { Equação } 13 \\
E^{\prime \prime}=\frac{\sigma_{0}}{\varepsilon_{0}} \operatorname{sen} \delta & \text { Equação } 14
\end{array}
$$


Definimos também a relação entre os dois módulos, que nos leva a tangente do ângulo de defasagem $\delta$ :

$$
\operatorname{tg} \delta=\frac{E^{\prime \prime}}{E^{\prime}} \quad \text { Equação } 15
$$

Ao realizar o ensaio varrendo uma faixa de temperatura que contenha a $T_{g}$ do polímero, é possível identificar esta transição através de um nítido e pronunciado decréscimo no módulo de armazenamento (Eq. 13) e um pico máximo do módulo de perda (Eq. 14) do polímero devido às relaxações mecânicas induzidas pela passagem do estado vítreo para o estado elastomérico. ${ }^{54}$ Essas alterações fazem com que, na temperatura de transição vítrea de um polímero, o valor de $\operatorname{tg} \delta$ (Eq. 15) atinga um pico.

Os componentes de teste usados em DMTA permitem que os ensaios sejam realizados de quatro modos diferentes: modo de tração, modo de compressão, modo de flexão e modo de cisalhamento. Além disso pode-se conduzir o experimento escolhendo diferentes modos de operação: varredura de temperatura, varredura de tempo, varredura de freqüência e varredura de tensão ou ainda fluência (creep). A escolha do modo de operação do equipamento depende do tipo de material, do tipo de corpo de prova e do tipo de informações que são desejadas.

As vantagens dos métodos mecânicos sobre os calorimétricos são a sua maior sensibilidade e o fato de fornecerem maiores informações sobre a morfologia do sistema. Suas desvantagens são a grande quantidade de material necessária e a preparação das amostras. ${ }^{54}$

\section{Objetivos}

Este trabalho tem por objetivo analisar as propriedades das blendas de PHB contendo diferentes concentrações em massa de PEG/PEO para avaliar a miscibilidade destas. É objetivo também deste trabalho, fazer uma análise dos resultados de diversos experimentos feitos acerca desta blenda, incluindo resultados obtidos por Érica Shiroma, Walker Soares Drumond, Gustavo Russo Blazek, buscando comparar estes resultados e hipóteses propostas com resultados obtidos e hipóteses levantadas por outros pesquisadores acerca do PHB e suas blendas. 


\section{Materiais e Métodos}

As matérias primas utilizadas neste projeto foram:

- PEG com duas massas molares diferentes, $300 \mathrm{~g} / \mathrm{mol}$ (PEG) e 4.000 .000 $\mathrm{g} / \mathrm{mol}$ (PEO).

- PHB de massa molar $263.000 \mathrm{~g} / \mathrm{mol}$ produzido pela PHB do Brasil, na unidade fabril localizada na Usina da Pedra, SP.

\subsection{Preparação das blendas:}

Para a preparação das blendas, além das matérias primas supra-citadas, foi utilizado clorofórmio, como solvente comum aos homopolímeros. Foram preparadas quatro blendas de PHB/PEG de diferentes composições e uma de PHB/PEO.

Os filmes preparados têm as seguintes composições:

Tabela 3: Proporções de PHB e PEG/PEO

\begin{tabular}{|c|c|c|c|c|c|}
\hline PHB (\%) & 70 & 80 & 90 & 95 & 95 \\
\hline PEG (\%) & 30 & 20 & 10 & 5 & 0 \\
\hline PEO (\%) & 0 & 0 & 0 & 0 & 5 \\
\hline
\end{tabular}

Para um peso total de $5 \mathrm{~g}$ de cada filme, foram utilizadas as massas representadas na Tabela 4, sendo o número indicado entre parênteses a massa calculada:

Tabela 4: Massa de material utilizada na preparação das amostras

\begin{tabular}{|c|c|c|c|c|c|}
\hline & $\begin{array}{c}\text { PHB/PEG } \\
70 / 30\end{array}$ & $\begin{array}{c}\text { PHB/PEG } \\
80 / 20\end{array}$ & $\begin{array}{c}\text { PHB/PEG } \\
90 / 10\end{array}$ & $\begin{array}{c}\text { PHB/PEG } \\
95 / 05\end{array}$ & $\begin{array}{c}\text { PHB/PEO } \\
95 / 05\end{array}$ \\
\hline PHB (g) & $3,503(3,5)$ & $4,007(4,0)$ & $4,510(4,5)$ & $4,750(4,75)$ & $4,751(4,75)$ \\
\hline PEG (g) & $1,500(1,5)$ & $1,011(1,0)$ & $0,518(0,5)$ & $0,266(0,25)$ & $0(0)$ \\
\hline PEO (g) & $0(0)$ & $0(0)$ & $0(0)$ & $0(0)$ & $0,252(0,25)$ \\
\hline
\end{tabular}

Os cinco filmes foram preparados segundo o seguinte procedimento: As quantidades de PHB foram pesadas em balança analítica e colocadas em béqueres de $50 \mathrm{ml}$, aos quais foram acrescentados aproximadamente $20 \mathrm{ml}$ de clorofórmio. As amostras foram então agitadas e tampadas com filme de polietileno para evitar a perda excessiva de solvente, como mostra a Figura 12. Esperou-se de 1 a 2 dias 
para que o PHB inchasse. Foi adicionado mais clorofórmio a cada béquer, de acordo com a necessidade de repor o solvente perdido por evaporação, a solução foi então dissolvida e agitada em placa de aquecimento. Após a dissolução obteve-se uma solução bastante viscosa.

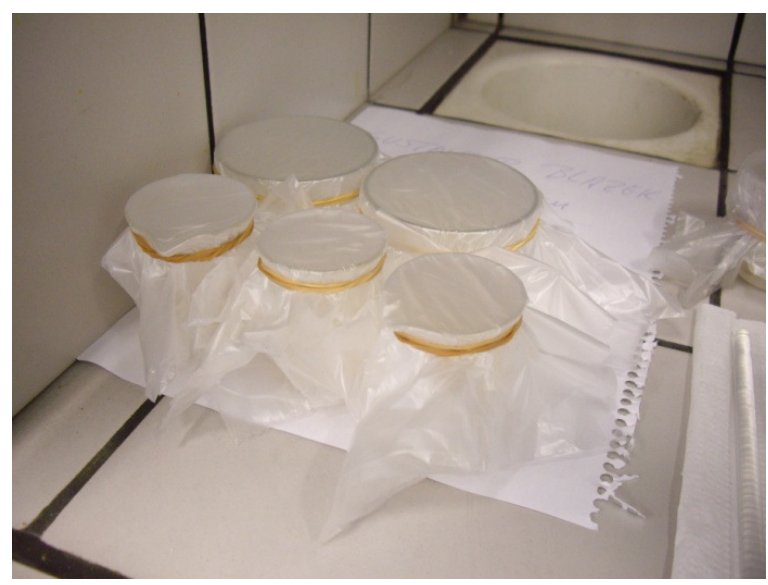

Figura 12: Soluções de PHB em clorofórmio em repouso por 2 dias.

As quantidades de PEG foram então pesadas, também em balança analítica, dissolvidas em clorofórmio e adicionadas cada uma à respectiva solução de PHB, agitando-as logo em seguida. As soluções foram então filtradas em um funil através de um chumaço de algodão para retirada de impurezas grosseiras, como demonstrado na Figura 13.

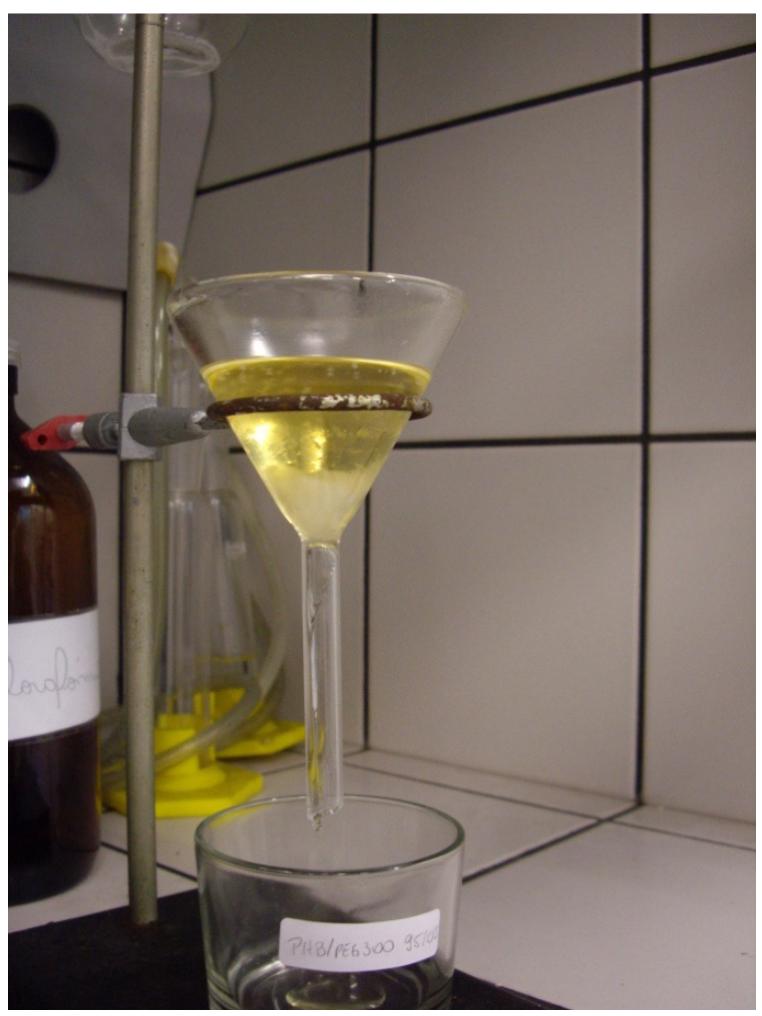

Figura 13: Retirada de impurezas grosseiras por filtragem. 
Enquanto isso, cinco placas de petri foram lavadas, bem secas e preparadas com uma fina camada de silicone, removendo-se o excesso com um chumaço de algodão, para facilitar a retirada dos filmes após a evaporação do solvente. As soluções filtradas foram então derramadas nas placas de petri. As placas foram colocadas em uma capela com um pote de sílica gel sobre elas e cobertas por um béquer, como mostrado na Figura 14. Esta disposição visa proteger as amostras da ação da umidade até a evaporação do solvente.
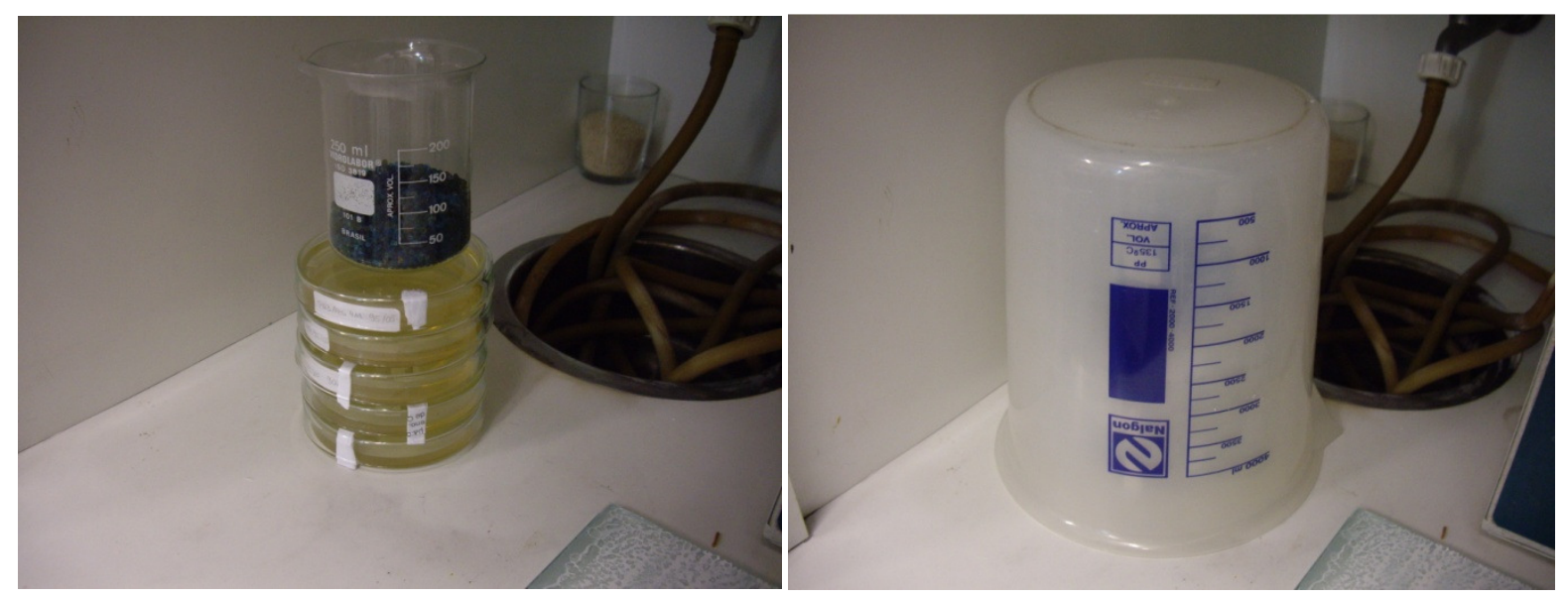

Figura 14: Disposição das amostras na capela visando a proteção contra a umidade.

Após a evaporação, os filmes foram colocados em estufa a vácuo a $40 \stackrel{\circ}{\mathrm{C}}$ por um dia.

\subsection{Análise Termogravimétrica (TG)}

Este método foi utilizado neste projeto com o objetivo de identificar a temperatura de degradação dos filmes preparados. Uma vez que ao atingir esta temperatura o polímero passa a perder massa, é possível identificar a temperatura de degradação de cada amostra a partir das curvas resultantes da TG.

Usou-se a seguinte quantidade de cada amostra para a análise termogravimétrica:

Tabela 5: Massa utilizada para análise termogravimétrica (TG)

\begin{tabular}{|c|c|c|c|c|c|}
\hline Amostra & $\begin{array}{c}\text { PHB/PEG } \\
70 / 30\end{array}$ & $\begin{array}{c}\text { PHB/PEG } \\
80 / 20\end{array}$ & $\begin{array}{c}\text { PHB/PEG } \\
90 / 10\end{array}$ & $\begin{array}{c}\text { PHB/PEG } \\
95 / 05\end{array}$ & $\begin{array}{c}\text { PHB/PEO } \\
95 / 05\end{array}$ \\
\hline Massa & 0,0117 & 0,0105 & 0,0123 & 0,0121 & 0,0118 \\
\hline
\end{tabular}


O equipamento utilizado foi um Shimadzu modelo TG 50. A taxa de aquecimento utilizada foi de $10^{\circ} \mathrm{C} / \mathrm{min}$ e a análise foi feita sob atmosfera inerte de nitrogênio $\left(\mathrm{N}_{2}\right)$. Sendo a amostra um material polimérico, a faixa de temperatura

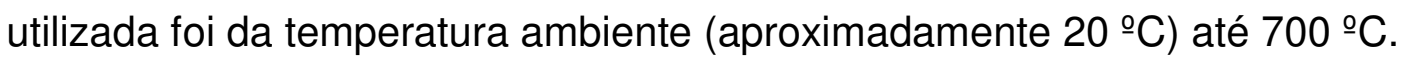

Para possibilitar uma visualização mais clara das temperaturas em que se dá a perda de massa, foram plotados também gráficos da taxa de variação de massa versus temperatura (DTG).

\subsection{Microscopia Eletrônica de Varredura (MEV)}

Foram feitas imagens da superfície obtida por fratura frágil (criogênica) de cada um dos filmes no microscópio eletrônico do Departamento de Engenharia Metalúrgica e de Materiais da EPUSP (PMT) (Phillips XL 30). Para produzir a fratura frágil, as amostras foram resfriadas abaixo da temperatura de transição vítrea $\left(T_{g}\right)$ em nitrogênio líquido e quebradas logo em seguida, as amostras foram então entregues ao laboratório de microscopia eletrônica aonde foram colocadas sobre uma fita condutora e receberam uma camada de 8-10 nm de espessura de ouro por sputtering.

As imagens obtidas foram comparadas com imagens de filmes de igual composição, porém envelhecidos por 3 meses, para analisar a segregação de fases ocorrida nas blendas.

\subsection{Difração de raio-X.}

Neste projeto, a difração de raio- $X$ foi utilizada para verificar o grau de cristalinidade das blendas.

Foi feita difração de raio-X de amostras recém-preparadas e envelhecidas, para medir a variação da cristalinidade em função da composição de cada blenda e do tempo de armazenamento. O procedimento foi feito no difratômetro de raio- $X$ de alto ângulo do Departamento de Engenharia de Minas e Petróleo da EPUSP (PMI).

Neste caso foi utilizada a radiação $\mathrm{K}_{\alpha}$ de $\mathrm{Cu}$ a $40 \mathrm{kV}$ e $40 \mathrm{~mA}$, com ângulo

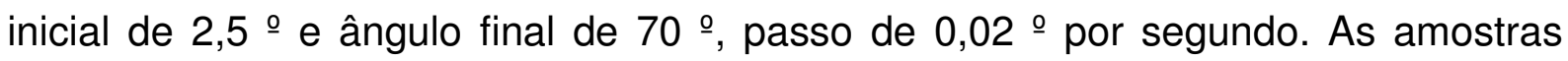
foram preparadas sem qualquer tratamento térmico para evitar qualquer alteração na cristalinidade das amostras. 
O grau de cristalinidade foi calculado utilizando-se o programa Origin 7.5. Foi selecionado o intervalo de $2 \theta$ entre $10 \cong$ e $33 \cong$ para análise, uma vez que este intervalo contém os principais picos característicos do PHB.

A figura 15 mostra a decomposição de curvas feita pelo software:
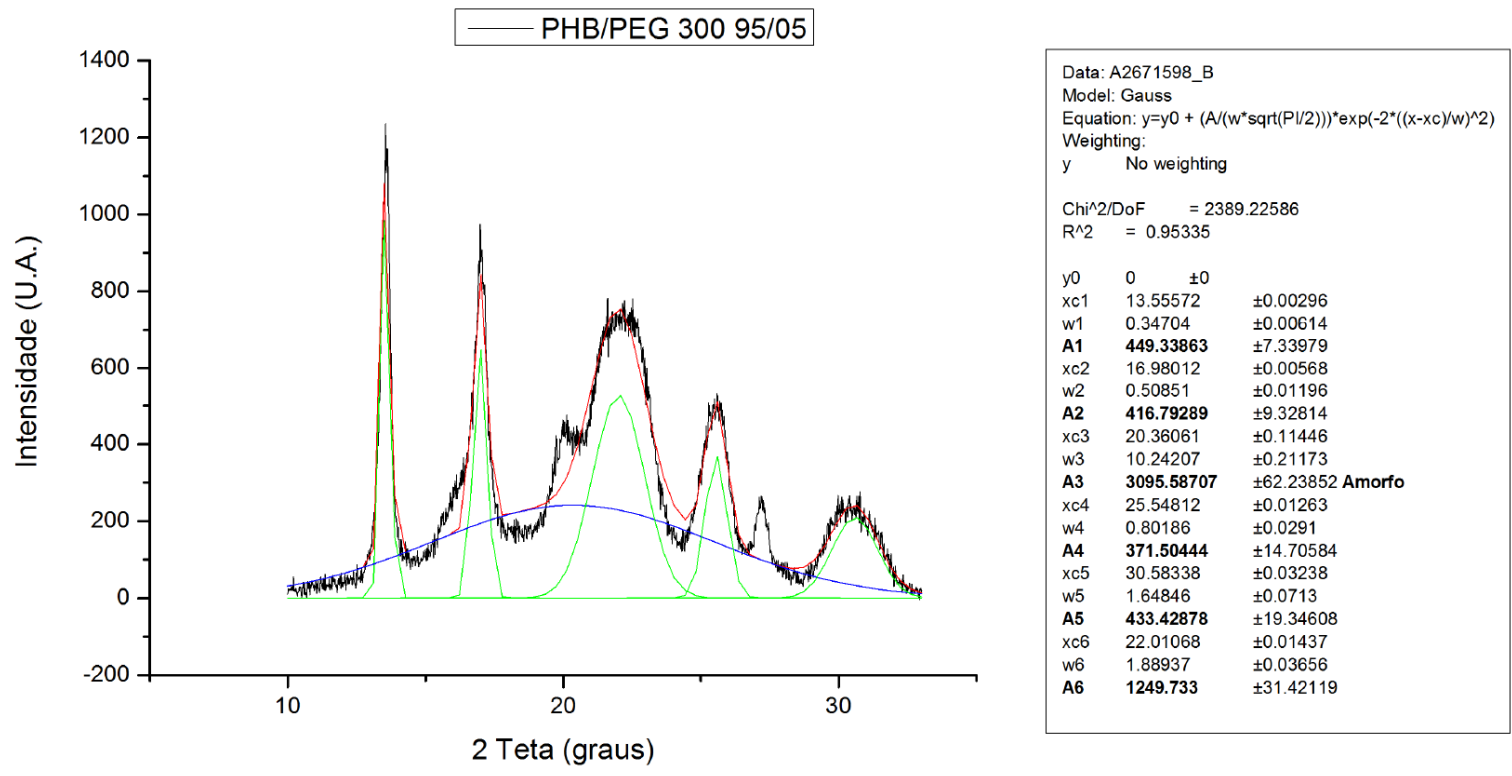

Figura 15 - Decomposição dos picos de difração de raio X.

Foi subtraída uma porção de background do gráfico de forma a aproximar uma base reta para os cálculos subsequentes. A partir desta base reta, os picos foram aproximados por gaussianas e tiveram suas áreas calculadas automaticamente pelo Origin 7.5.

O programa aproximou curvas para cada pico cristalino e para a porção amorfa. As curvas verdes representam os picos cristalinos, a curva azul representa a porção aproximada para a região amorfa e a curva vermelha representa a soma de ambos. Com uma aproximação ideal, a curva vermelha tende a coincidir com o gráfico original em preto.

O grau de cristalinidade foi então determinado pela soma das áreas sob os picos cristalinos sobre a soma das áreas amorfa e cristalina.

\subsection{Calorimetria Diferencial Exploratória (DSC)}

Um aparelho Shimadzu A50 foi utilizado para realizar as medidas de DSC sob atmosfera de nitrogênio. $O$ equipamento foi previamente calibrado com índio $\left(T_{m}=\right.$ $156,4 \stackrel{\circ}{\circ} \mathrm{C}$ e $\left.\Delta \mathrm{H}_{\mathrm{f}}=6,8 \mathrm{cal}^{\mathrm{g}} \mathrm{g}^{-1}\right)$. Cada amostra passou por uma etapa de aquecimento de -80 até $200 \stackrel{\circ}{\circ}$, seguida de resfriamento até $-80^{\circ} \mathrm{C}$ e novo aquecimento até 200 
$\stackrel{\circ}{ } \mathrm{C}$, todas as etapas foram realizadas a uma taxa de $20 \% \mathrm{~min}$.

O programa 'Proteus Thermal Analysis' da Netzsch foi utilizado para identificar as temperaturas das transições reveladas pelo ensaio e calcular a entalpia de fusão das amostras $\left(\Delta H_{f}\right)$. Este dado foi utilizado para calcular o grau de cristalinidade das blendas através da seguinte equação:

$$
X_{C}=\frac{\Delta H_{f} \times 100}{\Delta H_{0} \times w} \quad \text { (Equação 16) }
$$

Aonde:

$X_{c}=$ grau de cristalinidade do $\mathrm{PHB}$

$\Delta H_{f}=$ Entalpia de fusão da amostra

$\Delta H_{0}=$ Entalpia de fusão do PHB $100 \%$ cristalino, sendo esse valor tomado como $146 \mathrm{~J} / \mathrm{g}^{55}$

$w=$ fração em massa de PHB presente na blenda.

\subsection{Ensaio dinâmico-mecânico (DMTA)}

O ensaio dinâmico-mecânico foi realizado no modo de tração, utilizando-se um DMTA $V$ analyzer da Rheometrics. As amostras recém preparadas foram cortadas em pequenas barras retangulares com as seguintes dimensões: comprimento de $20 \mathrm{~mm}$, largura de $4 \mathrm{~mm}$ e espessura de $1 \mathrm{~mm}$. Um limite de deformação de $0,1 \%$ e uma freqüência de $1 \mathrm{~Hz}$ foram aplicadas a uma temperatura que variou de -80 a $150{ }^{\circ} \mathrm{C}$ a uma taxa de aquecimento de $2{ }^{\circ} \mathrm{C} / \mathrm{min}$.

\section{Resultados e Discussão}

\subsection{Análise termogravimétrica (TG) e Termogravimetria diferencial (DTG):}

É importante destacar que PEG com massa molar de $600 \mathrm{~g} \cdot \mathrm{mol}^{-1}$ apresenta taxa máxima de degradação (pico da curva DTG) em temperatura superior a $370{ }^{\circ} \mathrm{C}$, enquanto a partir de massa molar de $4000 \mathrm{~g} \cdot \mathrm{mol}^{-1}$ este pico é observado em valor superior a $400{ }^{\circ} \mathrm{C} .{ }^{56}$ Destaca-se também que $175 \stackrel{\circ}{ } \mathrm{C}$ é a temperatura de início de degradação térmica do PHB. ${ }^{57}$

Neste trabalho as temperaturas obtidas foram comparados com valores de referência, um método mais preciso para avaliar a miscibilidade envolveria realizar a 
análise dos homopolímeros por TG e, a partir dos resultados, fazer curvas simuladas do comportamento das blendas estudadas com miscibilidade total, comparando os resultados experimentais com os valores obtidos através da simulação.

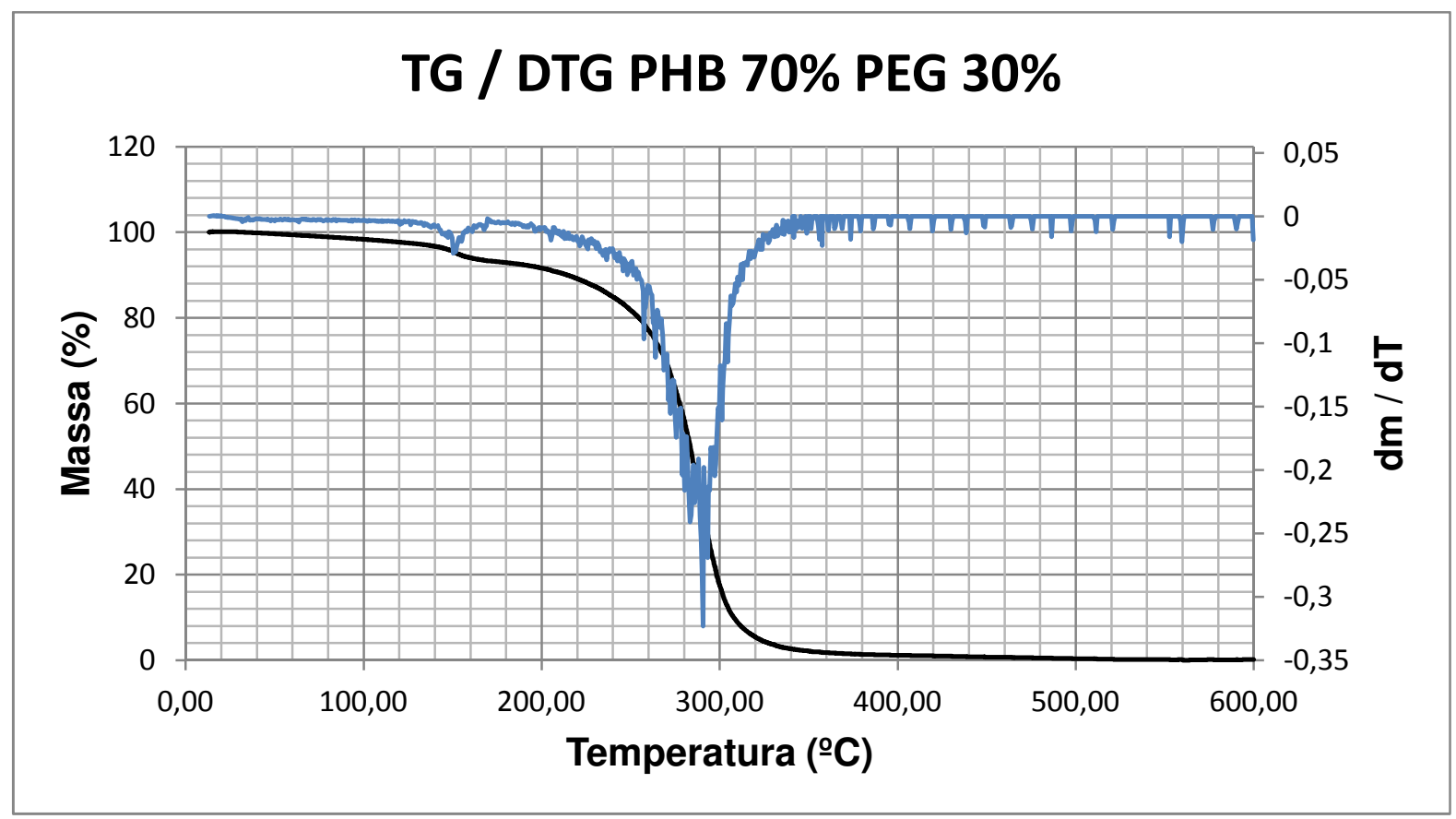

Figura 16 - Resultado TG / DTG - PHB/PEG 70/30

Na Figura 16 pode-se notar dois pontos a partir dos quais a massa sofre uma queda acentuada, um a aproximadamente $140 \stackrel{\circ}{\mathrm{C}}$, que indica uma provável evaporação de solvente ou impurezas presentes, e outro com início a aproximadamente $200{ }^{\circ} \mathrm{C}$, e considerável aumento na taxa de degradação a $260{ }^{\circ} \mathrm{C}$, que indica a etapa principal de degradação da blenda. O platô, observado na Figura 16, entre esses dois pontos não é de massa constante, apenas mostra a sobreposição de dois processos, oo final de evaporação de componentes voláteis e o início de degradação térmica do PHB em temperatura próxima a sua temperatura de fusão.

As temperaturas de degradação não são bem definidas, representando mais um intervalo de temperaturas do que uma temperatura exata. Também notamos que a perda de massa posterior à degradação do PHB não representa $30 \%$ da massa da amostra, indicando então que a degradação do PEG ocorre junto com o resto da blenda, em uma etapa única. Esses dois fatores apontam para uma certa miscibilidade entre os dois polímeros. 


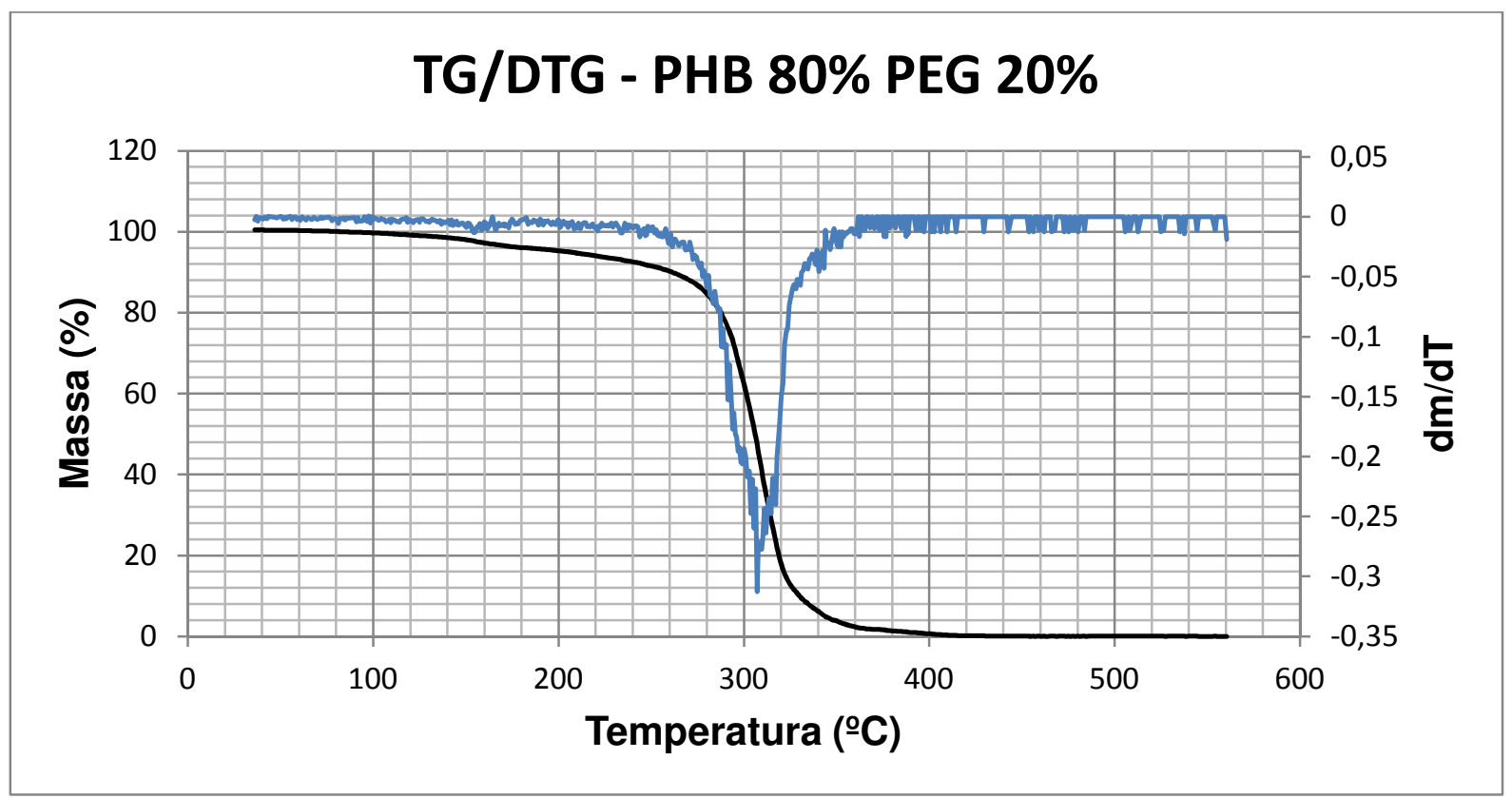

Figura 17 - Resultado TG / DTG - PHB/PEG 80/20

Para a amostra contendo 20 \% em massa de PEG (Figura 17), a saída de materiais voláteis se dá de forma menos acentuada.

A queda inicial pode ser identificada à aproximadamente $140^{\circ} \mathrm{C}$, mas não se identifica um platô definido entre essa temperatura e o ponto ande a degradação se acentua, a aproximadamente $260^{\circ} \mathrm{C}$, que representa o início da degradação da blenda. Notamos também que a queda se dá em uma única etapa principal, o que nos leva a crer que ocorre uma boa miscibilidade entre os polímeros.

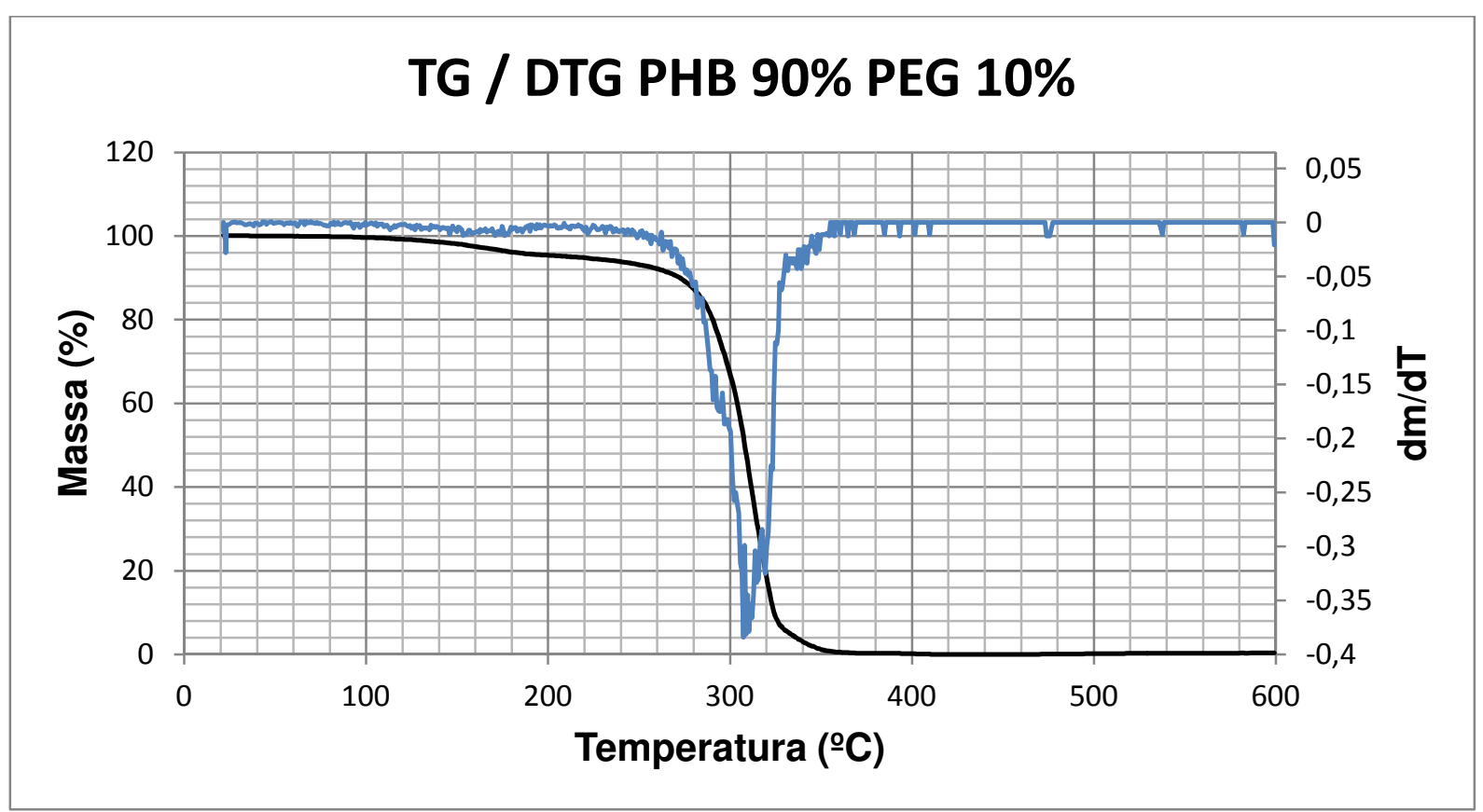

Figura 18 - Resultado TG / DTG - PHB/PEG 90/10 
Na Figura 18, percebemos uma primeira queda ainda menos acentuada. As temperaturas de degradação, medidas graficamente, são de aproximadamente 130 ○C para a saída de materiais voláteis e a acentuação da queda a $270{ }^{\circ} \mathrm{C}$ onde se inicia a degradação do PHB. A faixa de temperaturas em que a etapa principal degradação ocorre se mostra mais estreita, indicando melhor miscibilidade.

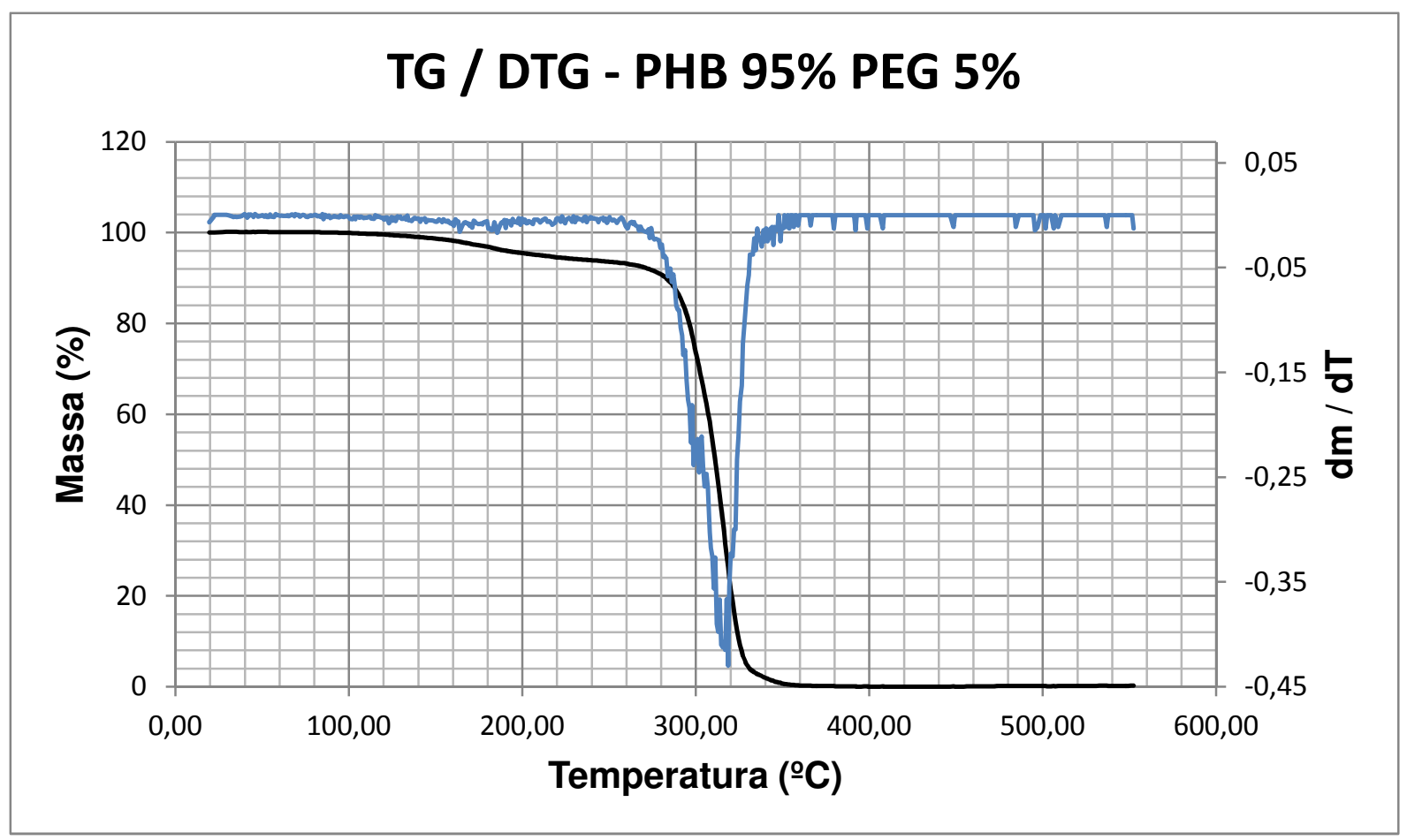

Figura 19 - Resultado TG / DTG - PHB/PEG 95/05

Para a amostra contendo $5 \%$ em massa de PEG (Figura 19), percebe-se uma queda quase que contínua entre $140^{\circ} \mathrm{C}$, quando se inicia a saída de materiais voláteis e $280 \stackrel{\circ}{\circ}$, quando a queda se acentua, representando o início da degradação da blenda. Para este mesmo intervalo nota-se que a taxa de perda de massa se altera levemente no início e se mantém constante até o momento em que se inicia a degradação do PHB.

A faixa de temperaturas da etapa principal se mostra ainda mais estreita, demonstrando uma melhor miscibilidade entre o PEG e o PHB.

Todas as blendas de PHB com PEG apresentaram durante a análise termogravimétrica um resíduo inferior a $2 \%$ a $370 \stackrel{\circ}{ } \mathrm{C}$, mostrando que ambos os polímeros encontravam-se essencialmente já degradados e evaporados nesta temperatura. 
Na Figura 20, para a blenda de composição 95/5 com PEO, a etapa principal de perda de massa se dá de forma tão definida quanto à da amostra contendo $5 \%$ de PEG, formando uma faixa entre 280 e $330 \stackrel{\circ}{\circ}$. Podemos observar nesta amostra, uma segunda etapa de degradação, separada da primeira, que se inicia a aproximadamente a $390^{\circ} \mathrm{C}$ e termina por volta de $430{ }^{\circ} \mathrm{C}$.

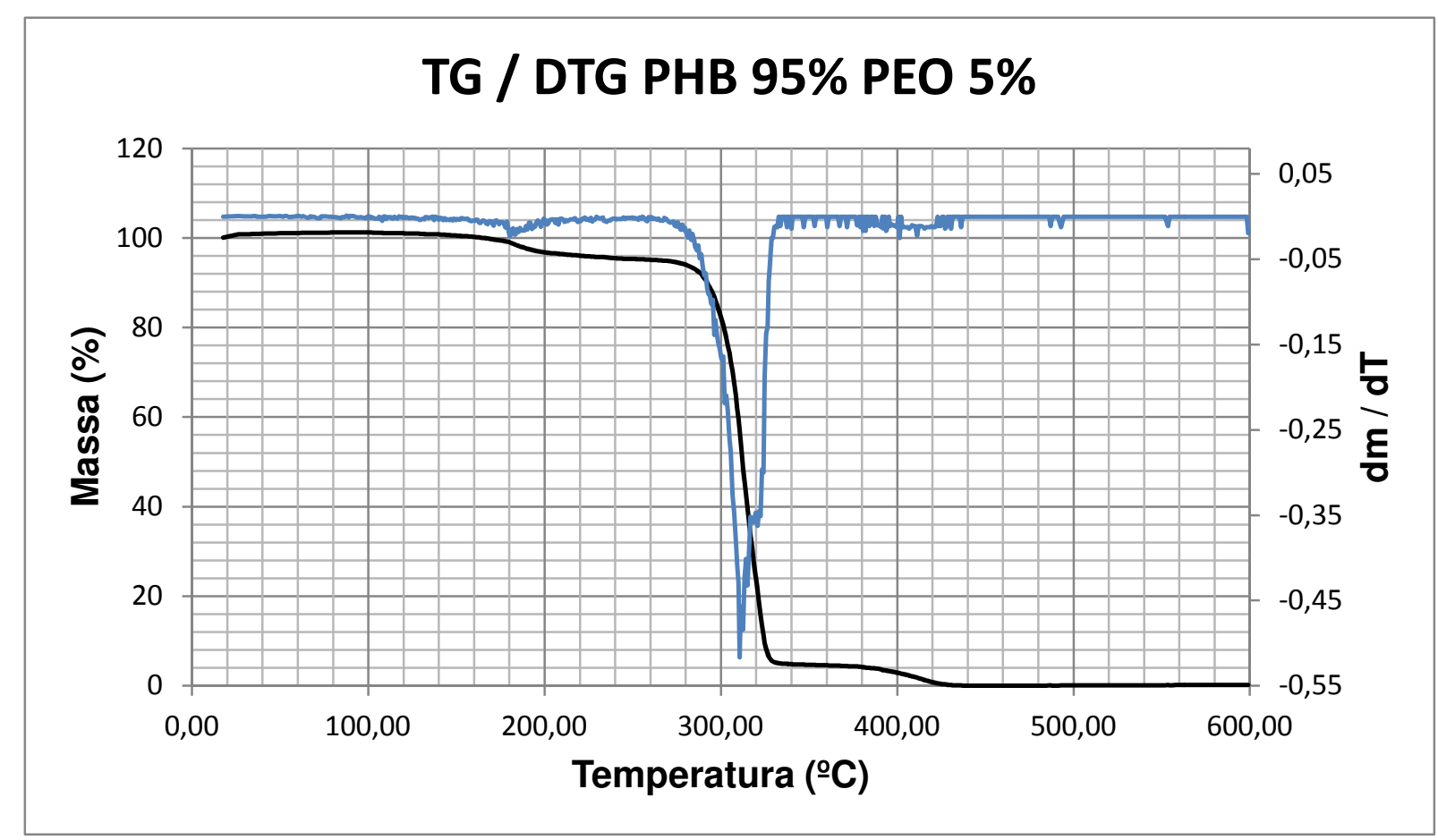

Figura 20 - Resultado TG - Amostra C1 (PHB/PEO 95/05)

A perda de massa correspondente à etapa 390-430 ${ }^{\circ} \mathrm{C}$ representa cerca de 5 $\%$ da massa total da amostra. De acordo com a literatura, a degradação térmica de poli(óxido de etileno) ocorreria nesta última faixa de temperatura. ${ }^{56}$ Observa-se que a principal etapa de degradação na faixa $280-330{ }^{\circ} \mathrm{C}$, com taxa máxima em $310^{\circ} \mathrm{C}$, apresenta-se em intervalo menor comparado com as blendas com PEG, cujos valores variaram de 60 a $120 \stackrel{\circ}{\circ}$, aumentando sistematicamente com o aumento da concentração de PEG.

O fato da degradação ocorrer em duas etapas distintas indica uma menor miscibilidade para a blenda de PHB / PEO. 


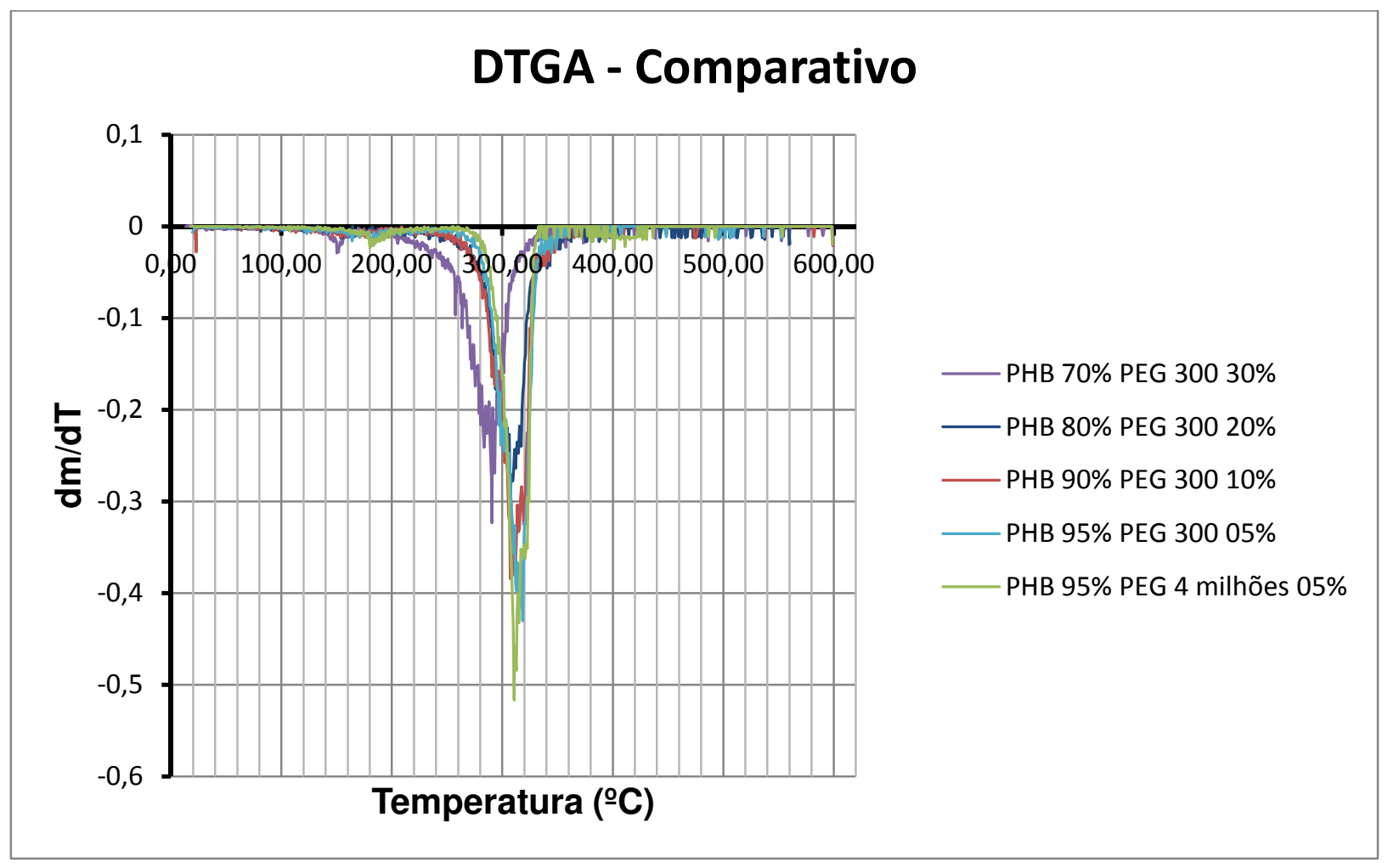

Figura 21 - Resultado DTG - Gráfico Comparativo

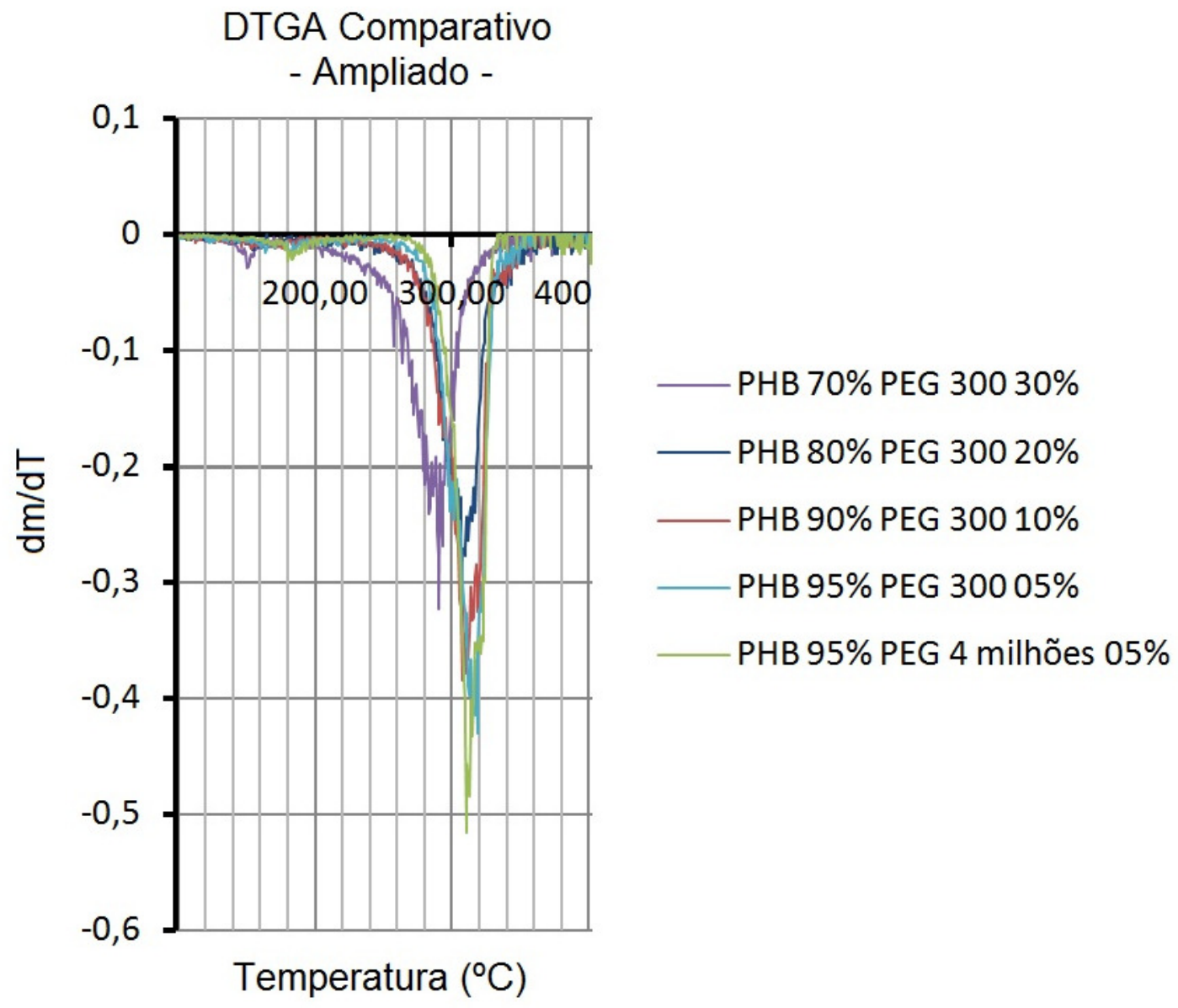

Figura 22 - Resultado TG - Gráfico comparativo ampliado 
Tabela 6: Temperaturas de degradação obtidas por TG e DTG

\begin{tabular}{|c|c|}
\hline Blenda & Faixa de Temperaturas de degradação $\left({ }^{\circ} \mathrm{C}\right)$ \\
\hline PHB/PEG 70/30 & $200-320$ \\
\hline PHB/PEG 80/20 & $260-340$ \\
\hline PHB/PEG 90/10 & $270-330$ \\
\hline PHB/PEG 95/05 & $280-330$ \\
\hline PHB/PEO 95/05 & $280-330$ \\
\hline
\end{tabular}

Nos gráficos comparativos (Figuras 21 e 22) e pela tabela 6, pode-se notar com mais clareza a influência que o PHB sofre em sua temperatura de degradação devido à presença do PEG/PEO como aditivo.

Nota-se que a temperatura de degradação do PHB aparenta diminuir com o aumento da concentração de PEG. Essa mudança é, no entanto, relativamente pequena para concentrações de PEG até $20 \%$ em massa, sendo mais significativa para a composição PHB/PEG 70/30.

\subsection{Microscopia Eletrônica de Varredura (MEV)}

Abaixo encontram-se as fotos comparativas dos filmes de PHB/PEG em diferentes composições e estágios de envelhecimento

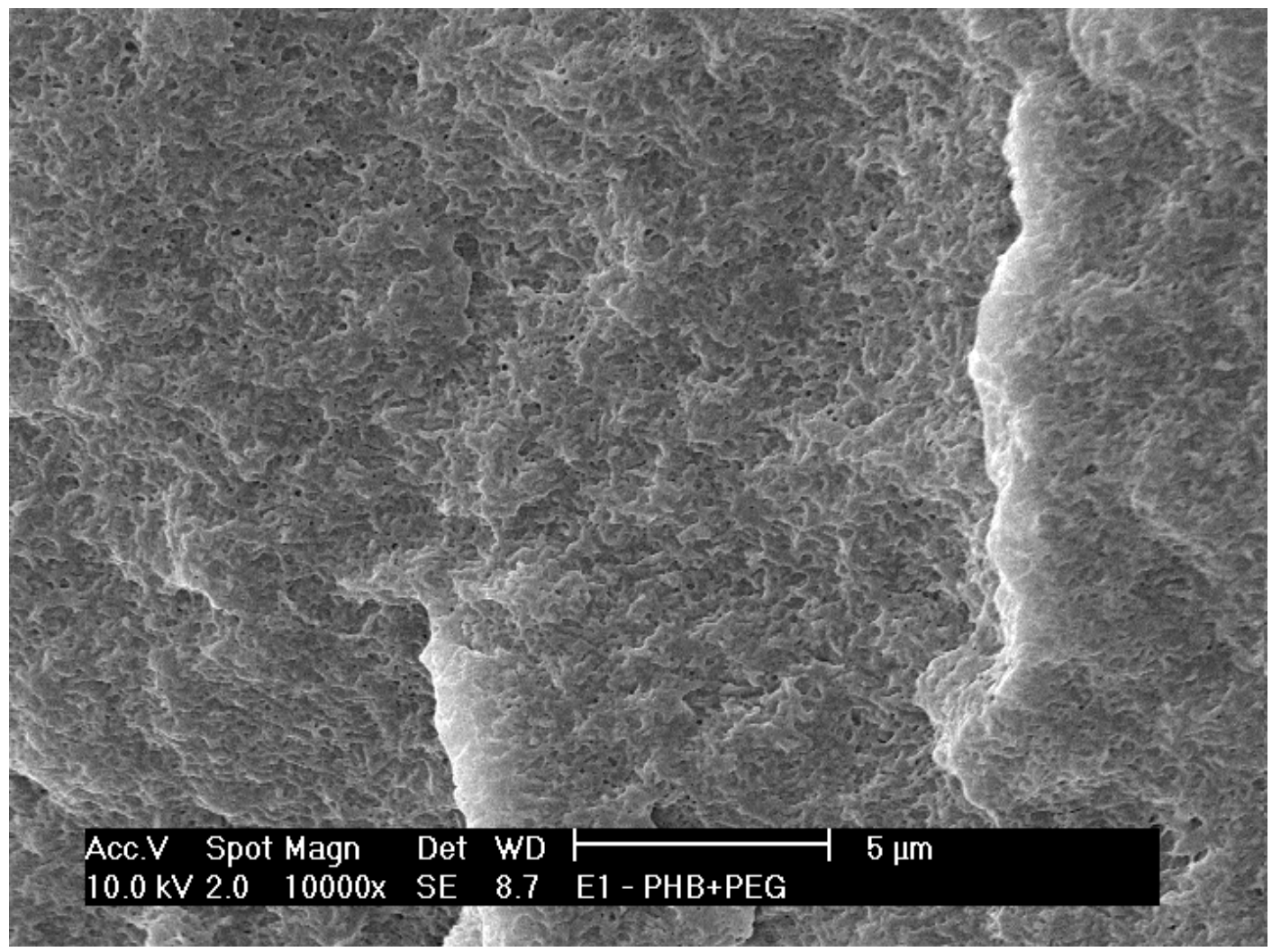

Figura 23: PHB/PEG 95/05 Recém Preparada 


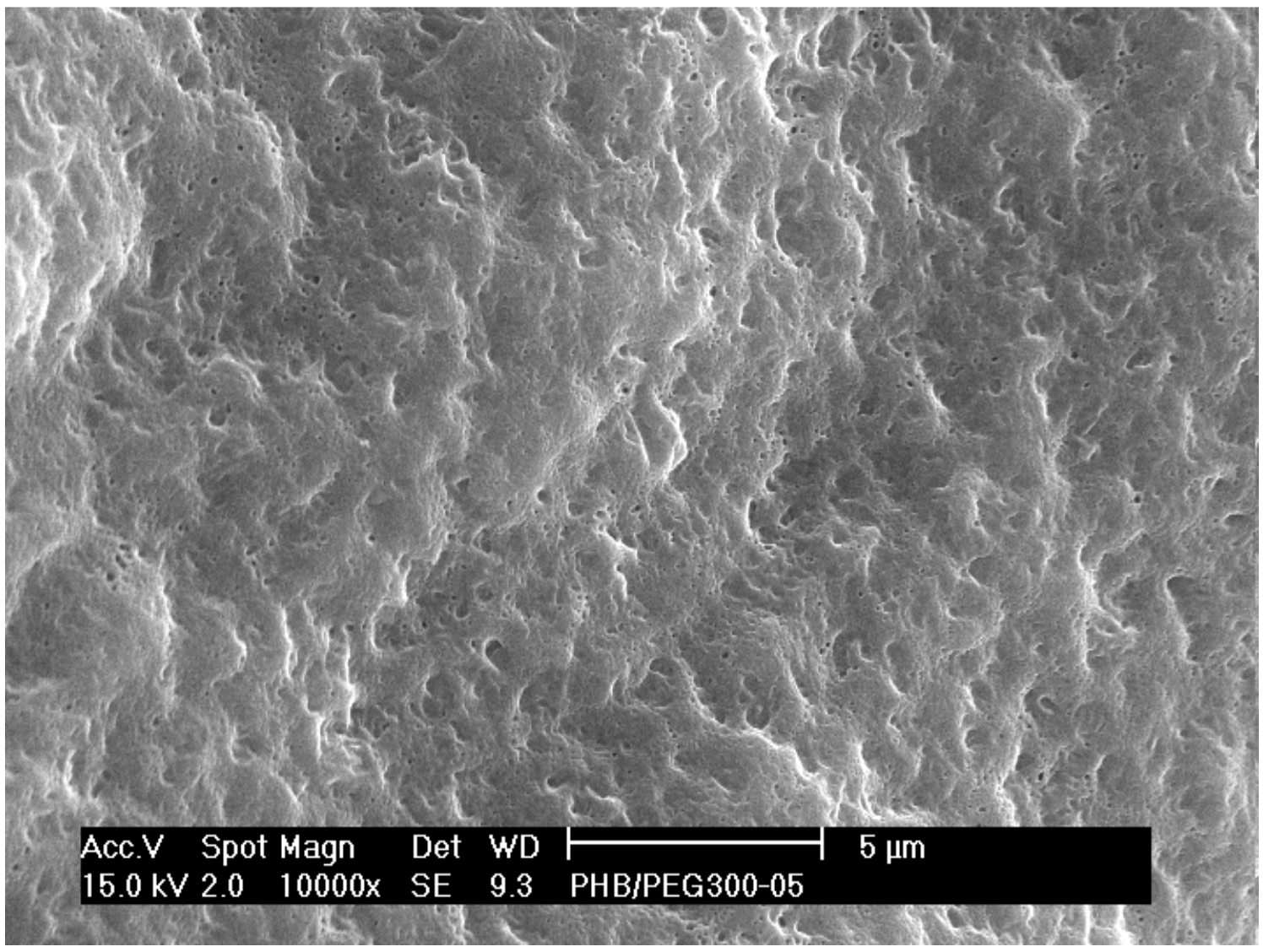

Figura 24: PHB/PEG 95/05 Envelhecida

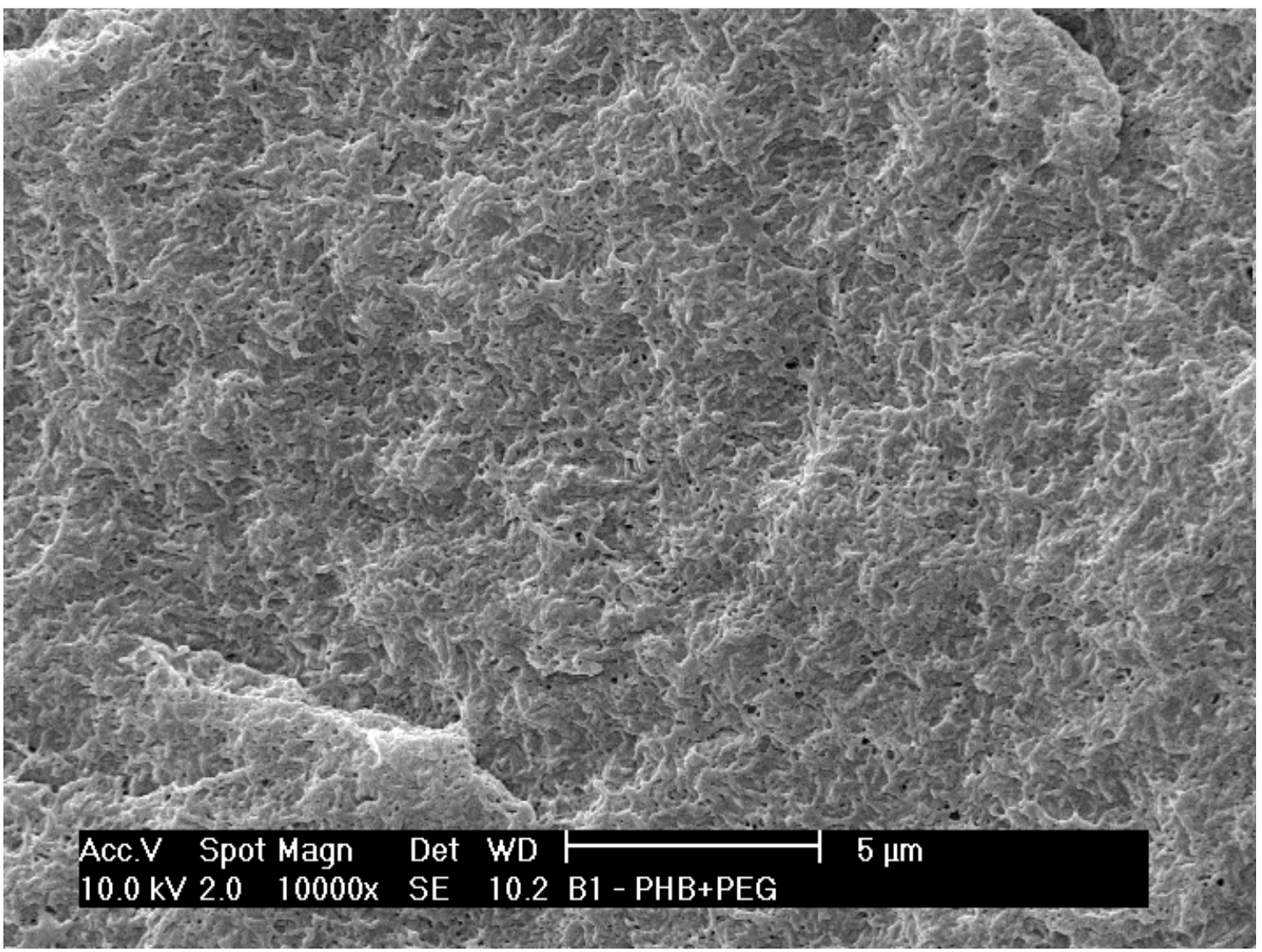

Figura 25: PHB/PEG 90/10 Recém Preparada 


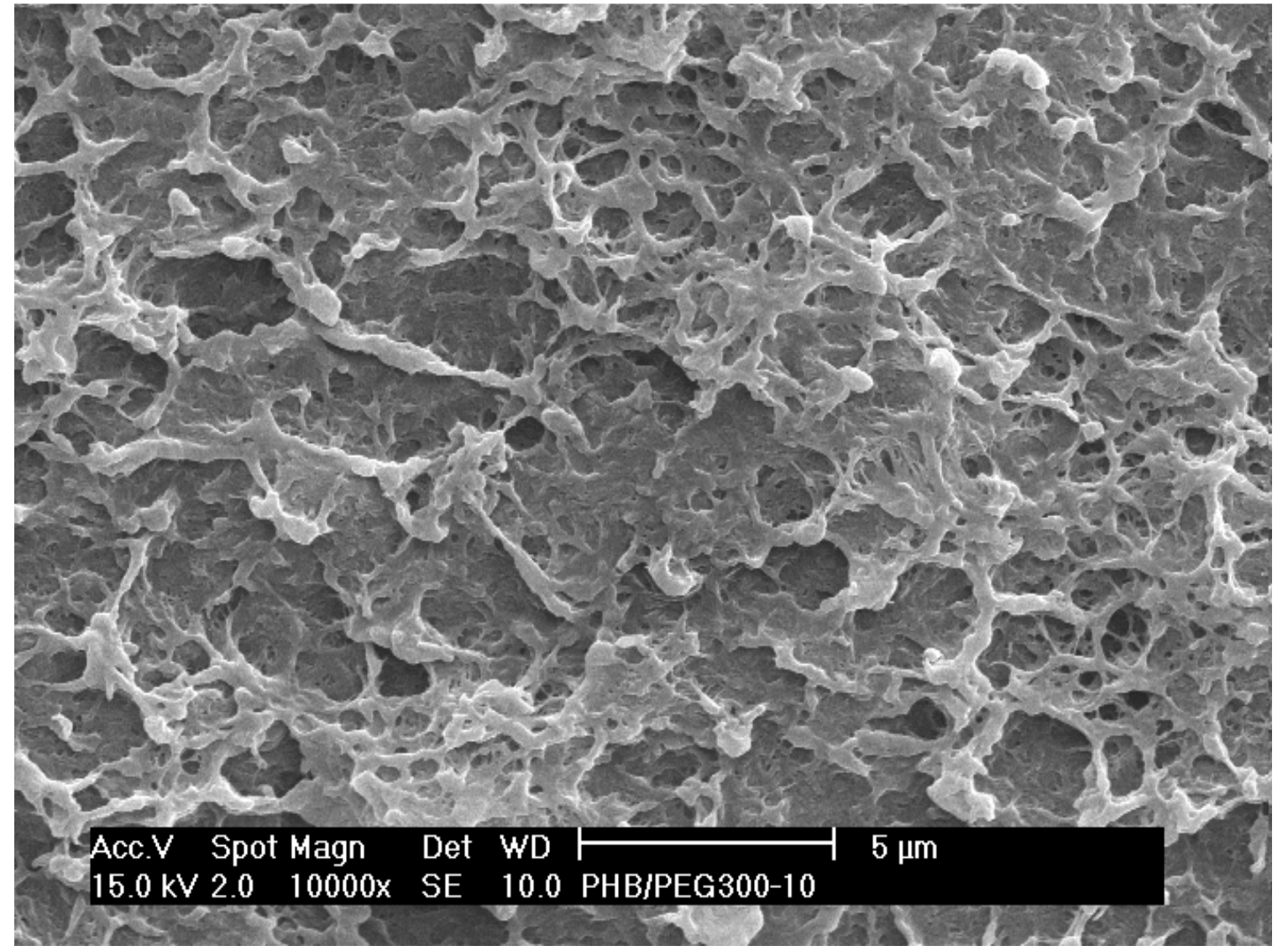

Figura 26: PHB/PEG 90/10 Envelhecida

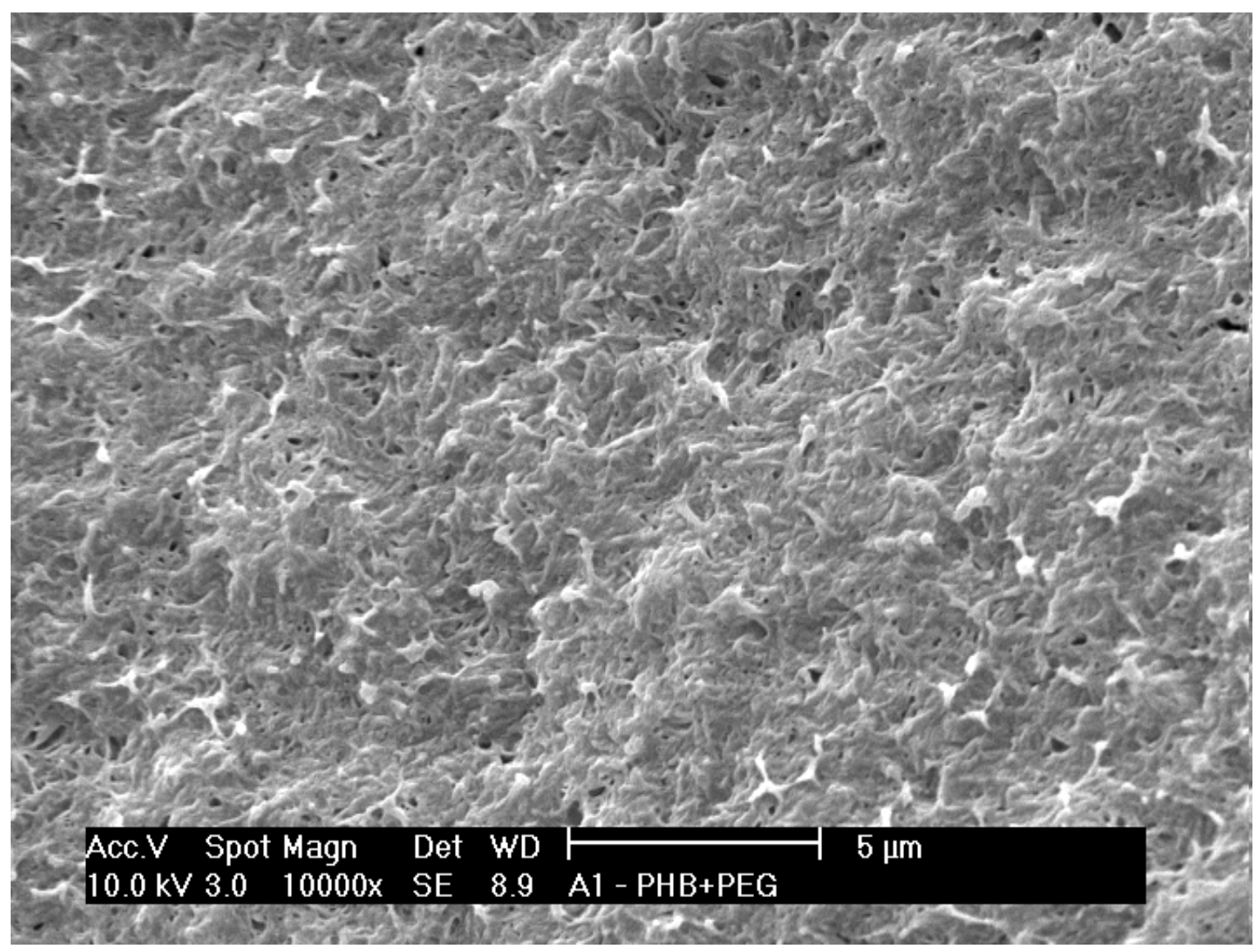

Figura 27: PHB/PEG 80/20 Recém Preparada 


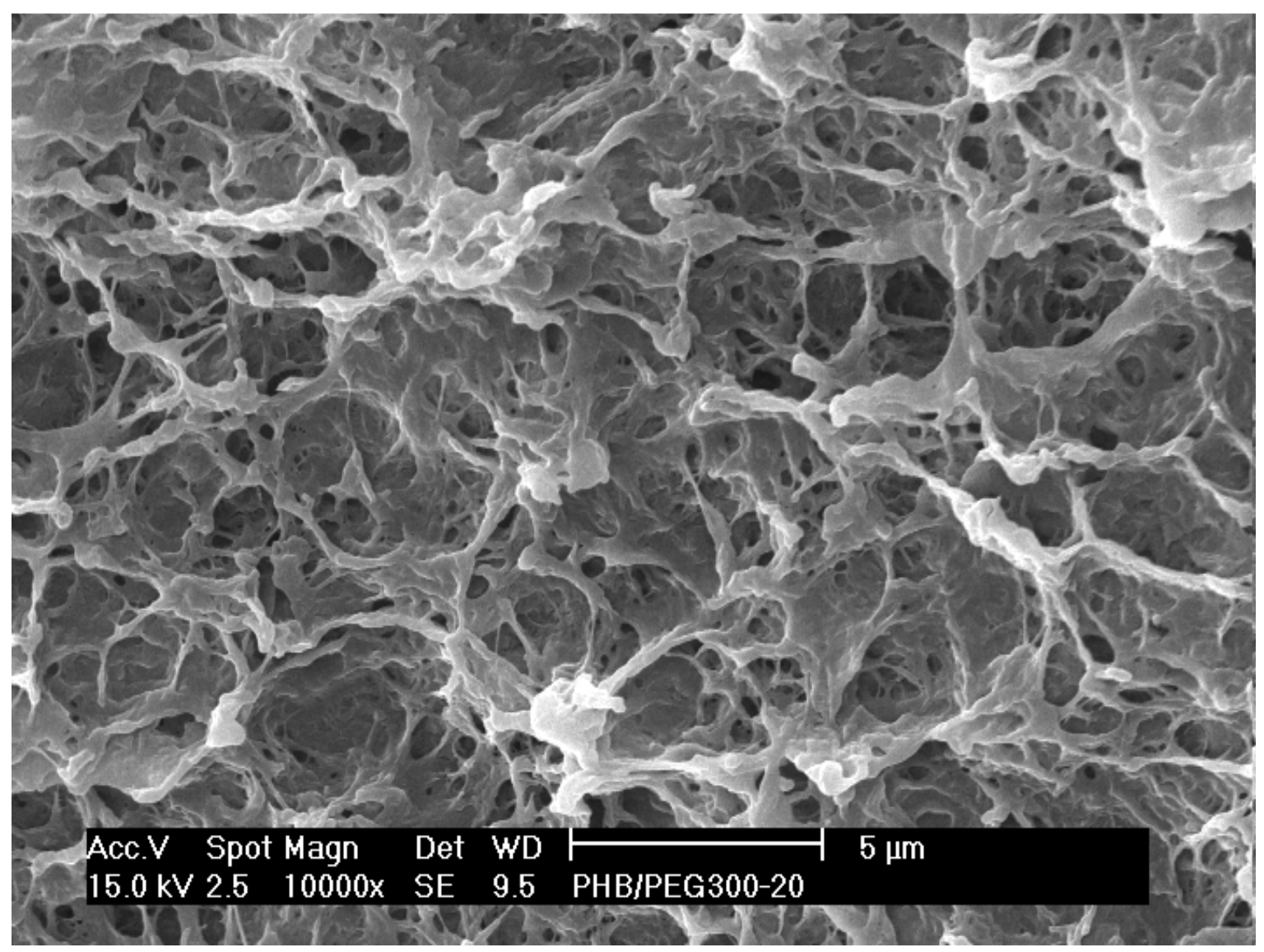

Figura 28: PHB/PEG 80/20 Envelhecida

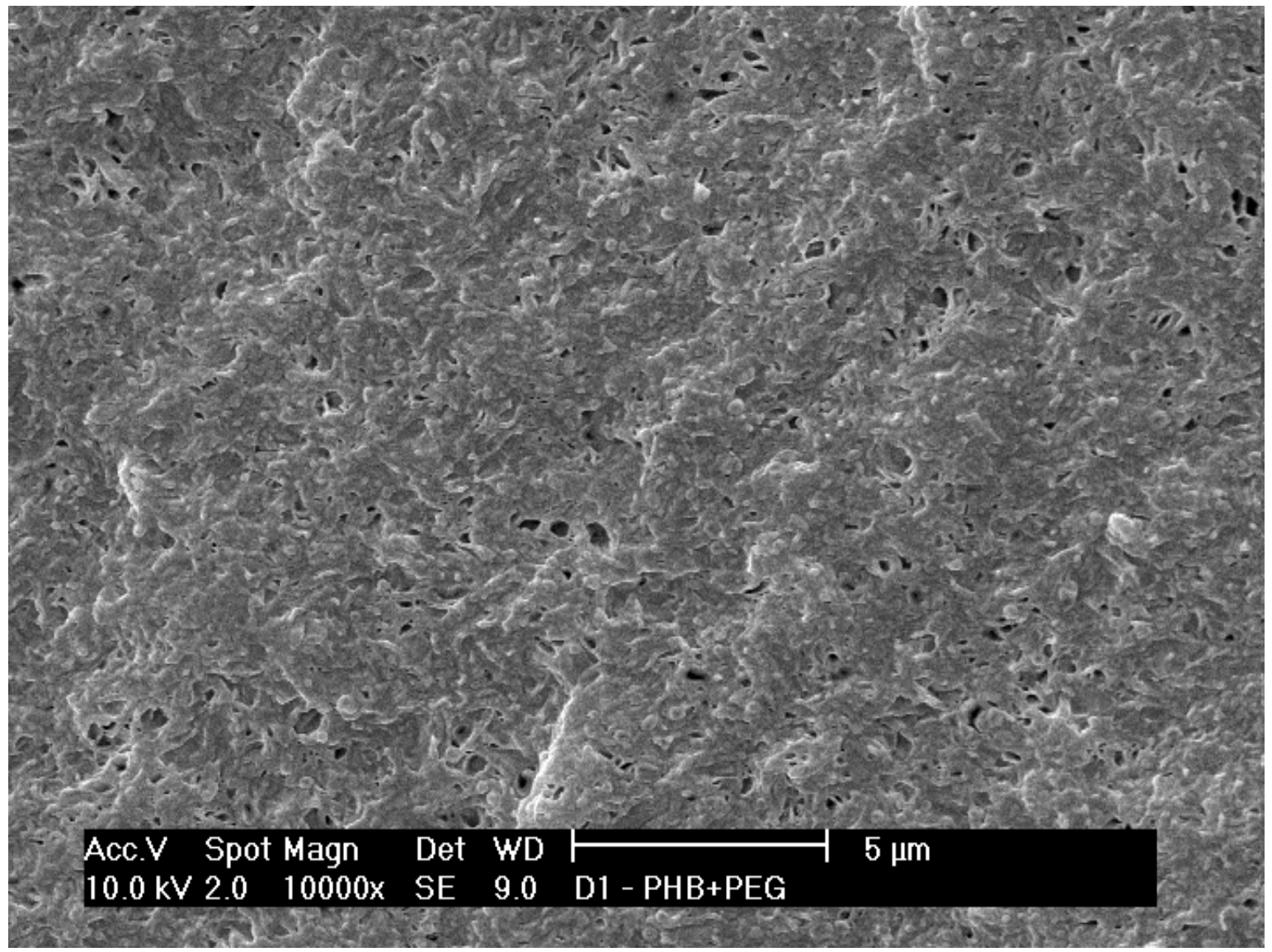

Figura 29: PHB/PEG 70/30 Recém Preparada 


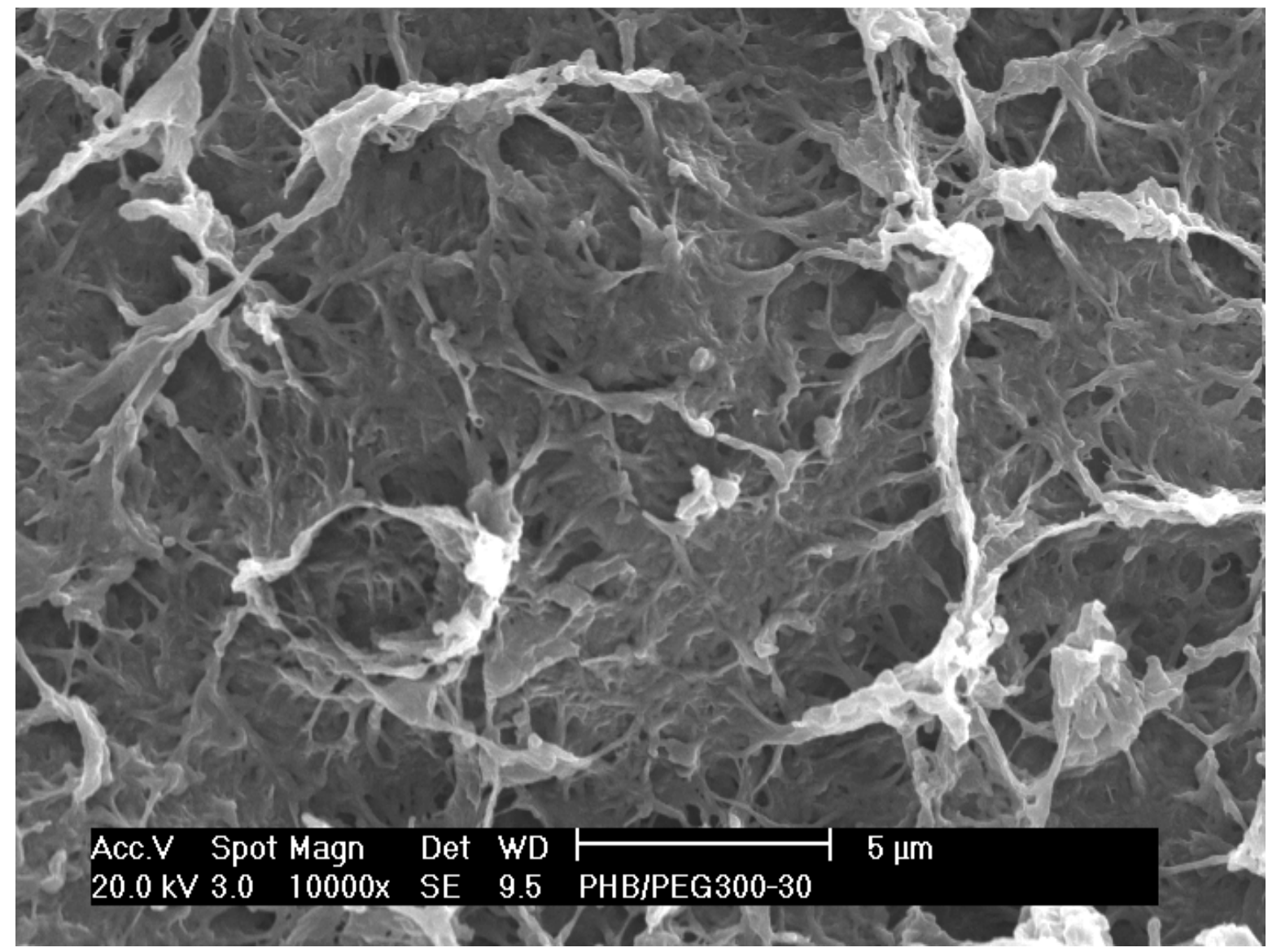

Figura 30: PHB/PEG 70/30 Envelhecida

As amostras da blenda de PHB/PEO recém preparada e envelhecida não demonstraram diferenças morfológicas no MEV, porém as blendas de PHB/PEG demonstram uma separação de fases, que aparece na forma de espaços vazios na matriz, como podemos ver nas Figuras 23-30. Estes espaços ocorrem devido à volatilização do PEG sob o alto vácuuo do MEV, e crescem de acordo com o aumento no teor de PEG e também com o maior tempo de estocagem (envelhecimento). 


\subsection{Difração de raios-X}

A Figura 31 mostra as curvas de difração de raios-X de alto ângulo (WAXS) das blendas de PEG/PEO e PHB.

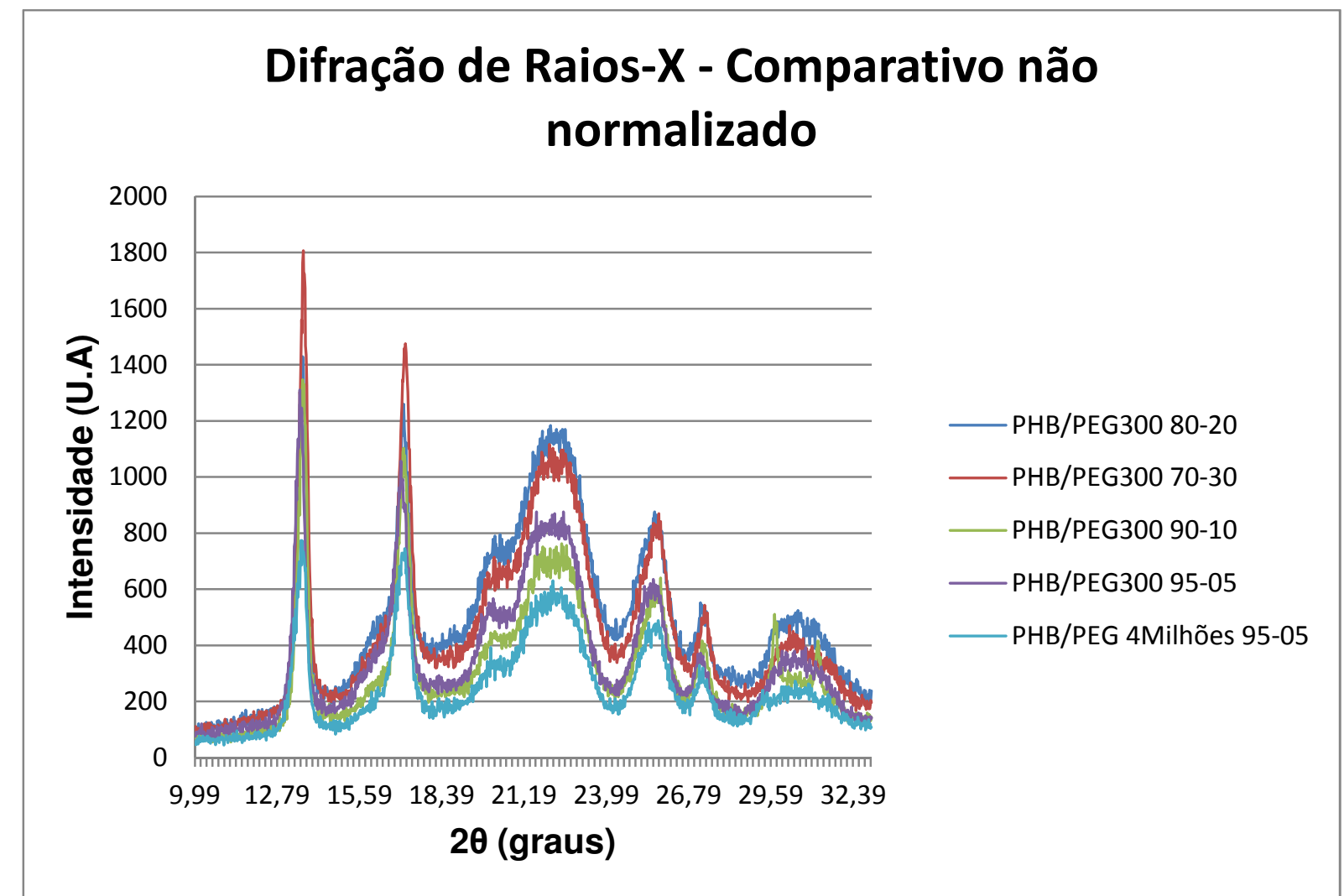

Figura 31 - Comparativo entre as difrações de raios-X (WAXD) das blendas recém-preparadas.

A partir das curvas de difração podemos observar que os planos de difração (posição 20) não variam conforme a composição das misturas, indicando que não há mudança na rede cristalina. Porém pode-se notar uma diferença na intensidade relativa dos picos de difração. Para determinarmos o grau de cristalinidade das misturas devemos descobrir a razão entre a intensidade de difração das regiões cristalinas e amorfas. Isso foi feito utilizando-se o programa Origin 7.5, conforme citado anteriormente. Os gráficos obtidos, tanto das amostras recém-preparadas como das amostras envelhecidas, já com as áreas calculadas, foram os seguintes: 

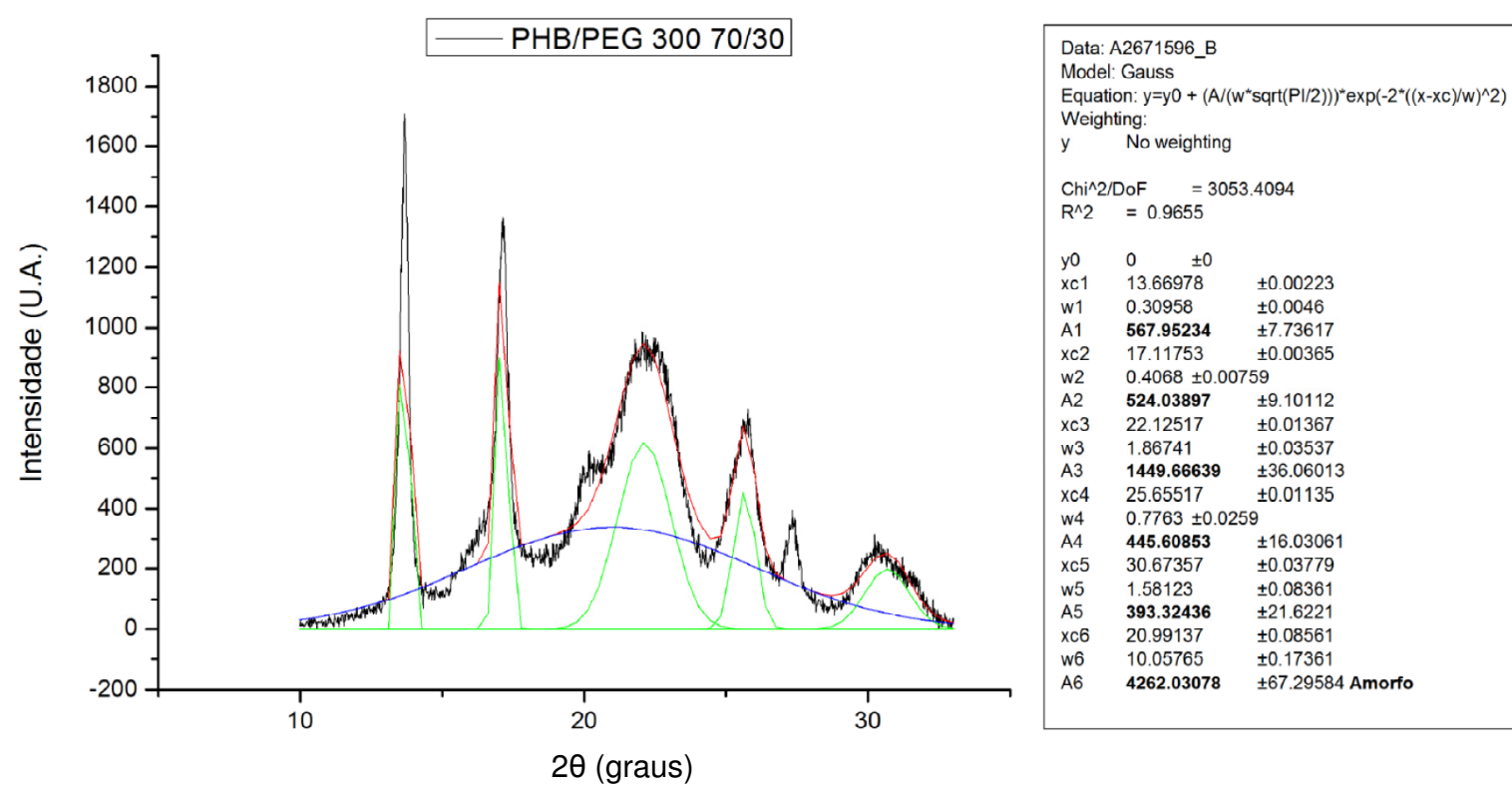

$2 \theta$ (graus)

Figura 32: Curva de difração de raios-X da blenda $\mathrm{PHB/PEG}$ de composição 70/30 recém preparada.
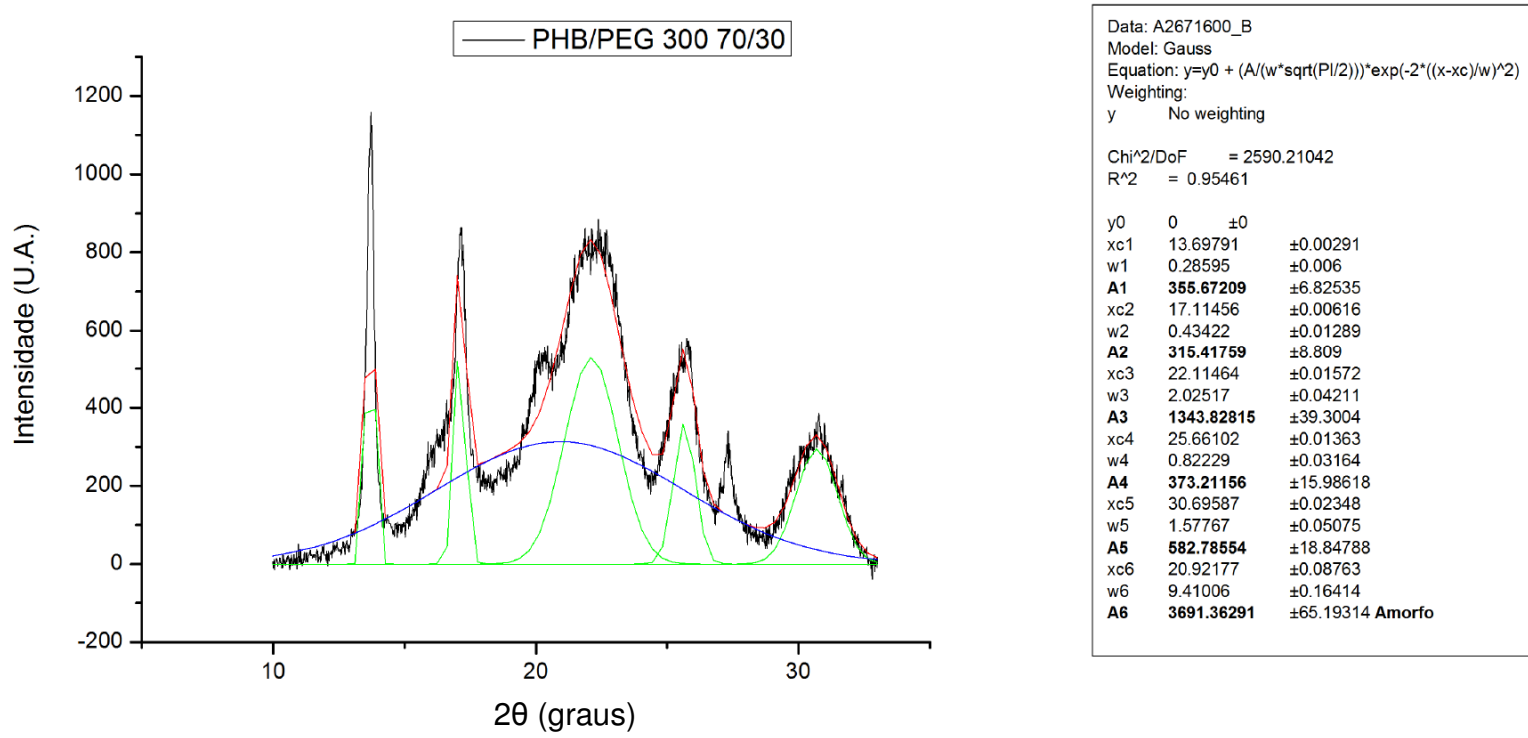

$2 \theta$ (graus)

Figura 33: Curva de difração de raios-X da blenda PHB/PEG de composição 70/30 envelhecida. 


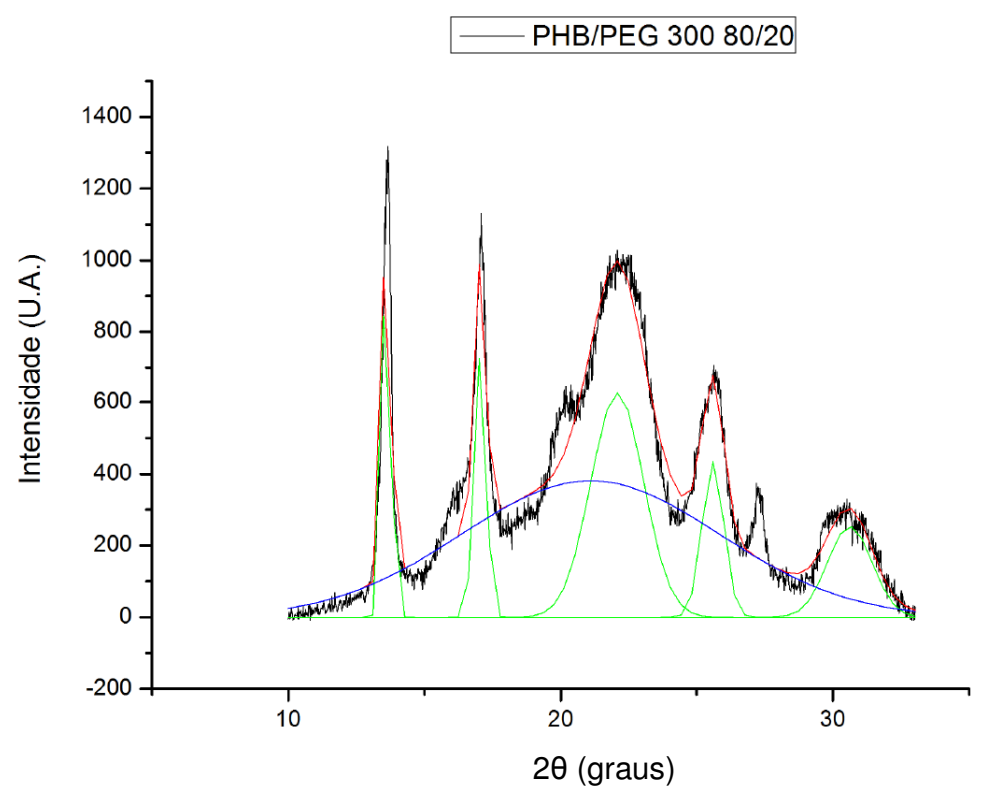

\begin{tabular}{|c|c|c|}
\hline \multicolumn{3}{|c|}{$\begin{array}{l}\text { Model: Gauss } \\
\text { Equation: } y=y 0+\left(A /\left(w^{*} \operatorname{sqr}((P I / 2))\right)^{*} \exp \left(-2^{*}((x-x c) / w)^{\wedge} 2\right)\right. \\
\text { Weighting: }\end{array}$} \\
\hline $\mathrm{y}$ & No weighting & \\
\hline Chis & $\mathrm{OOF} \quad=30$ & .05631 \\
\hline$R^{\wedge} 2$ & $=0.96228$ & \\
\hline y0 & $0 \quad \pm 0$ & \\
\hline$x c 1$ & 13.62253 & \pm 0.00294 \\
\hline $\mathrm{w} 1$ & 0.31913 & \pm 0.00608 \\
\hline A1 & 450.59159 & \pm 7.8969 \\
\hline$x c 2$ & 17.04916 & \pm 0.00529 \\
\hline w2 & $0.4362 \pm 0.0$ & \\
\hline A2 & 401.55195 & \pm 9.53332 \\
\hline$x c 3$ & 22.08346 & \pm 0.01395 \\
\hline w3 & 1.93814 & \pm 0.03723 \\
\hline A3 & 1521.00772 & \pm 40.29599 \\
\hline$x c 4$ & 25.5964 & \pm 0.01218 \\
\hline w4 & 0.80067 & \pm 0.02813 \\
\hline A4 & 435.53402 & \pm 16.87648 \\
\hline$x c 5$ & 30.61835 & \pm 0.03015 \\
\hline w5 & $1.629 \pm 0.0$ & \\
\hline A5 & 517.45781 & \pm 21.61774 \\
\hline$x c 6$ & 21.09563 & \pm 0.07597 \\
\hline w6 & 9.51022 & \pm 0.15231 \\
\hline A6 & 4537.84451 & \pm 68.81035 Amorfo \\
\hline
\end{tabular}

Figura 34: Curva de difração de raios-X da blenda PHB/PEG de composição 80/20 recém preparada.
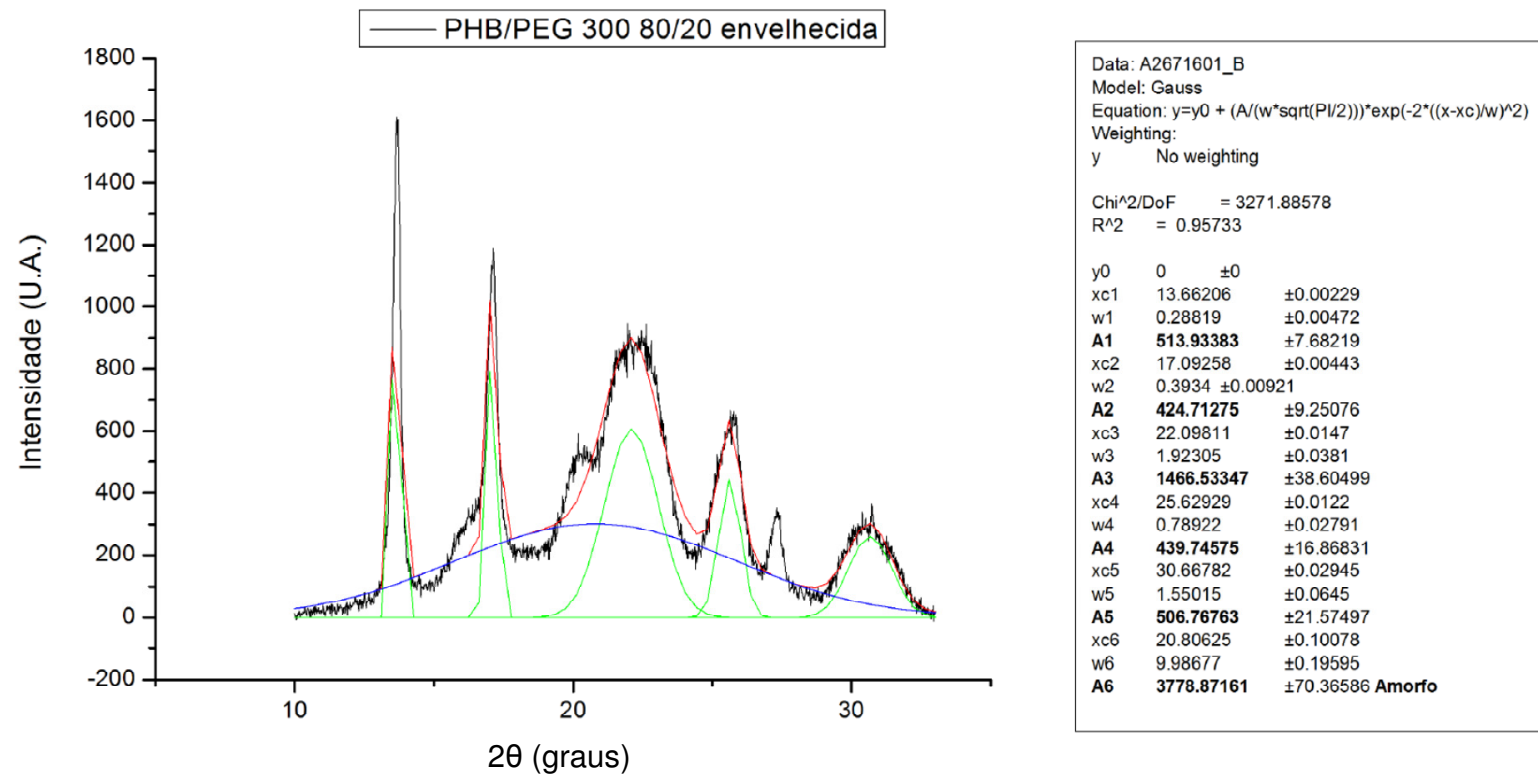

Figura 35: Curva de difração de raios-X da blenda PHB/PEG de composição 80/20 envelhecida. 


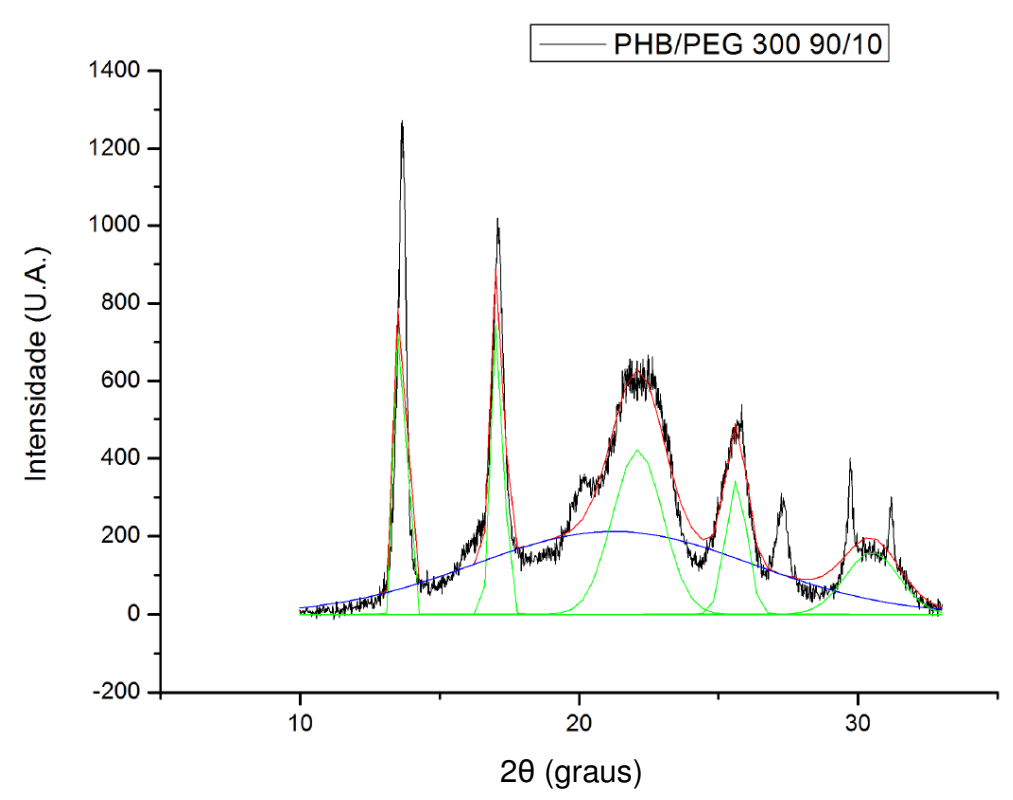

\begin{tabular}{|c|c|c|}
\hline $\begin{array}{l}\text { Equation: } y=y 0+\left(A /\left(w^{*} s q r t(P I / 2)\right)\right)^{*} \exp \left(-2^{*}((x-x c) / w)^{2} 2\right) \\
\text { Weighting: }\end{array}$ & $\begin{array}{l}\text { A2671597_B } \\
\text { Gauss } \\
\text { on: } y=y 0+(A /) \\
\text { ting: }\end{array}$ & $\left.\left.{ }^{*} \operatorname{sqrt}(P \mathrm{P} / 2)\right)\right)^{*} \exp \left(-2^{*}((\mathrm{x}-\mathrm{xc}) / \mathrm{w})^{\wedge} 2\right)$ \\
\hline \multicolumn{3}{|c|}{ y No weighting } \\
\hline \multicolumn{3}{|c|}{ Chi^2/DoF $\quad=2275.29729$} \\
\hline$R^{\wedge} 2$ & $=0.94914$ & \\
\hline yo & $0 \pm 0$ & \\
\hline xc1 & 13.65086 & \pm 0.00255 \\
\hline w1 & 0.31836 & \pm 0.00526 \\
\hline A1 & 447.80215 & \pm 6.79321 \\
\hline xc2 & 17.08422 & \pm 0.0042 \\
\hline $\mathrm{w} 2$ & 0.42381 & \pm 0.00873 \\
\hline A2 & 418.18982 & \pm 8.03626 \\
\hline$x<3$ & 21.22984 & \pm 0.12311 \\
\hline w3 & 9.95971 & \pm 0.25578 \\
\hline A3 & 2649.01692 & \pm 61.23436 Amorfo \\
\hline $\mathrm{xc4}$ & 25.63762 & \pm 0.01295 \\
\hline w4 & $0.7606 \pm 0.03$ & \\
\hline A4 & 327.14896 & \pm 14.22737 \\
\hline xc5 & 30.49776 & \pm 0.04594 \\
\hline w5 & 1.92981 & \pm 0.10642 \\
\hline A5 & 383.97536 & \pm 23.75421 \\
\hline$x c 6$ & 22.10566 & \pm 0.01708 \\
\hline w6 & 1.79391 & \pm 0.04402 \\
\hline A6 & 946.51263 & \pm 30.27084 \\
\hline
\end{tabular}

Figura 36: Curva de difração de raios-X da blenda PHB/PEG de composição 90/10 recém preparada.
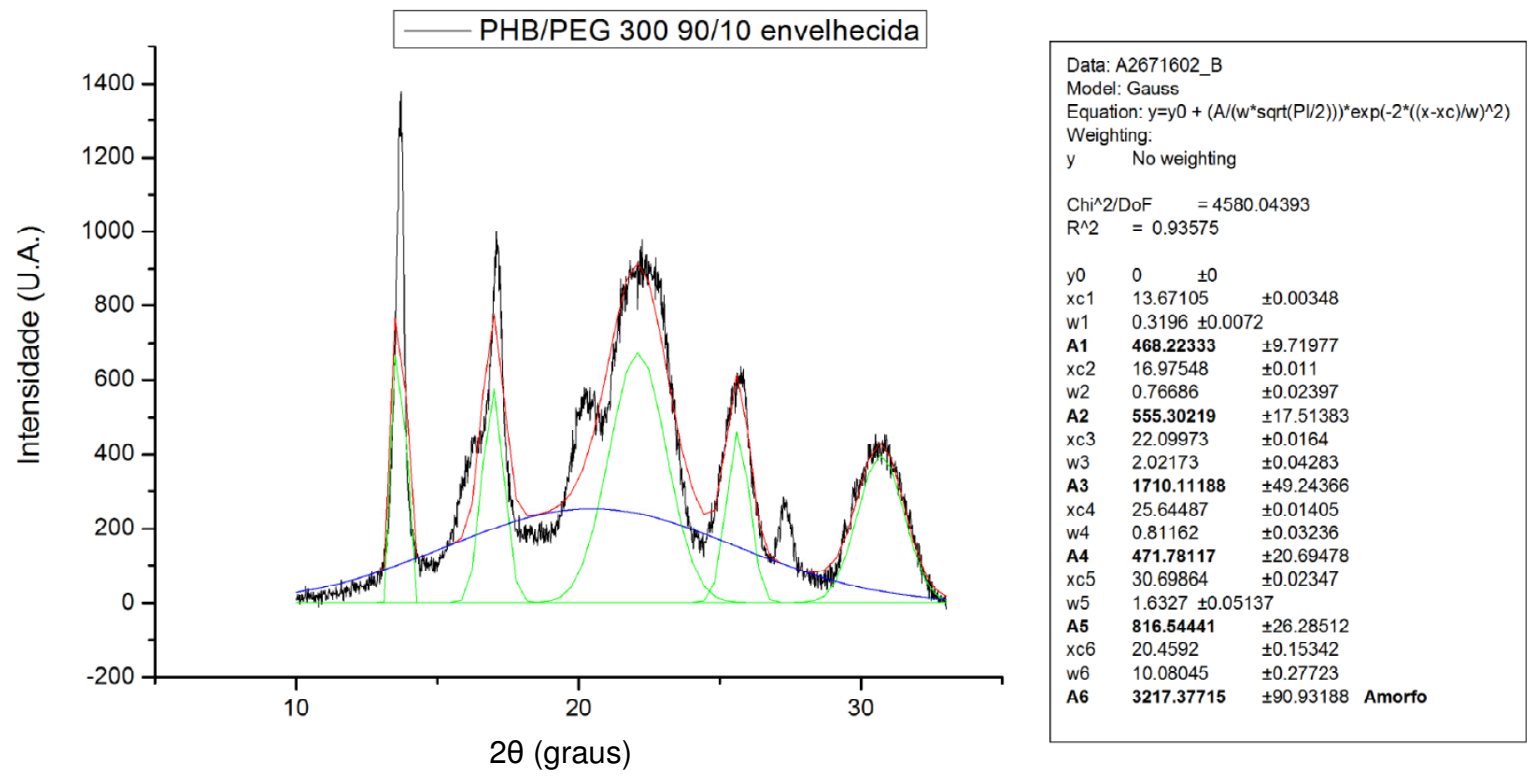

Figura 37: Curva de difração de raios-X da blenda PHB/PEG de composição 90/10 envelhecida. 

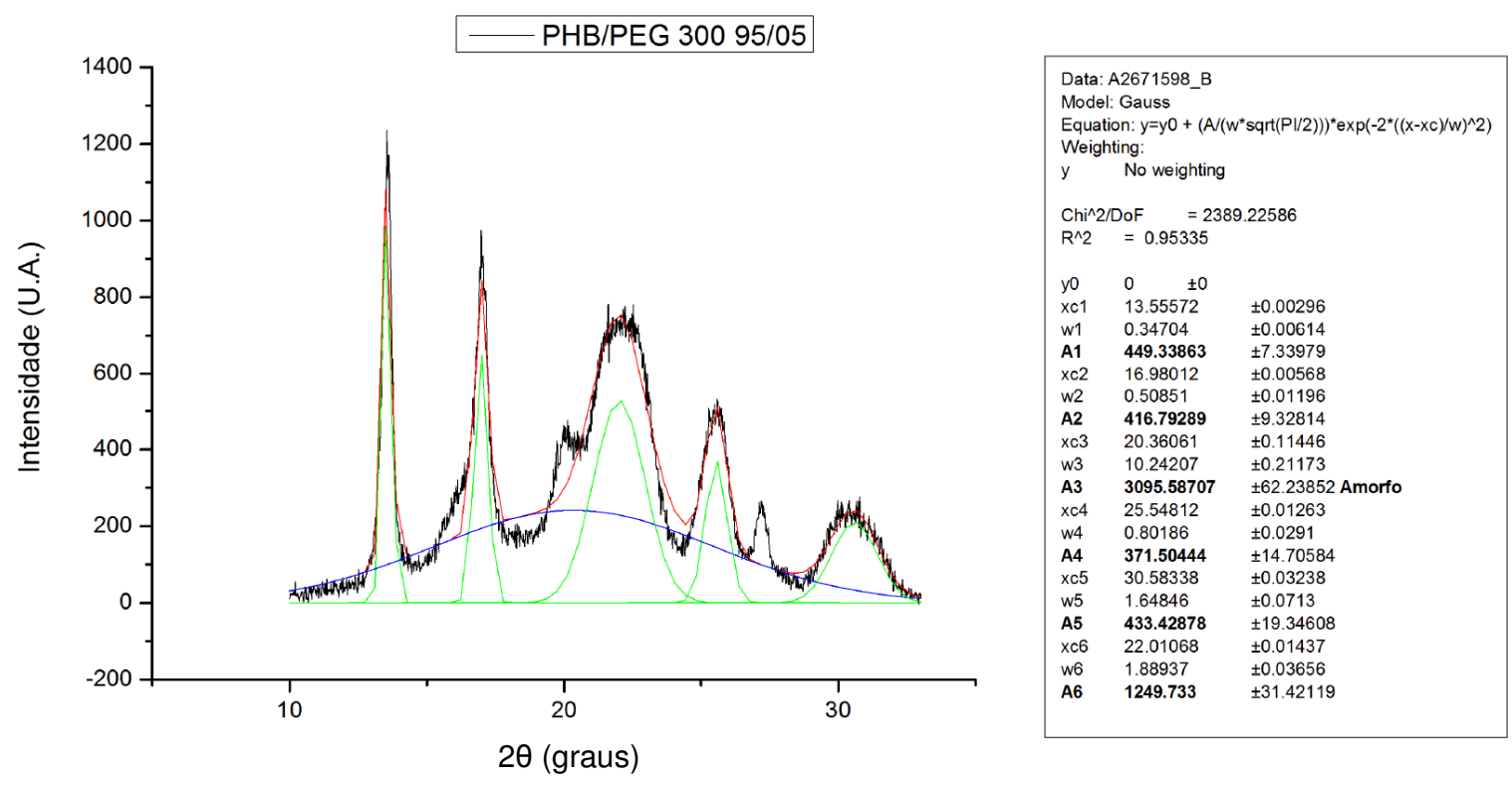

Figura 38: Curva de difração de raios-X da blenda PHB/PEG de composição 95/05 recém preparada.

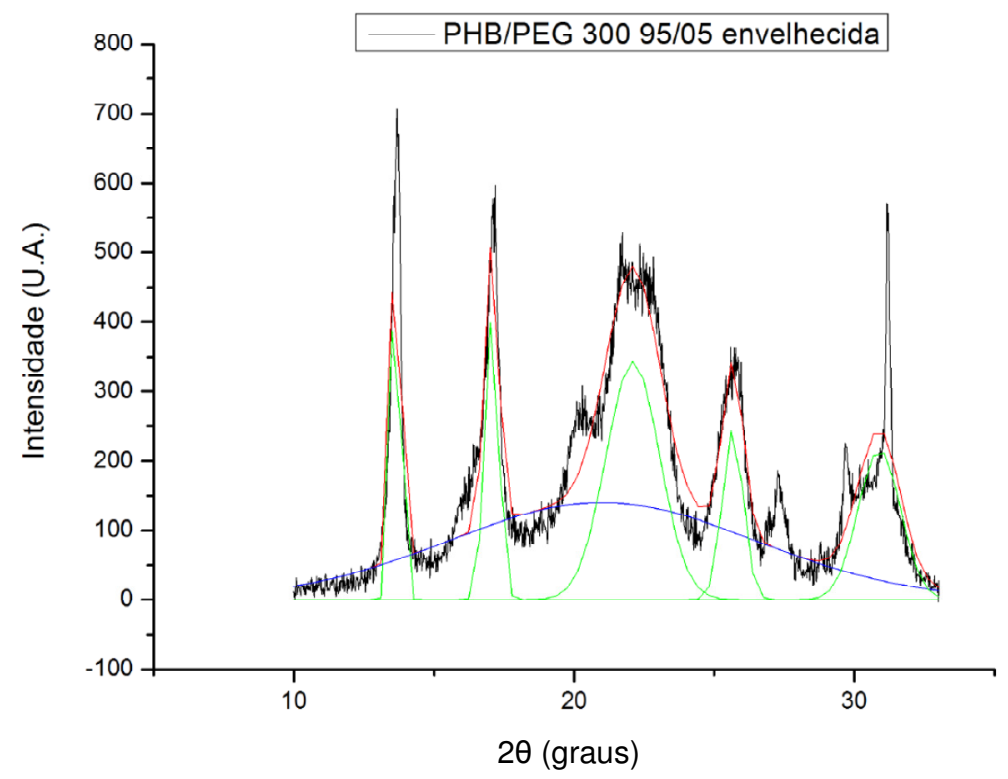

\begin{tabular}{|c|c|c|}
\hline \multicolumn{3}{|c|}{$\begin{array}{l}\text { Model: Gauss } \\
\text { Equation: } y=y 0+\left(A /\left(w^{*} \operatorname{sqr}((P / / 2))\right)^{*} \exp \left(-2^{*}((x-x c) / w)^{\wedge} 2\right)\right. \\
\text { Weighting: }\end{array}$} \\
\hline y & \multicolumn{2}{|c|}{ No weighting } \\
\hline \multirow{2}{*}{\multicolumn{3}{|c|}{$\begin{array}{l}\text { Chi^2/DoF }=1835.33293 \\
\mathrm{R}^{\wedge} 2=0.90872\end{array}$}} \\
\hline & & \\
\hline y0 & & \\
\hline$x c 1$ & 1365485 & +0.00433 \\
\hline w1 & 0.32727 & \pm 0.00894 \\
\hline A1 & 246.40147 & \pm 6.17695 \\
\hline xc2 & 17.06169 & \pm 0.00794 \\
\hline w2 & 0.50001 & \pm 0.01669 \\
\hline A2 & 254.50165 & \pm 8.05996 \\
\hline $\mathrm{xc} 3$ & 21.00042 & \pm 0.16231 \\
\hline w3 & 11.0875 & \pm 0.36491 \\
\hline A3 & 1937.21366 & \pm 52.88248 Amorfo \\
\hline $\mathrm{xc4}$ & 25.66063 & \pm 0.01602 \\
\hline w4 & 0.74448 & \pm 0.03568 \\
\hline A4 & 229.71768 & \pm 11.50604 \\
\hline$x c 5$ & 30.89019 & \pm 0.02596 \\
\hline w5 & 1.50428 & \pm 0.05824 \\
\hline A5 & 409.4264 & \pm 16.73574 \\
\hline$x c 0$ & 22.09709 & \pm 0.01913 \\
\hline w6 & 1.90991 & \pm 0.04923 \\
\hline A6 & 822.26892 & \pm 27.35907 \\
\hline
\end{tabular}

Figura 39: Curva de difração de raios-X da blenda PHB/PEG de composição 95/05 envelhecida. 

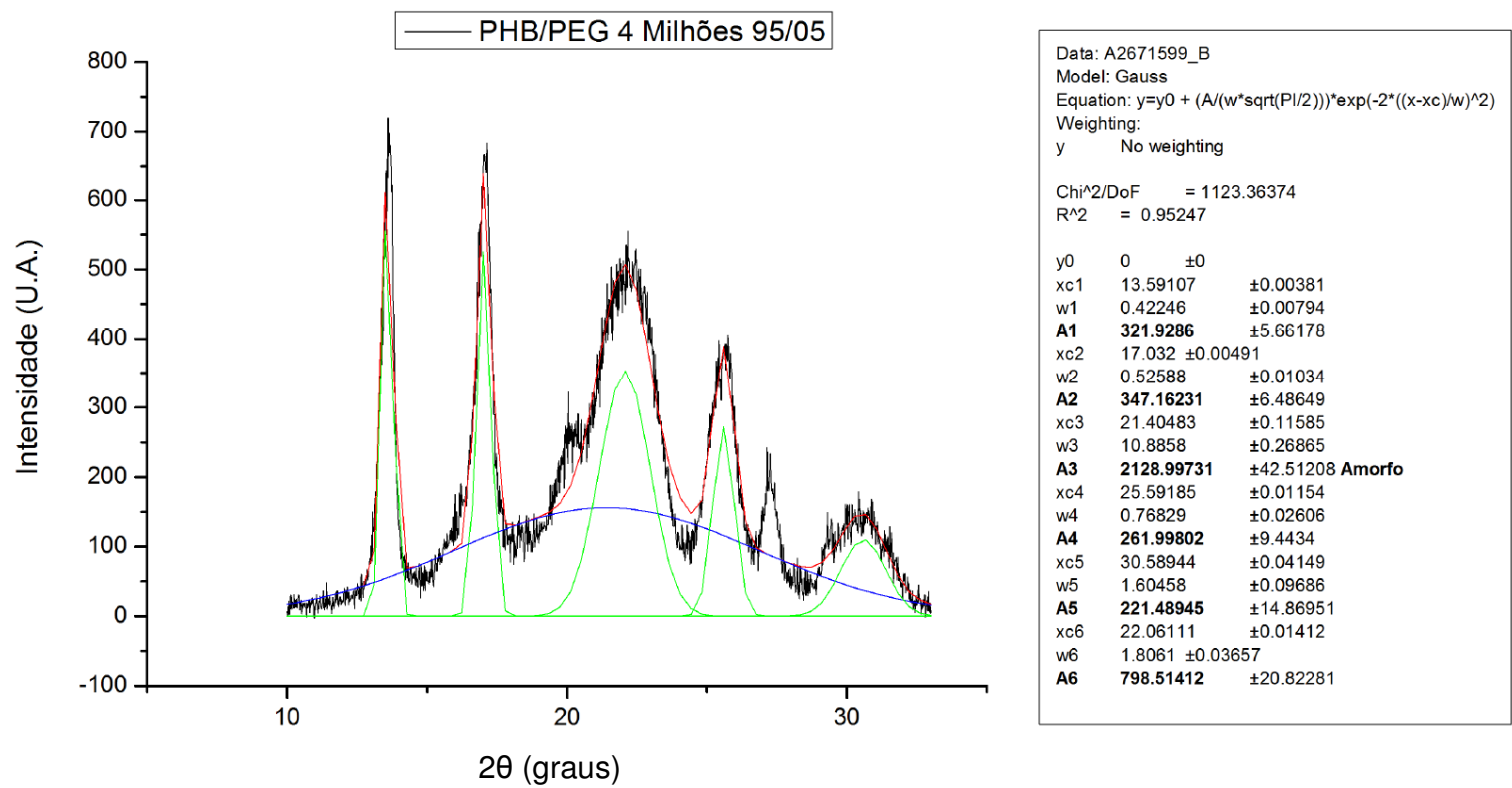

Figura 40: Curva de difração de raios-X da blenda PHB/PEO de composição 95/05 recém preparada.
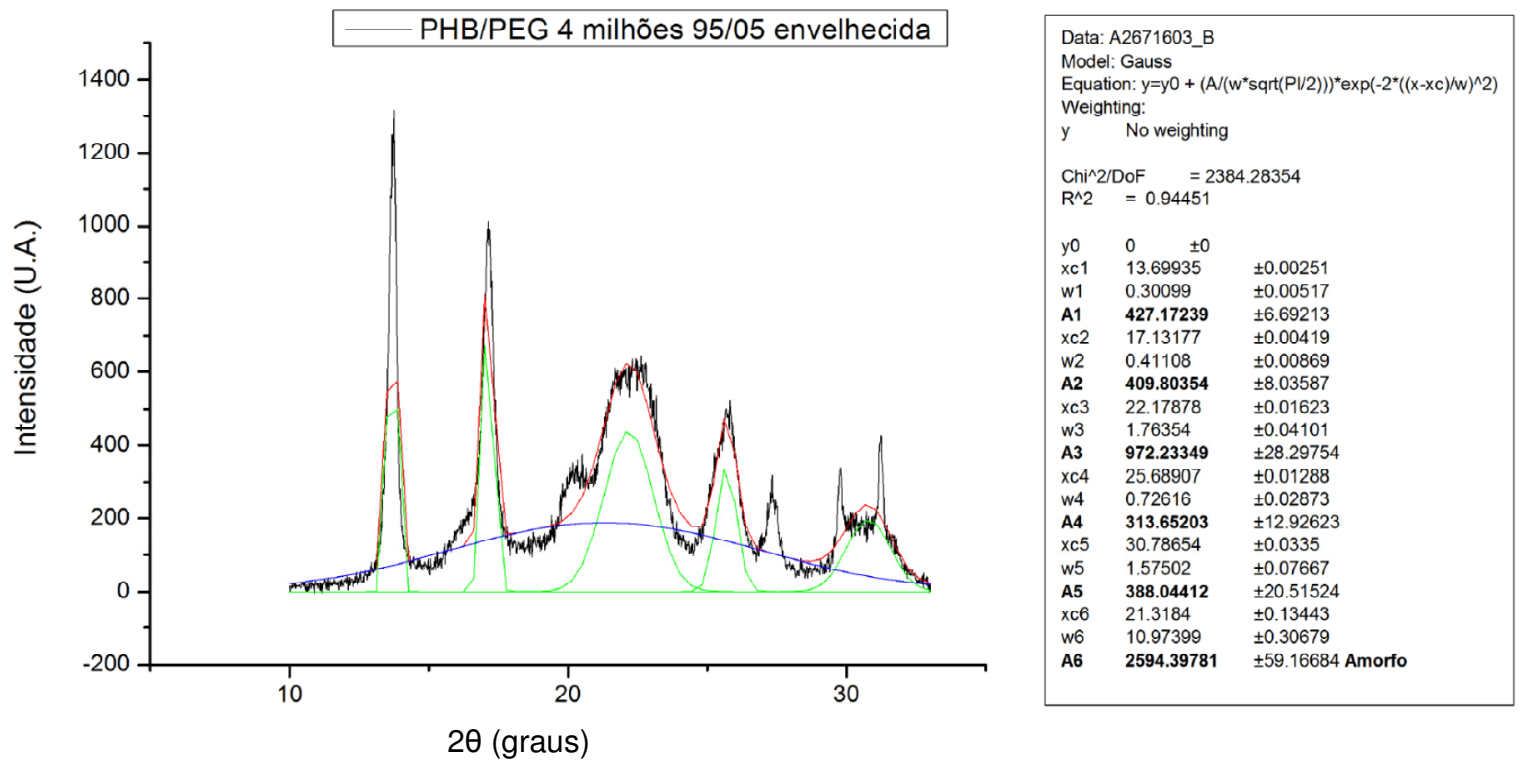

Figura 41: Curva de difração de raios-X da blenda PHB/PEO de composição 95/05 envelhecida.

O grau de cristalinidade calculado de cada amostra é dado na tabela abaixo:

Tabela 7 - Grau de cristalinidade das misturas PHB/PEG/PEO recém-preparadas e envelhecidas

\begin{tabular}{|c|c|c|c|c|c|}
\hline Amostra & $(95 / 5) \%$ PEO & $(95 / 5) \%$ PEG & $(90 / 10) \%$ & $(80 / 20) \%$ & $(70 / 30) \%$ \\
\hline nova & $47,8 \%$ & $48,5 \%$ & $48,8 \%$ & $42,3 \%$ & $44,2 \%$ \\
\hline envelhecida & $49,2 \%$ & $51,1 \%$ & $55,6 \%$ & $47,0 \%$ & $44,5 \%$ \\
\hline
\end{tabular}

Através da Tabela 7 podemos ver que a adição de PEG/PEO leva à uma diminuição substancial no grau de cristalinidade do PHB, já que o PHB puro 
apresenta cerca de $60-70 \%$ de cristalinidade ${ }^{1}$ e a incorporação de $5 \%$ de PEG reduz esse valor para aproximadamente $48,5 \%$. Por outro lado, o aumento no teor de PEG não causa diminuição significativa no grau de cristalinidade da amostra em relação as amostras de menor teor.

O grau de cristalinidade é uma propriedade cuja a análise é fundamental para este estudo, uma vez que as características quebradiças do PHB são em grande parte atribuídas ao seu alto grau de cristalinidade. Assim sendo, a adição de uma pequena quantidade de PEG (5\%) já traz uma potencial melhora para a tenacidade da blenda.

Os dados acima também apontam para uma recristalização da blenda com o tempo de armazenamento. As amostras contendo PEG sofreram um aumento de até $7 \%$ no seu grau de cristalinidade após três meses de armazenamento.

PEO aparenta ter um efeito semelhante na cristalinidade da blenda se comparado ao PEG, e aparentemente demonstra menor recristalinização com o tempo de armazenamento em relação às amostras contendo PEG.

\subsection{Calorimetria diferencial exploratória (DSC)}

As Figuras 42-59, abaixo, trazem os resultados individuais das três etapas dos ensaios de DSC, primeiro aquecimento, resfriamento e segundo aquecimento. 


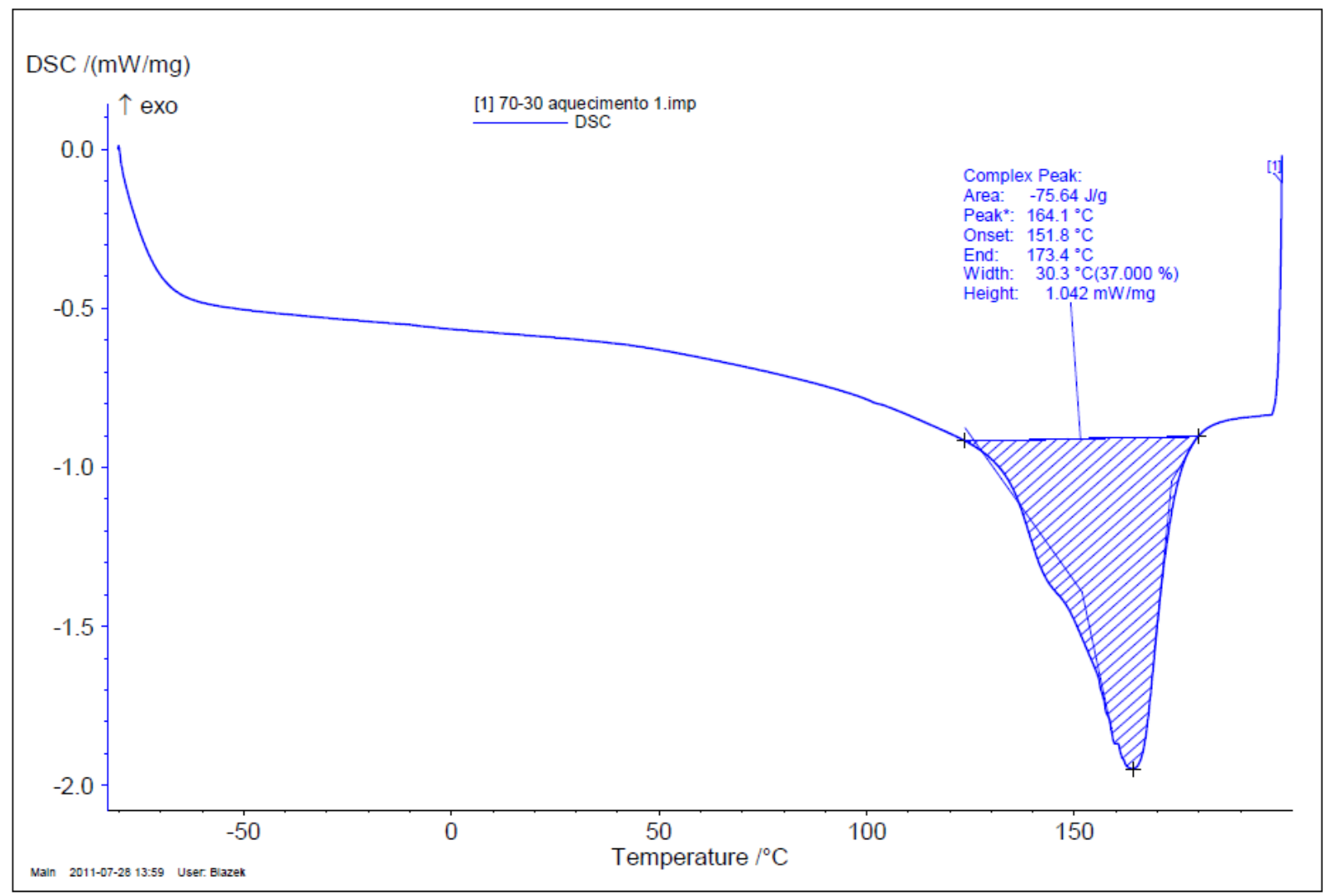

Figura 42: DSC da blenda PHB/PEG de composição 70/30, 1ำ aquecimento

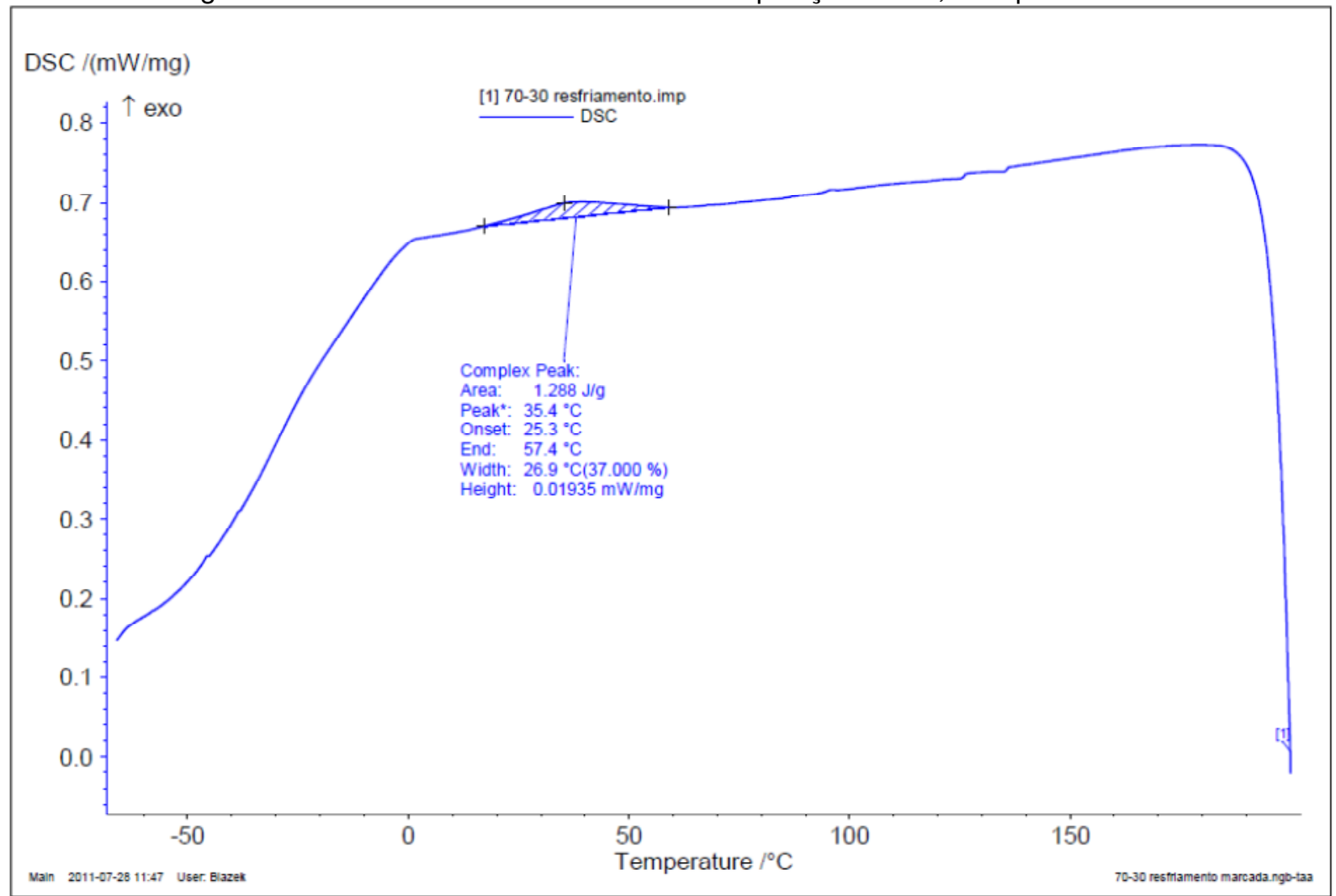

Figura 43: DSC da blenda PHB/PEG de composição 70/30, resfriamento 


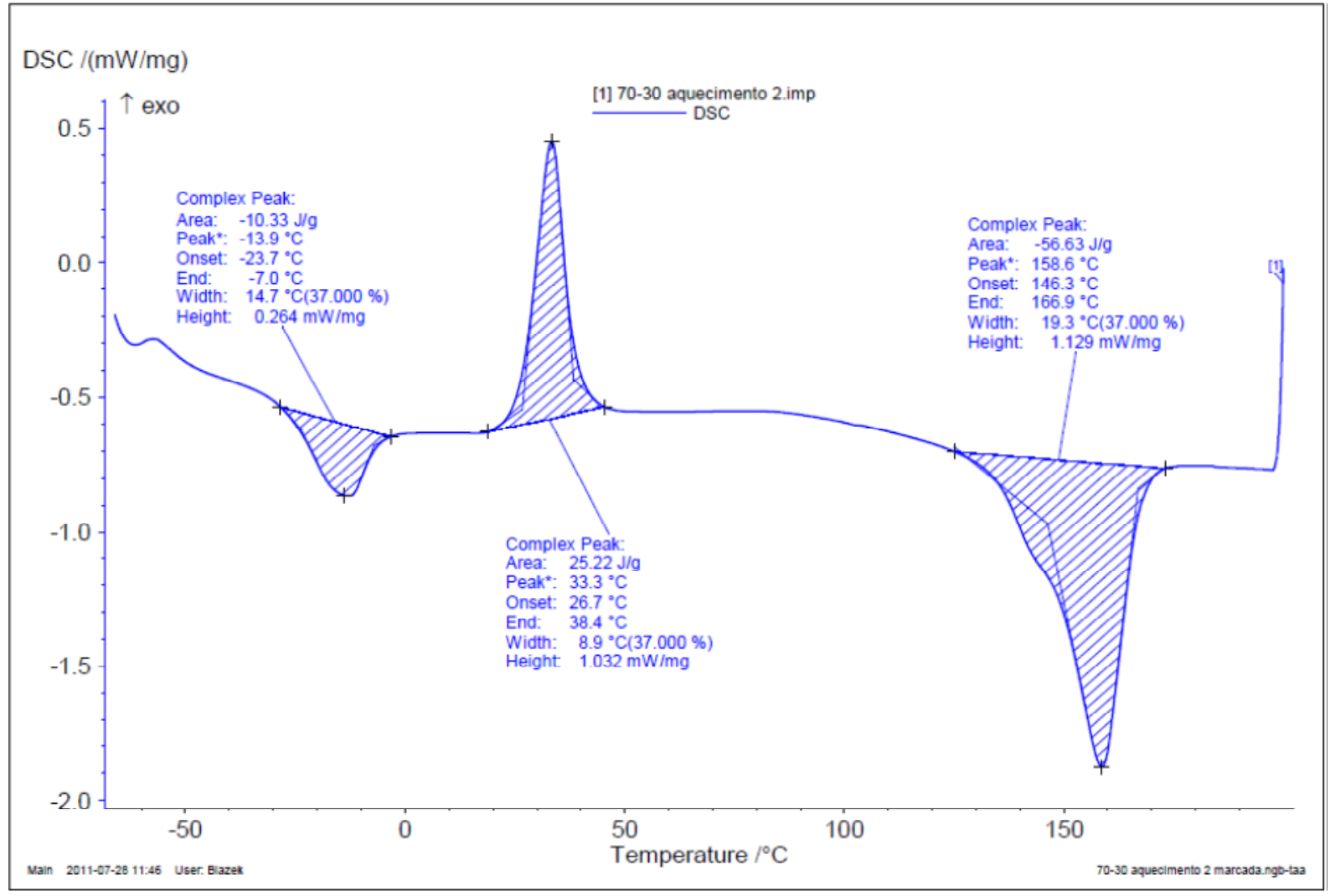

Figura 44: DSC da blenda PHB/PEG de composição 70/30 2 aquecimento

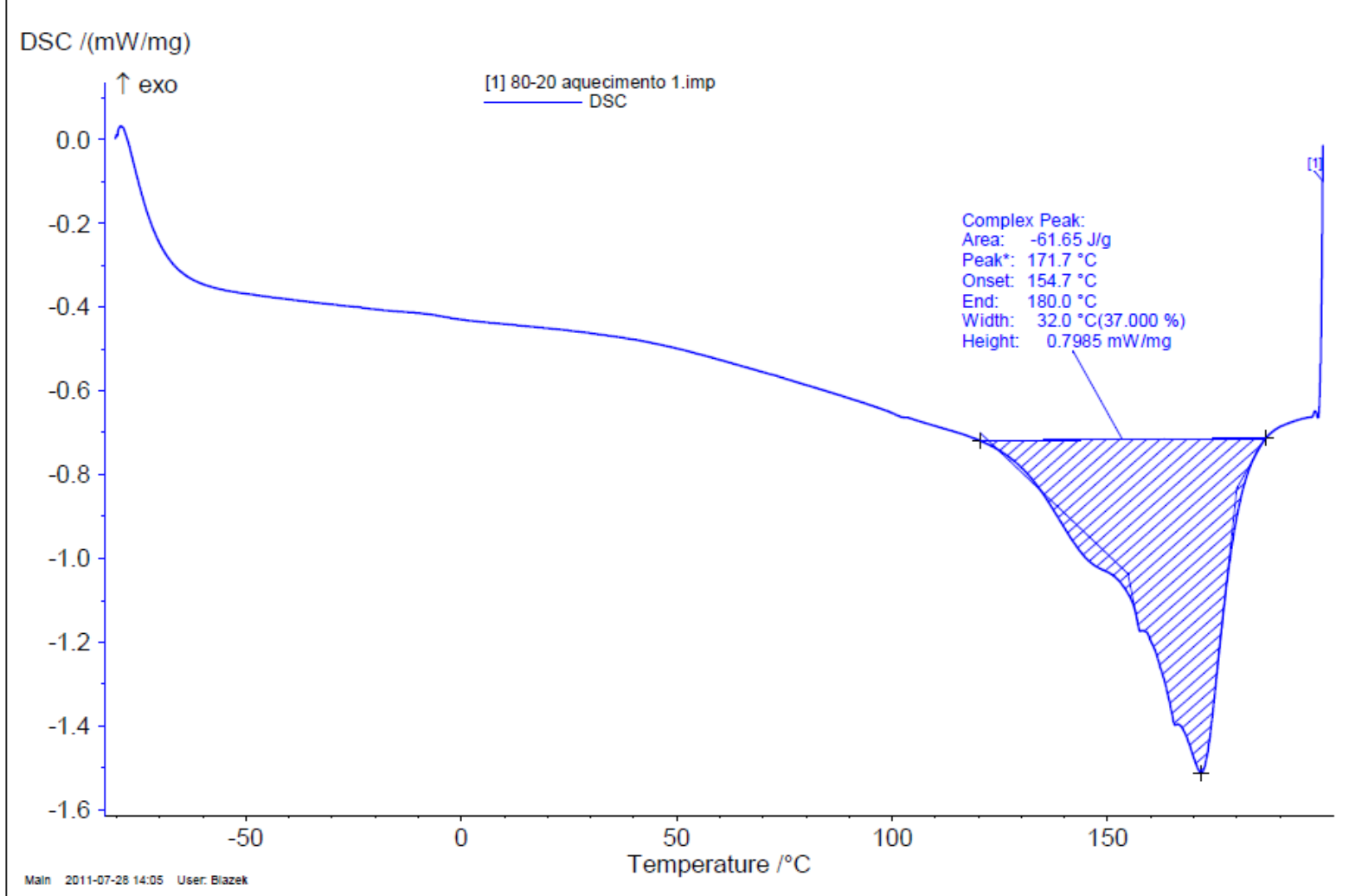

Figura 45: DSC da blenda PHB/PEG de composição 80/20 1ำ aquecimento 


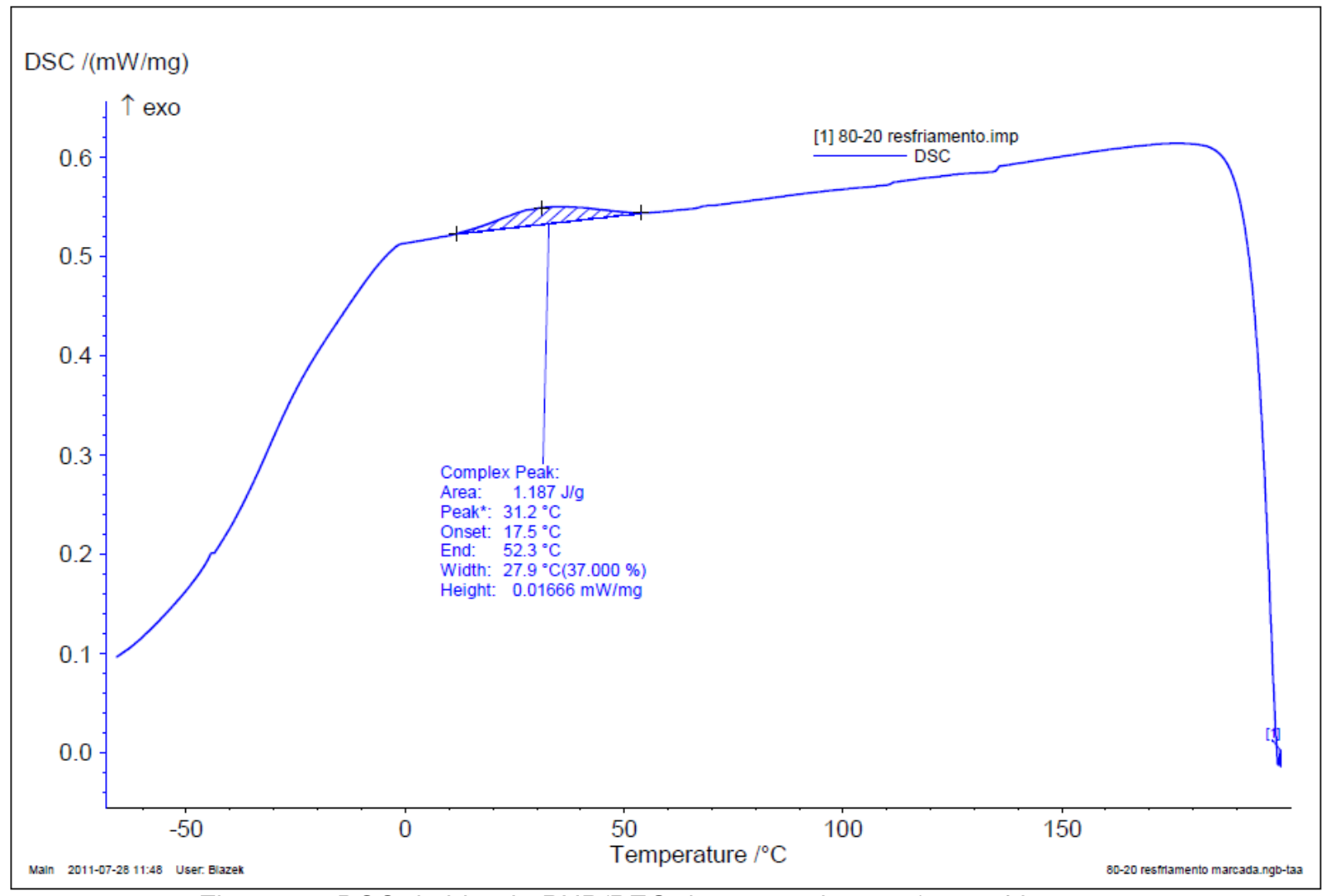

Figura 46: DSC da blenda PHB/PEG de composição 80/20 resfriamento

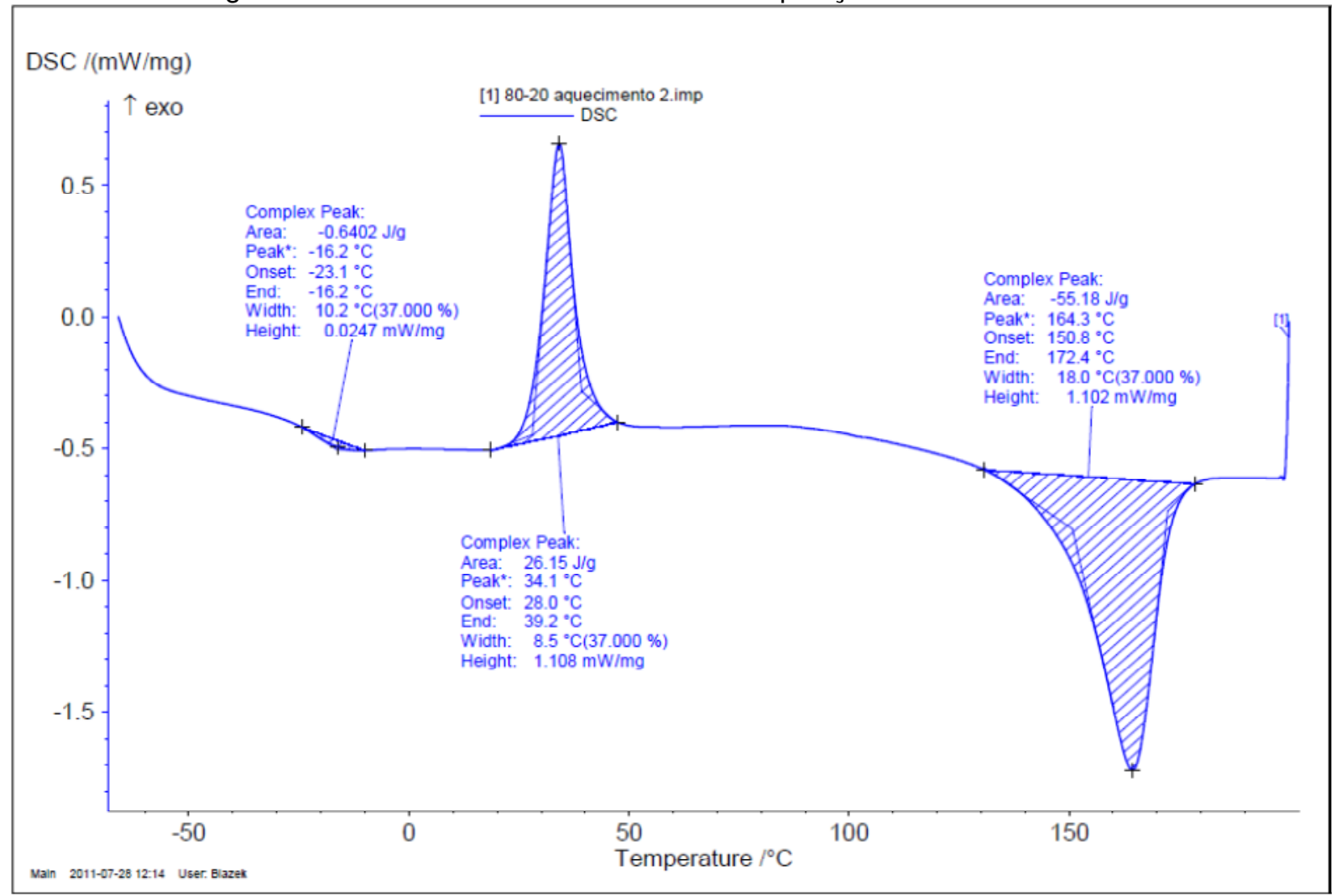

Figura 47: DSC da blenda PHB/PEG de composição 80/20 $2^{\circ}$ aquecimento 


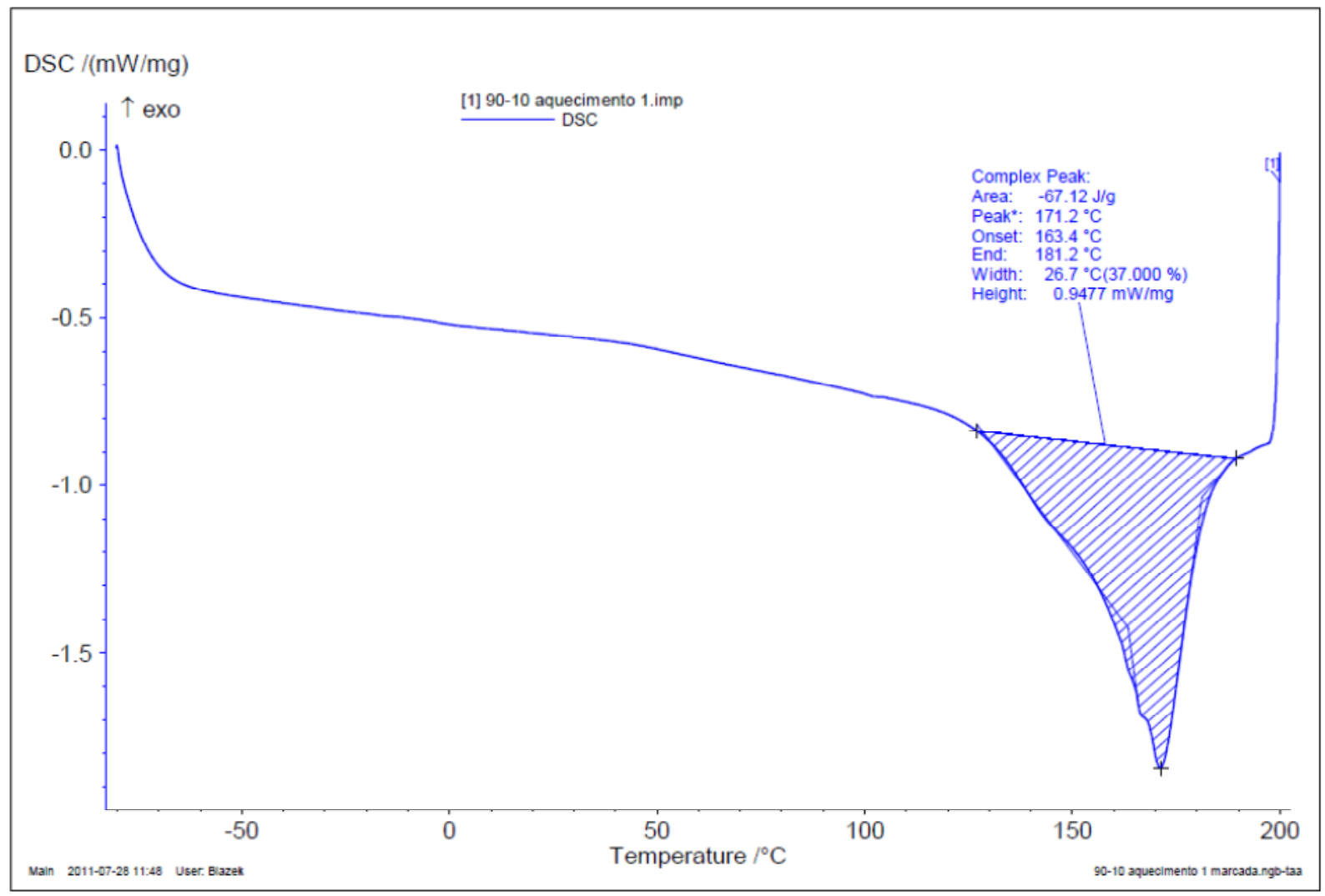

Figura 48: DSC da blenda PHB/PEG de composição 90/10 1ำ aquecimento

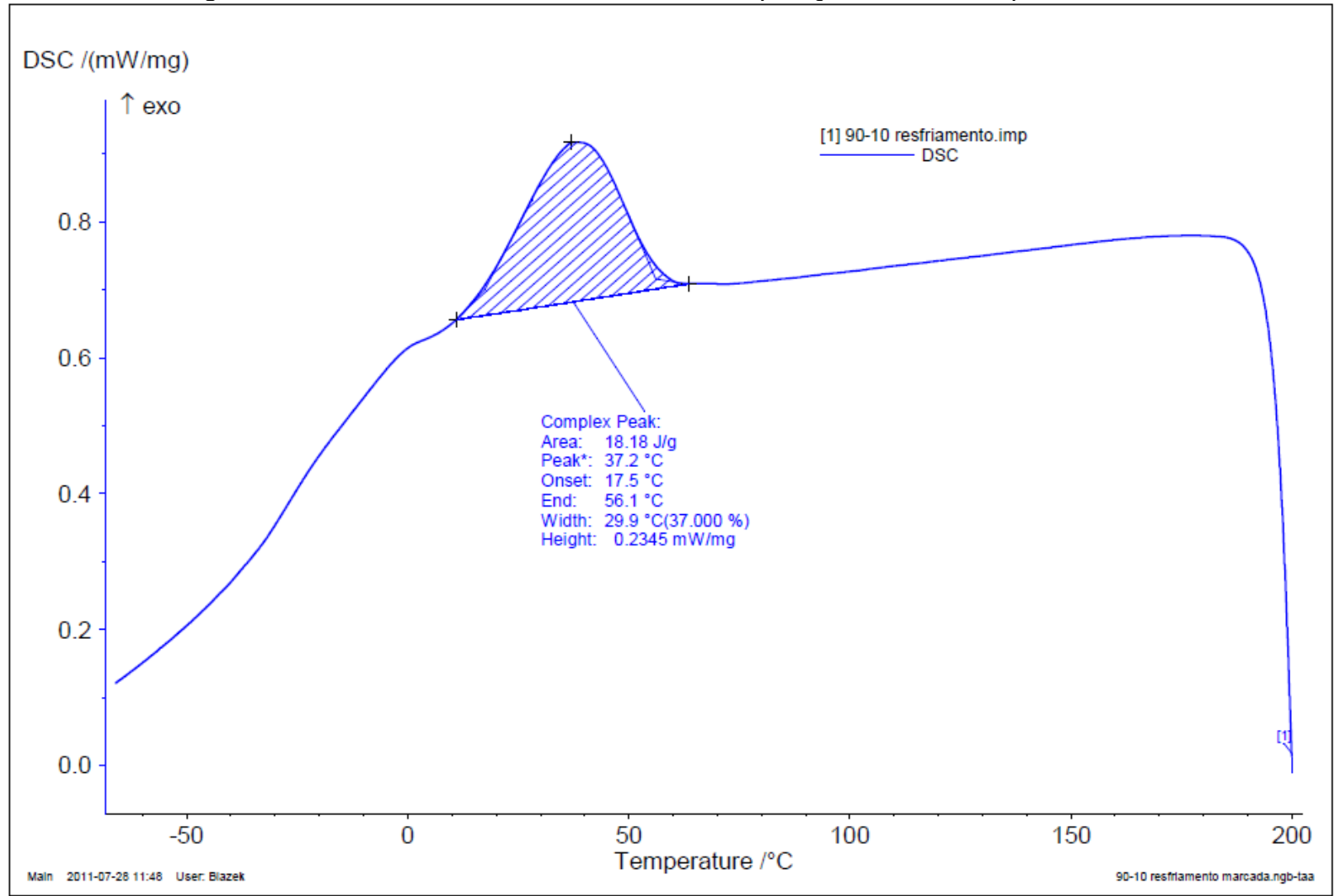

Figura 49: DSC da blenda PHB/PEG de composição 90/10 resfriamento 


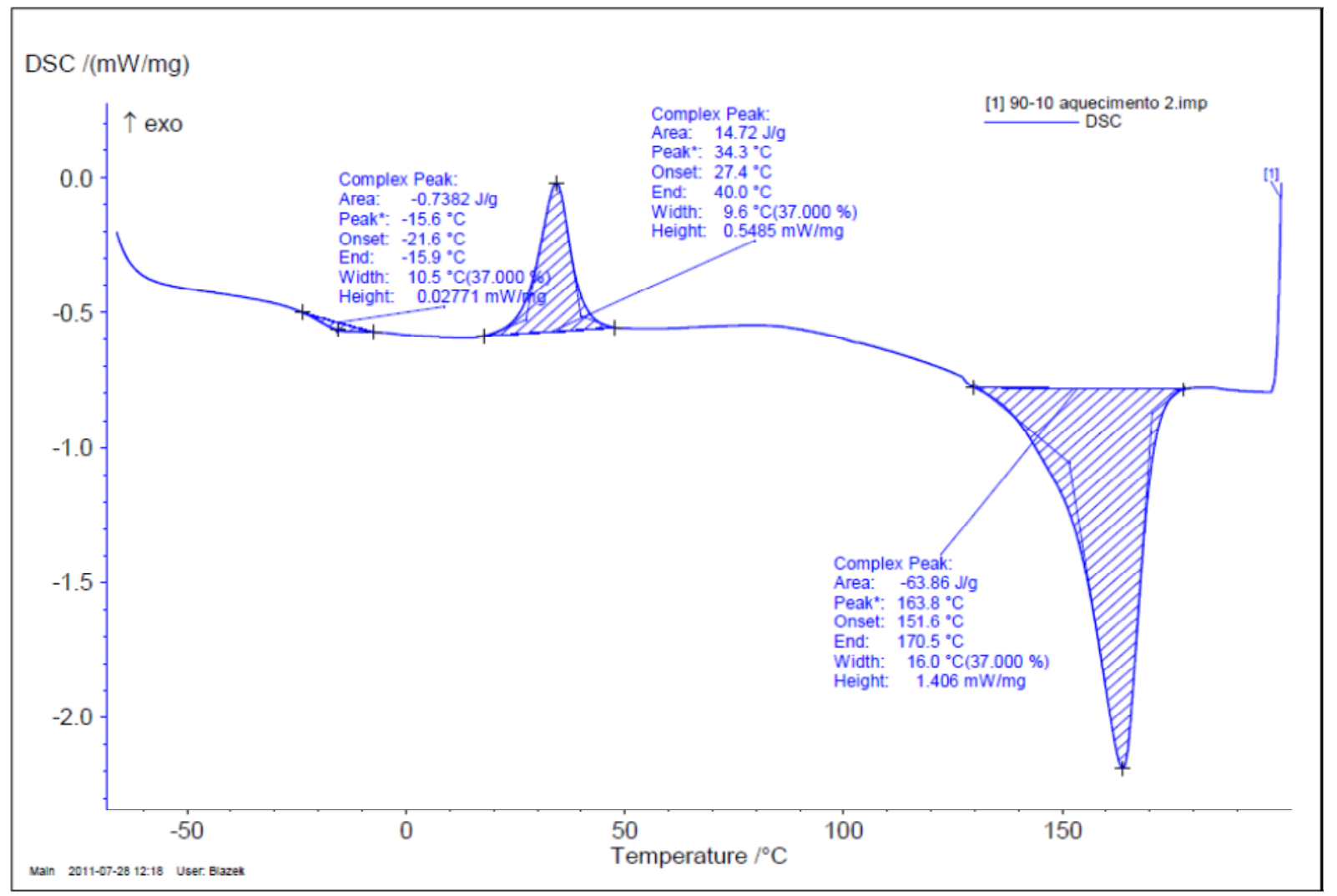

Figura 50: DSC da blenda PHB/PEG de composição 90/10 2 aquecimento

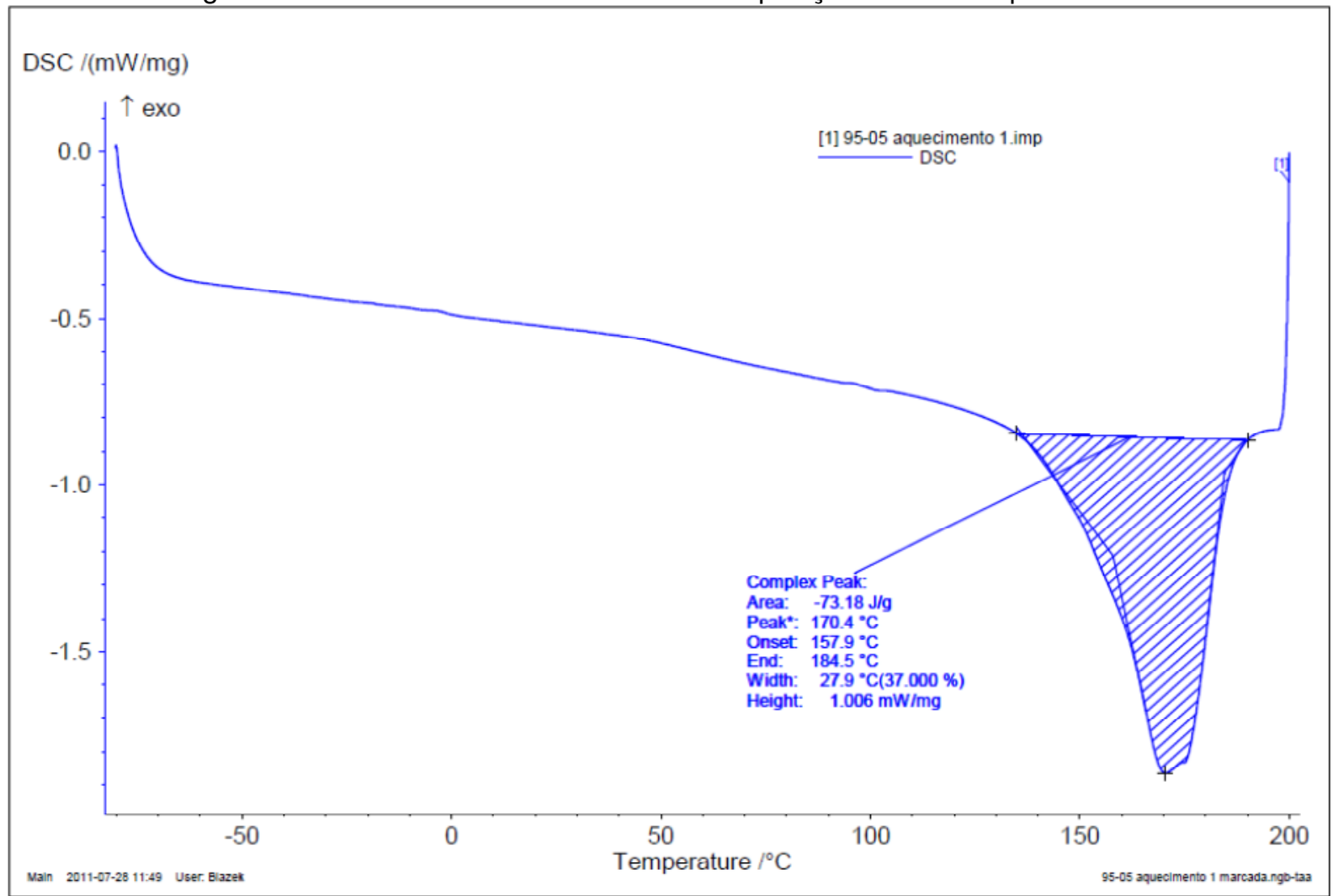

Figura 51: DSC da blenda PHB/PEG de composição 95/05 1ำ aquecimento 


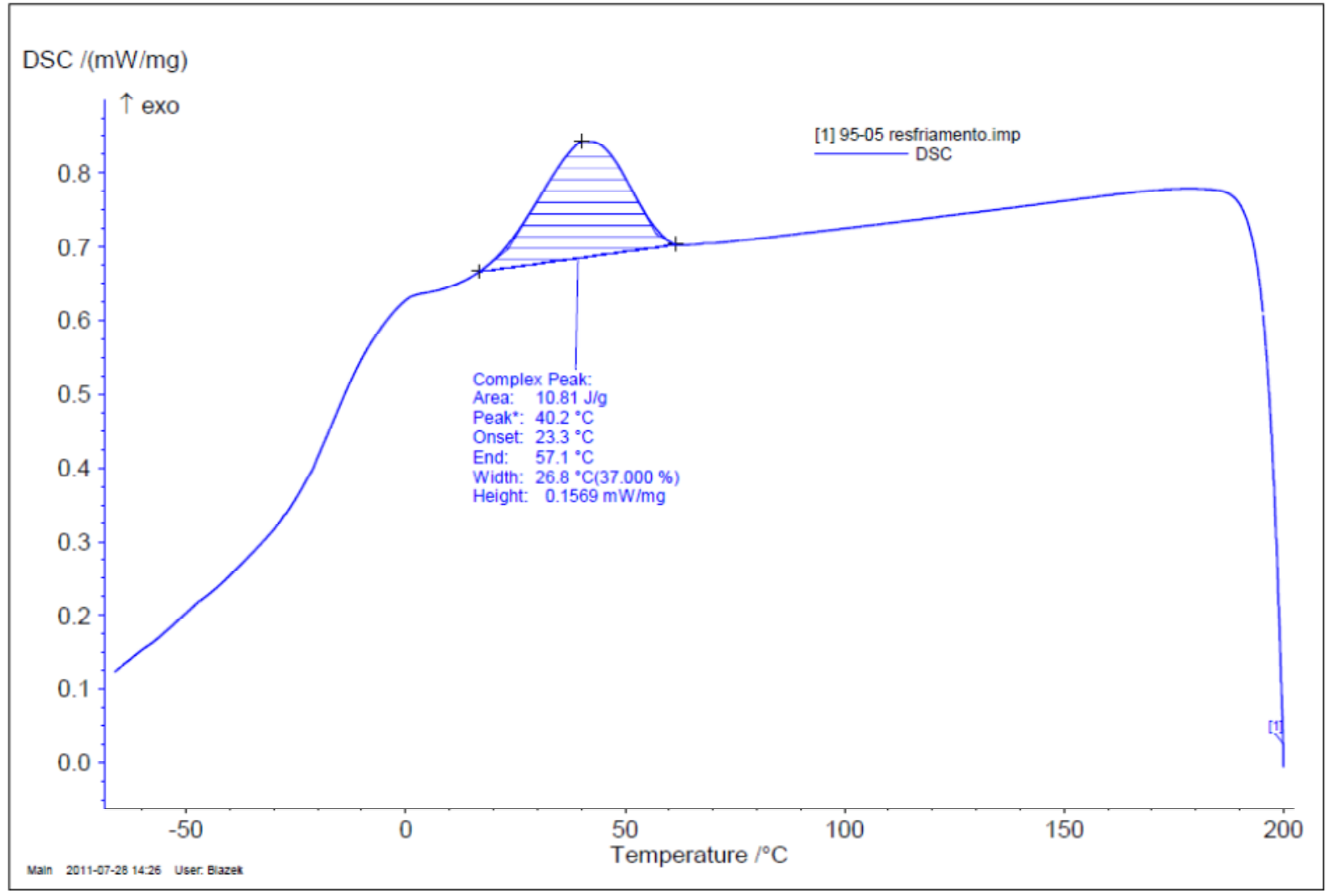

Figura 52: DSC da blenda PHB/PEG de composição 95/05 resfriamento

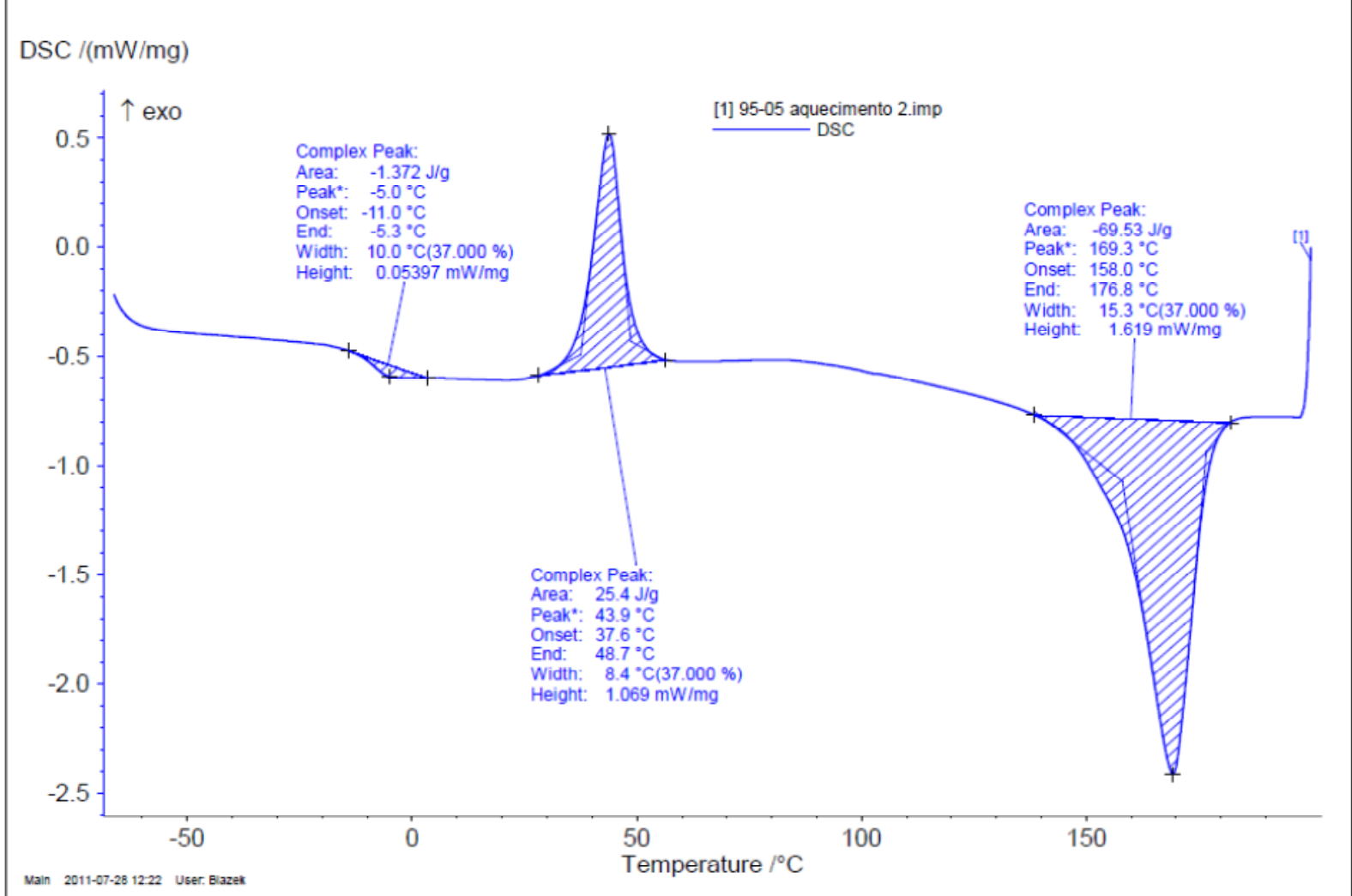

Figura 53: DSC da blenda PHB/PEG de composição 95/05 2º aquecimento 


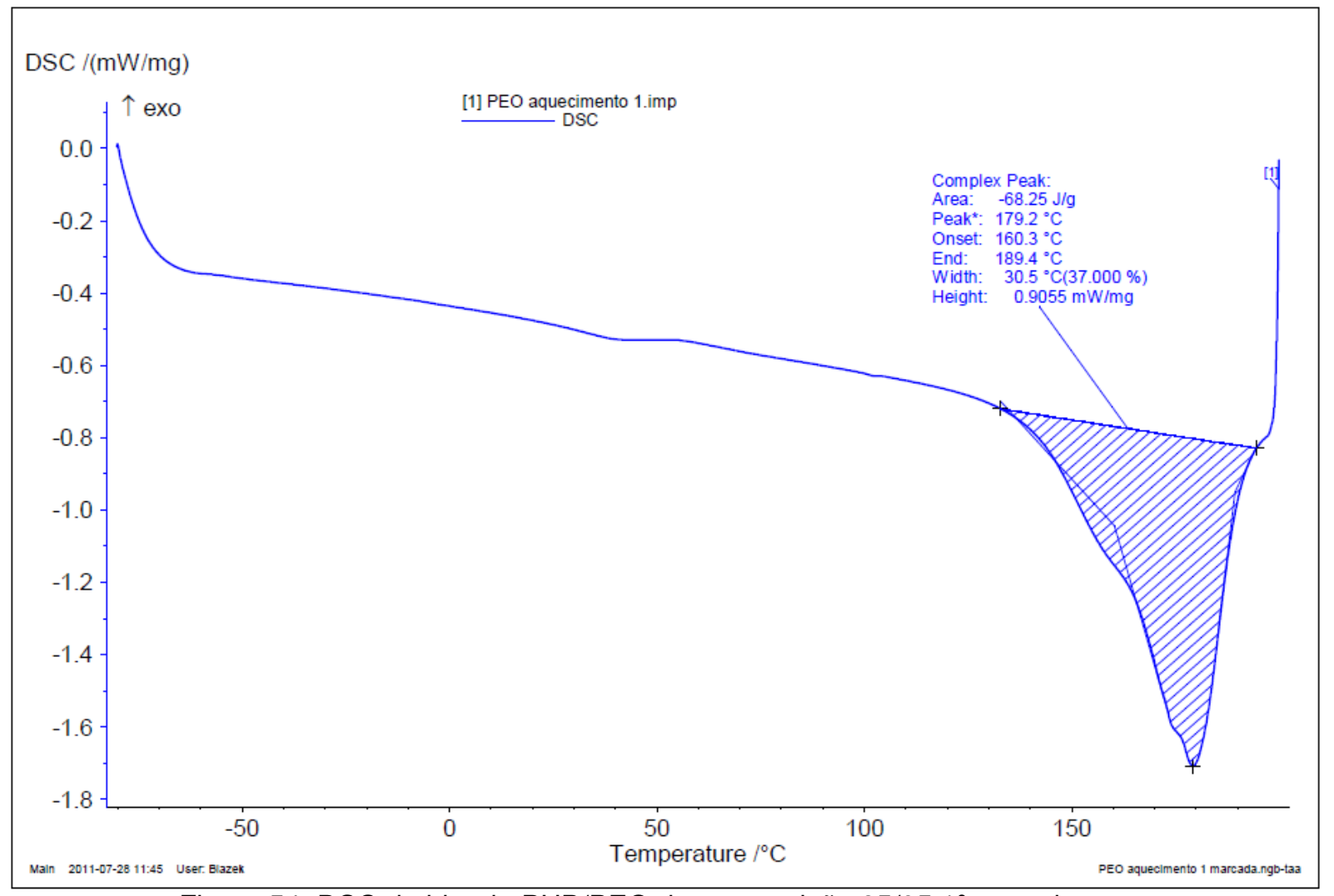

Figura 54: DSC da blenda PHB/PEO de composição 95/05 1º aquecimento

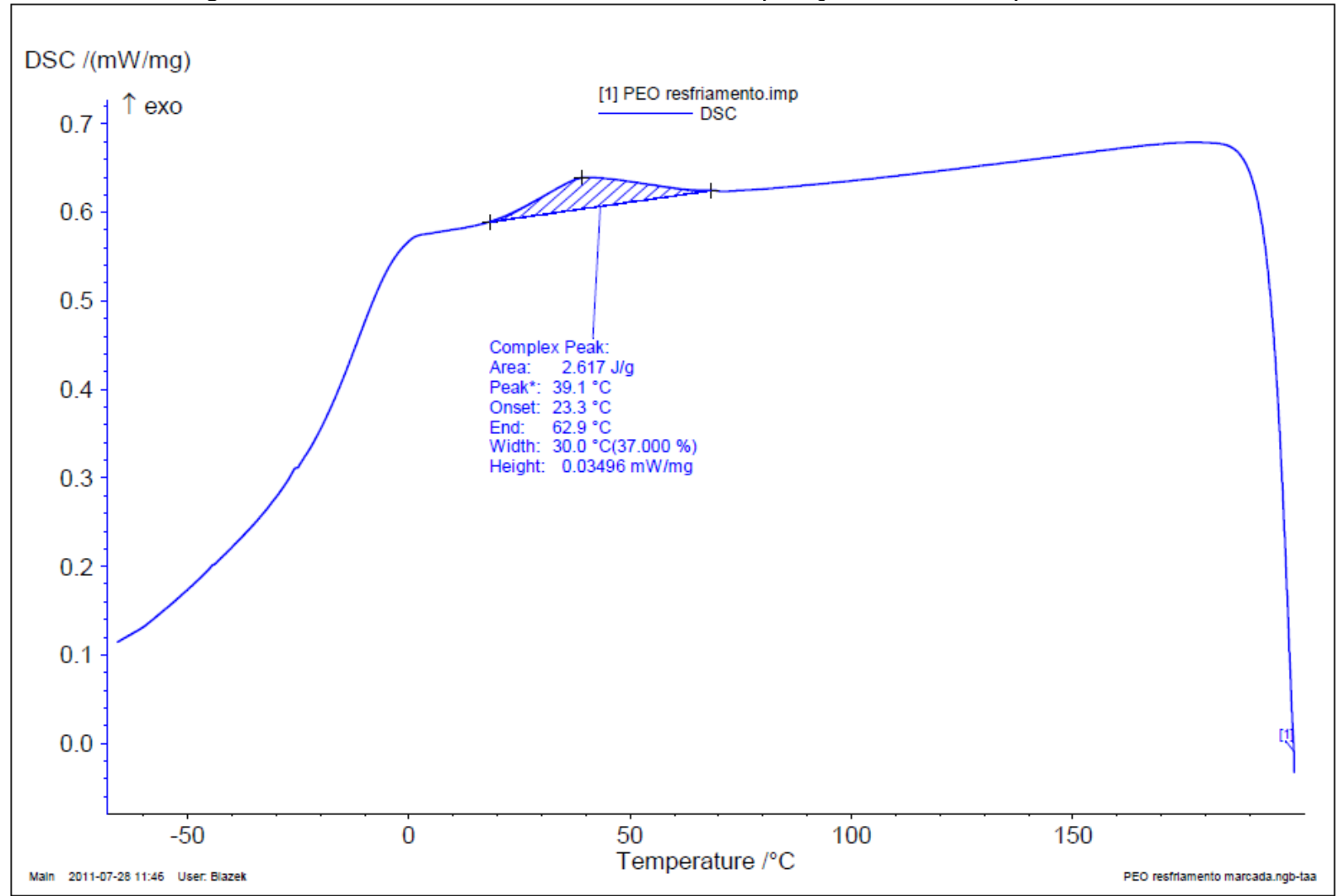

Figura 55: DSC da blenda PHB/PEO de composição 95/05 resfriamento 


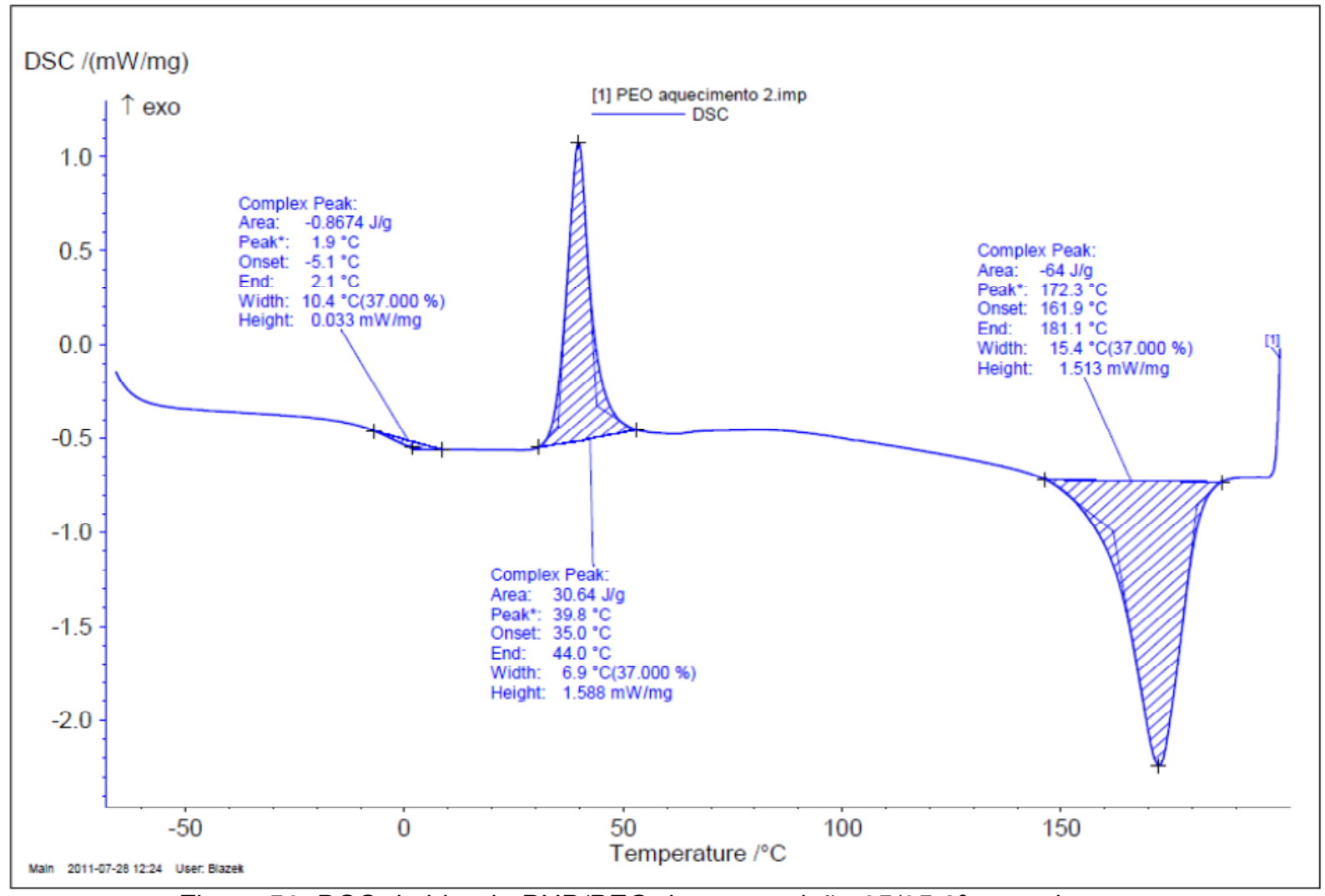

Figura 56: DSC da blenda PHB/PEO de composição 95/05 2º aquecimento

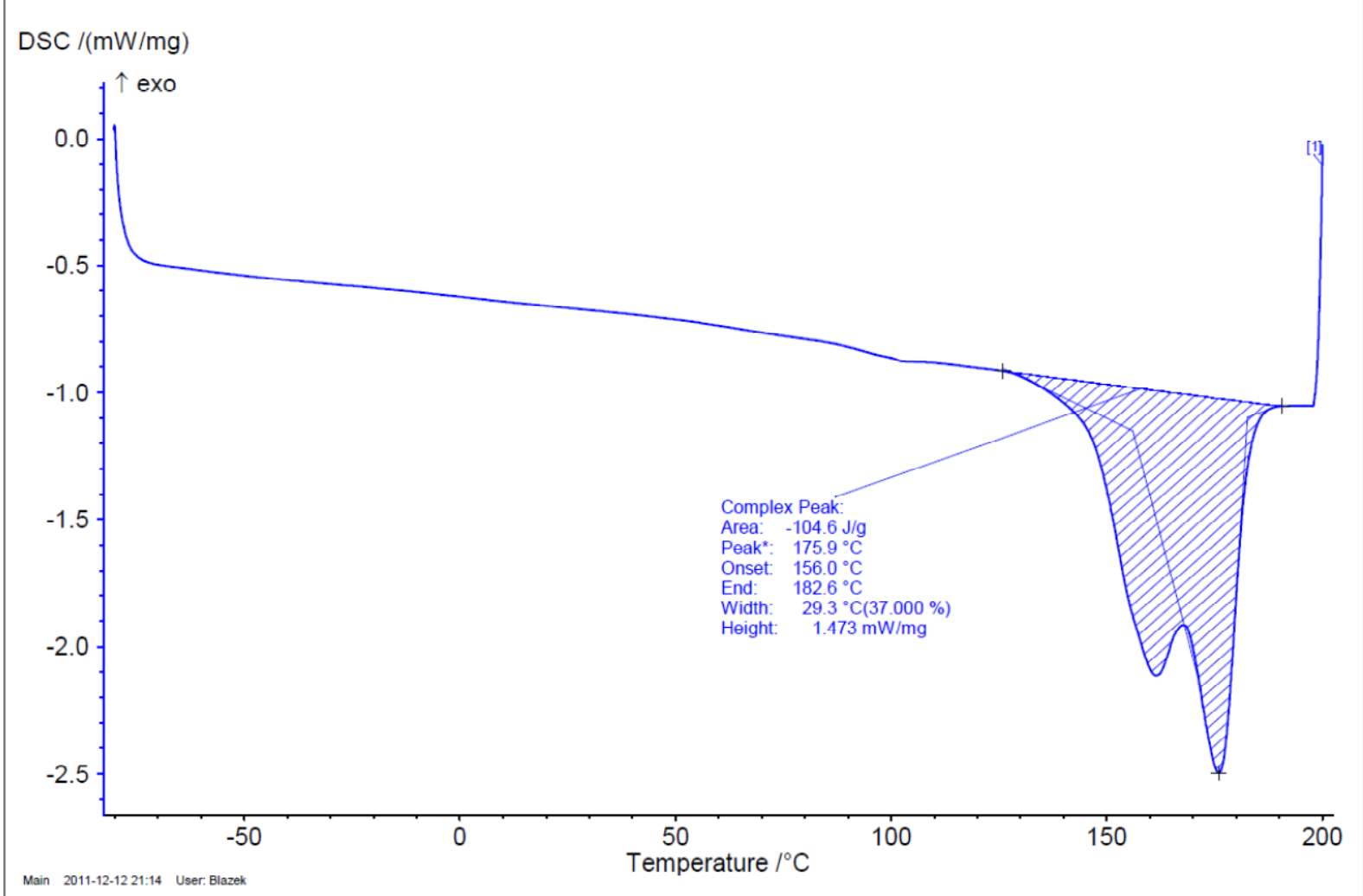

Figura 57: DSC do PHB puro $1^{\circ}$ aquecimento 


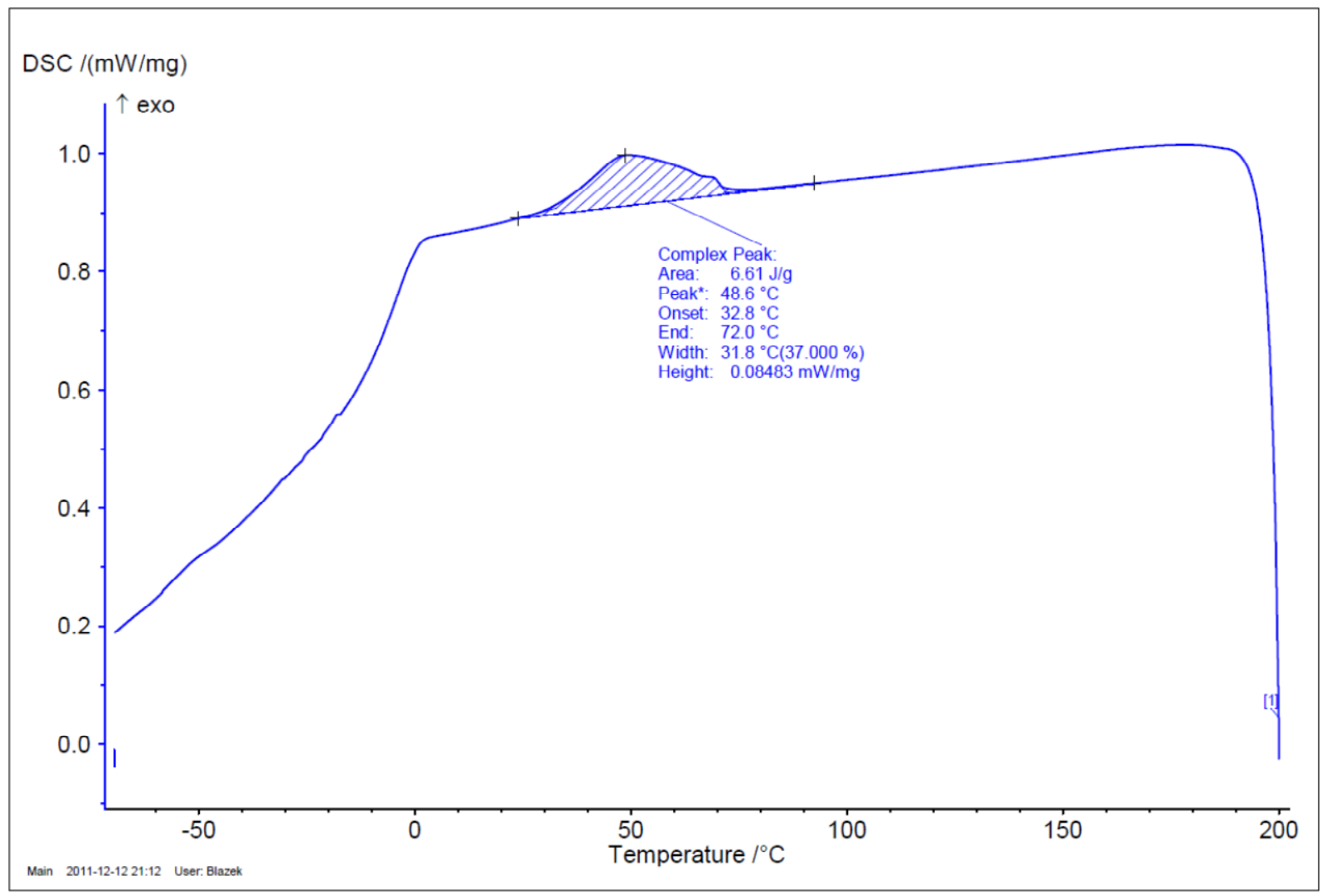

Figura 58: DSC do PHB puro resfriamento

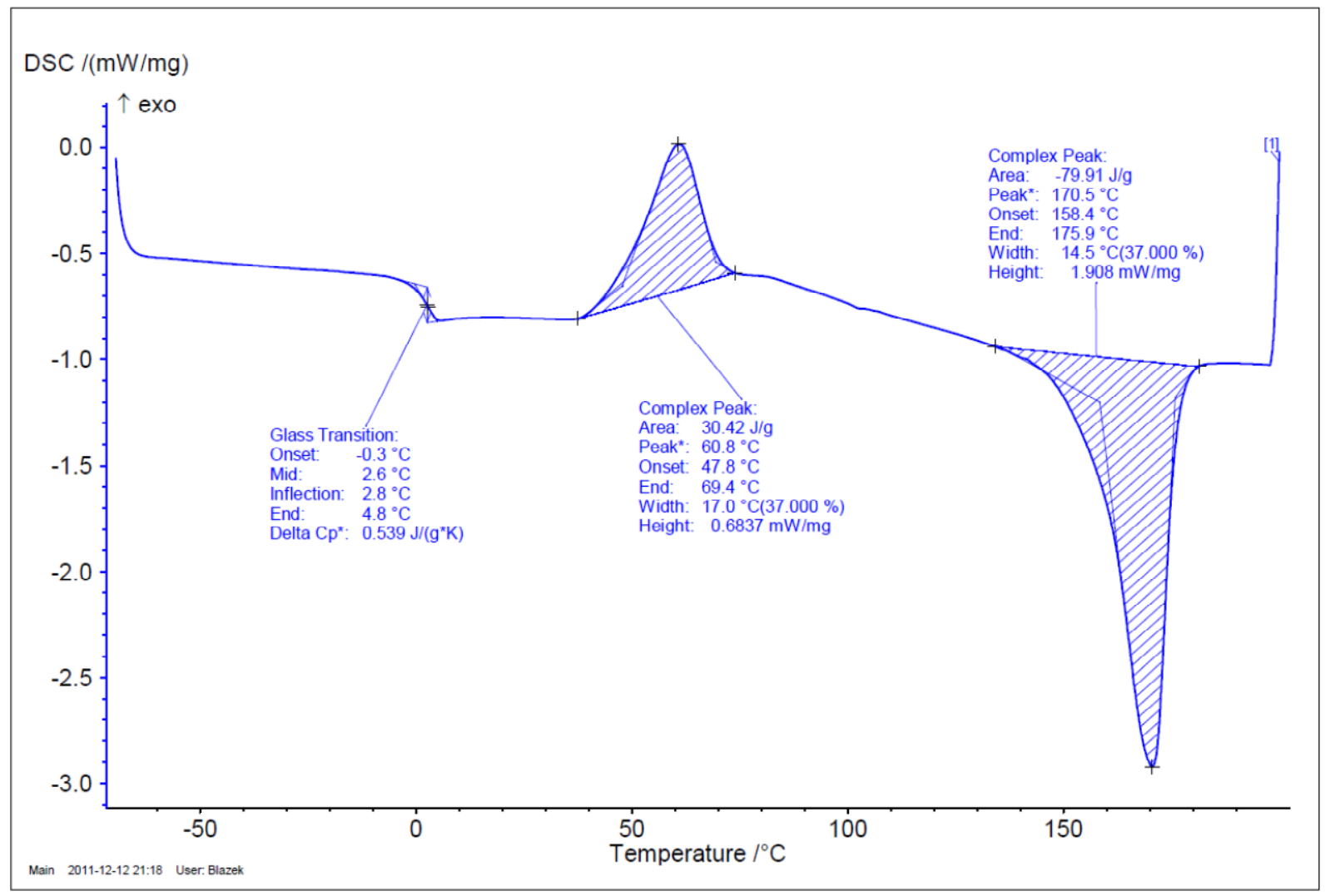

Figura 59: DSC do PHB puro $2^{\circ}$ aquecimento

Dos ensaios de DSC foram obtidas as temperaturas de fusão, cristalização e cristalização a frio, além dos valores de entalpia de fusão das blendas $\left(\Delta \mathrm{H}_{\mathrm{f}}\right)$. A partir 
destes valores de entalpia, foi calculado o grau de cristalinidade $\left(X_{c}\right)$ de cada amostra. As temperaturas de transição são descritas na Tabela 8 , e os valores de $\Delta \mathrm{H}_{\mathrm{f}}$ e $\mathrm{X}_{\mathrm{c}}$ se encontram na Tabela 9 , juntamente com os valores calculados através da difração de raios- $X$, para efeitos comparativos:

Tabela 8: Temperaturas de transição identificadas através do ensaio de DSC.

\begin{tabular}{|c|c|c|c|c|c|c|c|c|c|}
\hline & \multicolumn{3}{|c|}{$\mathrm{T}_{\mathrm{m}}{ }^{\mathrm{a}}\left({ }^{\circ} \mathrm{C}\right)$} & \multicolumn{3}{|c|}{$\mathrm{T}_{\mathrm{m}}^{\mathrm{b}}\left({ }^{\circ} \mathrm{C}\right)$} & \multirow{2}{*}{$\begin{array}{c}\mathrm{T}_{\mathrm{g}} \mathrm{PHB} \\
\left({ }^{\circ} \mathrm{C}\right)\end{array}$} & \multirow{2}{*}{$\begin{array}{c}\mathrm{T}_{\mathrm{c}} \text { a frio } \\
\left({ }^{\mathrm{o}} \mathrm{C}\right)\end{array}$} & \multirow{2}{*}{$\begin{array}{l}\mathrm{T}_{\mathrm{c}}^{\mathrm{c}} \\
\left({ }^{\circ} \mathrm{C}\right)\end{array}$} \\
\hline & PEG/PEO & $\mathrm{PHB}_{1}$ & $\mathrm{PHB}_{2}$ & PEG & $\mathrm{PHB}_{1}$ & $\mathrm{PHB}_{2}$ & & & \\
\hline PHB/PEG-30 & - & 151,8 & 164,1 & $-13,9$ & 146,3 & 158,6 & - & 26,7 & 57,4 \\
\hline PHB/PEG-20 & - & 154,7 & 171,7 & $\begin{array}{l}-16,2 \\
\end{array}$ & 150,8 & 164,3 & - & 28,0 & 52,3 \\
\hline PHB/PEG-10 & - & 163,4 & 171,2 & $-15,6$ & 151,6 & 163,8 & - & 27,4 & 56,1 \\
\hline PHB/PEG-05 & - & 157,9 & 170,4 & $-5,0$ & 158,0 & 169,3 & - & 37,6 & 57,1 \\
\hline PHB/PEO-05 & - & 160,3 & 179,2 & - & 161,9 & 172,3 & 1,9 & 35,0 & 62,9 \\
\hline PHB Puro & - & 156,0 & 175,9 & - & 158,4 & 170,5 & 2,6 & 47,8 & 72,0 \\
\hline
\end{tabular}

Aonde:

a - Dados referentes ao primeiro aquecimento.

b - Dados referentes ao segundo aquecimento.

c - Dados referentes à etapa de resfriamento.

DRX - Cristalinidade calculada por difração de raios-X.

1 - Leitura do ponto "Onset"

2 - Leitura do ponto "Peak"

Tabela 9: Entalpia de fusão e grau de cristalinidade das amostras através de DSC

\begin{tabular}{|c|c|c|c|c|c|c|}
\hline & $\begin{array}{c}\text { PHB/PEG } \\
\mathbf{7 0 / 3 0}\end{array}$ & $\begin{array}{c}\text { PHB/PEG } \\
\mathbf{8 0 / 2 0}\end{array}$ & $\begin{array}{c}\text { PHB/PEG } \\
\mathbf{9 0 / 1 0}\end{array}$ & $\begin{array}{c}\text { PHB/PEG } \\
\mathbf{9 5 / 0 5}\end{array}$ & $\begin{array}{c}\text { PHB/PEO } \\
\mathbf{9 5 / 0 5}\end{array}$ & $\begin{array}{c}\text { PHB } \\
\text { Puro }\end{array}$ \\
\hline$\Delta \mathrm{H}_{\mathrm{f}}(\mathrm{J} / \mathrm{g})^{\mathrm{a}}$ & $\mathbf{7 5 , 6 4}$ & 61,65 & 67,12 & 73,18 & 68,25 & 104,6 \\
\hline $\mathrm{X}_{\mathrm{c}}(\%)^{\mathrm{a}}$ & $\mathbf{7 4 , 0} \%$ & $\mathbf{5 2 , 8} \%$ & $\mathbf{5 1 , 1} \%$ & $\mathbf{5 2 , 8} \%$ & $\mathbf{4 9 , 2} \%$ & $\mathbf{7 1 , 6 \%}$ \\
\hline$\Delta \mathrm{H}_{\mathrm{f}}(\mathrm{J} / \mathrm{g})^{\mathrm{b}}$ & 56,63 & 55,18 & 63,86 & 69,53 & 64,00 & 79.9 \\
\hline $\mathrm{X}_{\mathrm{c}}(\%)^{\mathrm{b}}$ & $\mathbf{5 5 , 4} \%$ & $\mathbf{4 7 , 2} \%$ & $\mathbf{4 8 , 6 \%}$ & $\mathbf{5 0 , 1} \%$ & $\mathbf{4 6 , 1} \%$ & $\mathbf{5 4 , 7 \%}$ \\
\hline $\begin{array}{c}\text { DRX } \\
\text { nova }\end{array}$ & $\mathbf{4 4 , 2} \%$ & $\mathbf{4 2 , 3} \%$ & $\mathbf{4 8 , 8} \%$ & $\mathbf{4 8 , 5} \%$ & $\mathbf{4 7 , 8} \%$ & - \\
\hline DRX env. & $\mathbf{4 4 , 5} \%$ & $\mathbf{4 7 , 0} \%$ & $\mathbf{5 5 , 6} \%$ & $\mathbf{5 1 , 1} \%$ & $\mathbf{4 9 , 2} \%$ & - \\
\hline
\end{tabular}




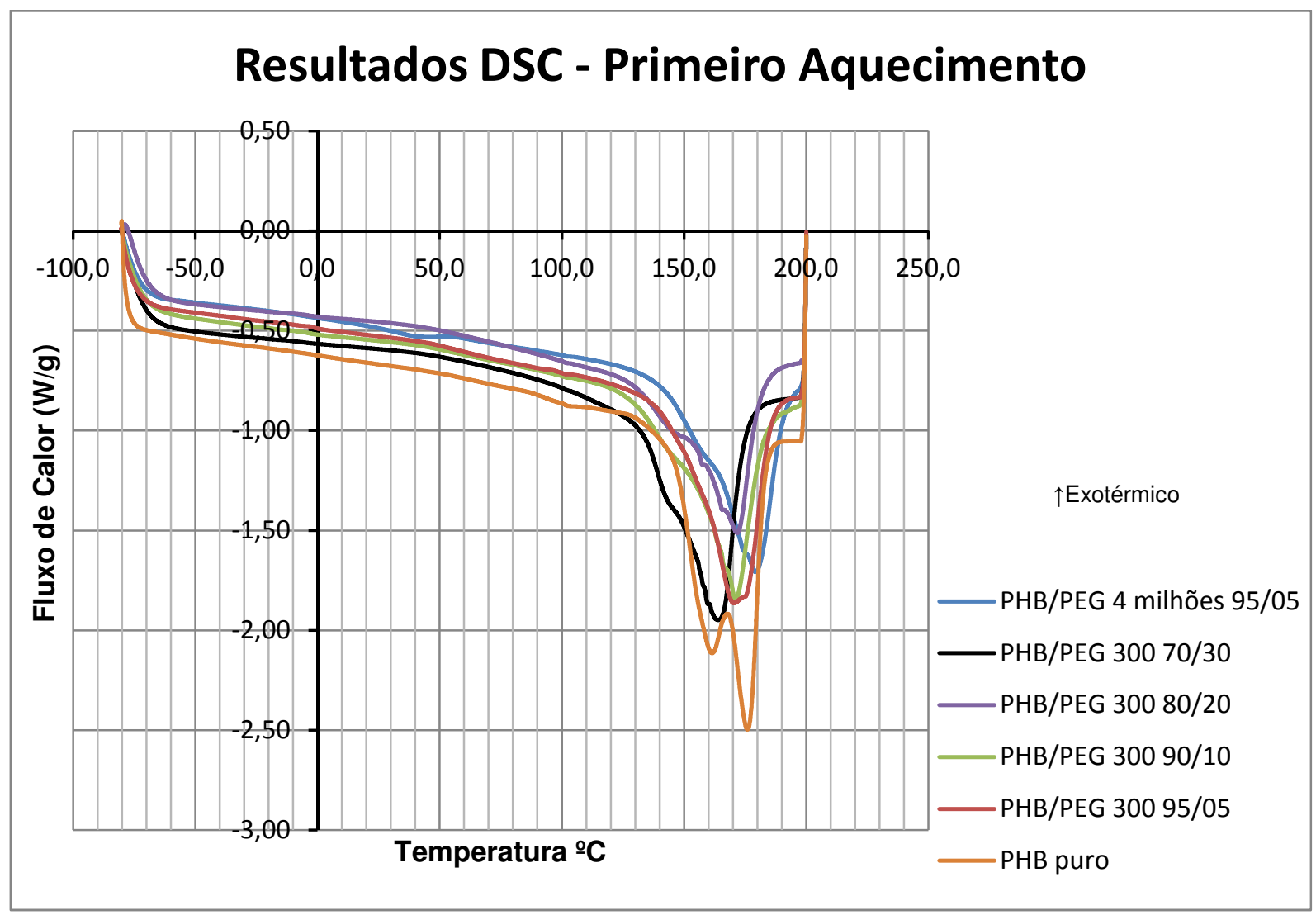

Figura 60: Resultados da análise de calorimetria diferencial exploratória, primeiro aquecimento.

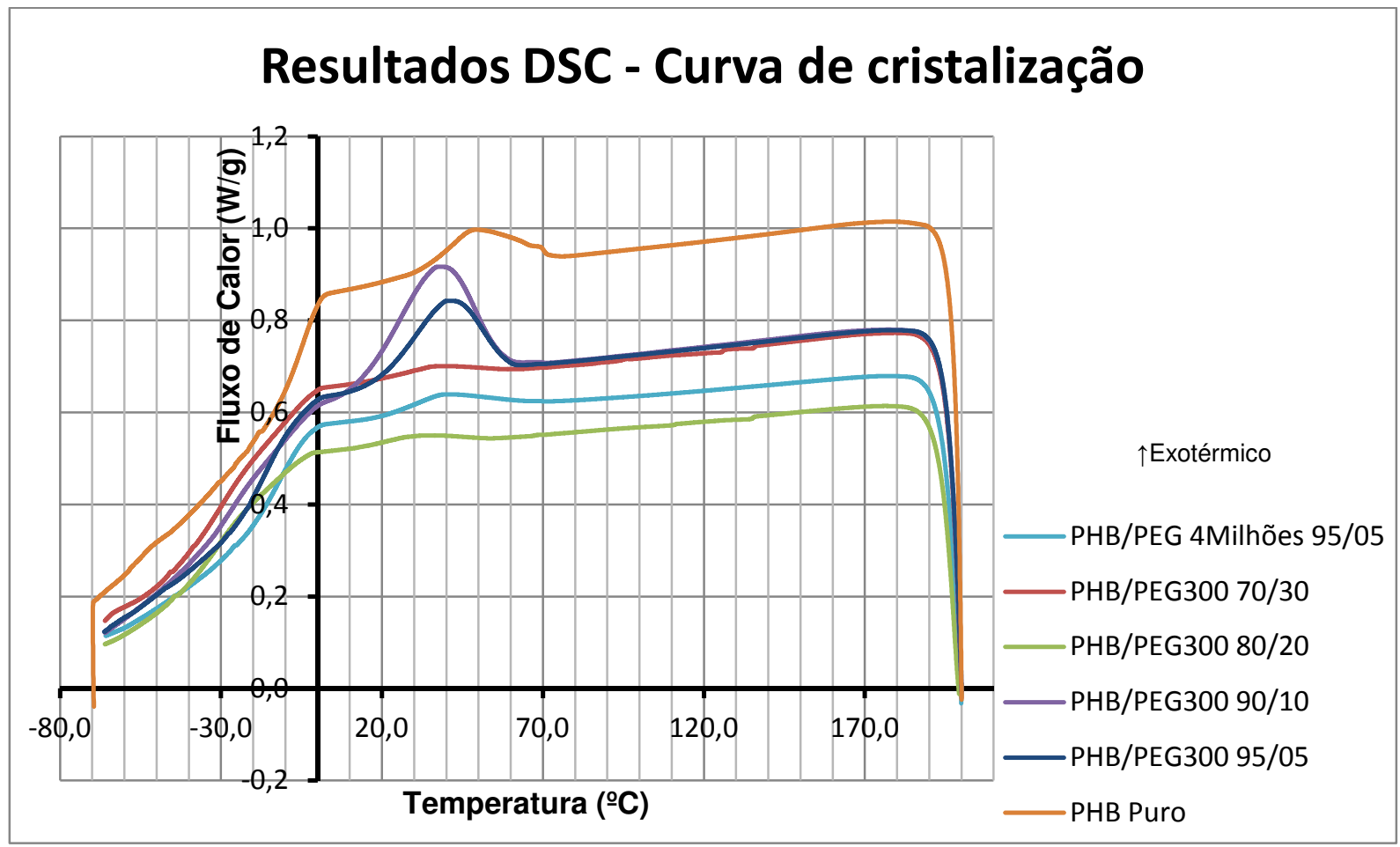

Figura 61: Resultados da análise de calorimetria diferencial exploratória, resfriamento. 


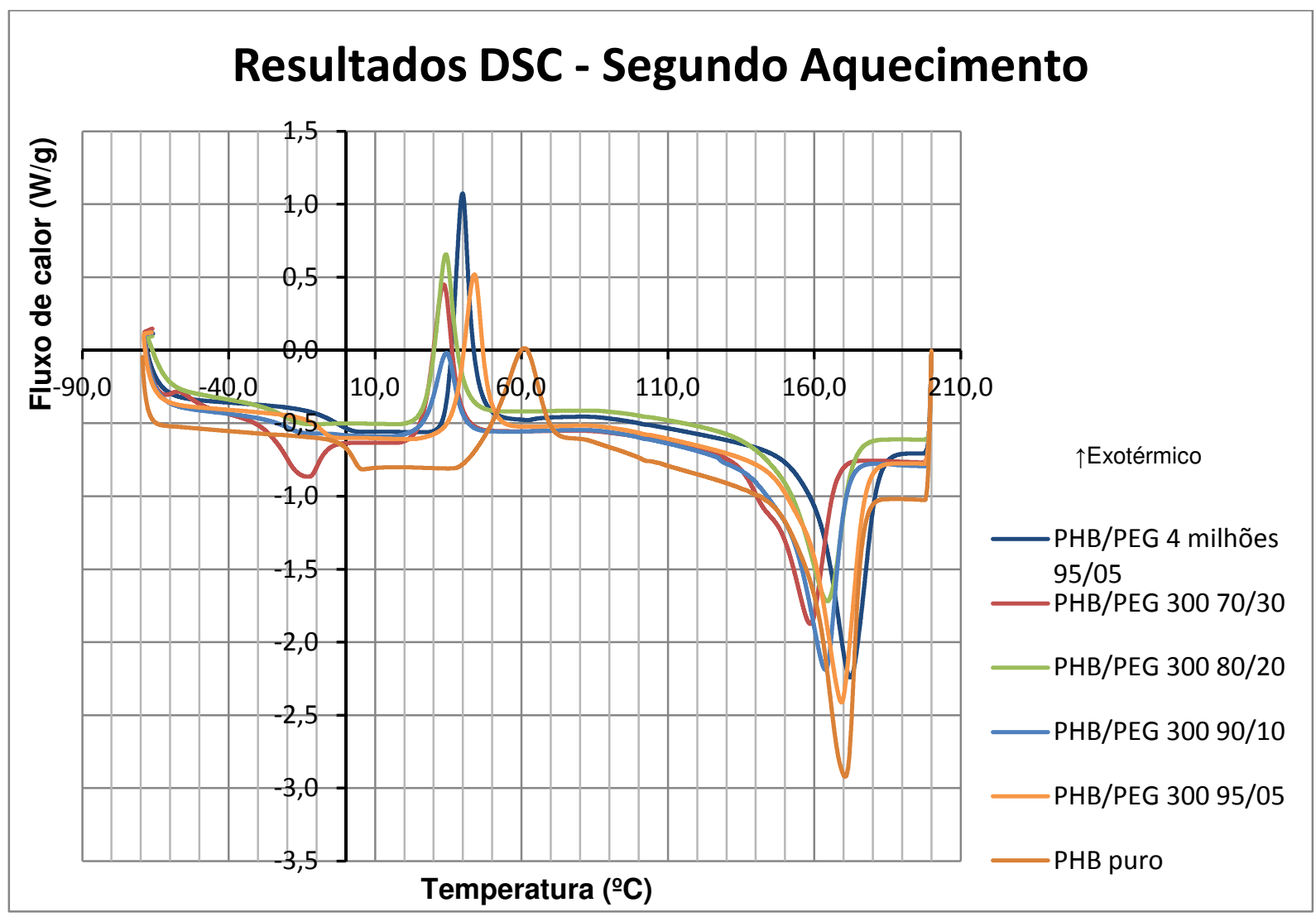

Figura 62: Resultados da análise de calorimetria diferencial exploratória, segundo aquecimento.

Os gráficos comparativos acima (Figuras 60-62) permitem uma melhor visualização do efeito da adição de PEG/PEO em diferentes teores ao PHB. Em todas as blendas, foi observada uma redução na $T_{m}$ associada à fase cristalina do PHB com o aumento da concentração de PEG.

Deve ser levado em consideração, que durante o primeiro ciclo térmico, as amostras são aquecidas acima de sua temperatura de fusão, sofrendo decomposição espinodal, ou seja, a separação das porções não termodinamicamente miscíveis dos componentes. No segundo aquecimento, portanto, as blendas mostram etapas de cristalização a frio e sinais de separação de fases, como por exemplo indícios da presença de uma $T_{m}$ para o PEG.

$A T_{m}$ do PEG não é detectada durante o primeiro aquecimento, porém picos de baixa intensidade no segundo aquecimento podem ser associados à $T_{m}$ do PEG e a um relaxamento de tensões após a $T_{g}$ do PHB. A amostra contendo $30 \% \mathrm{em}$ massa de PEG apresenta este pico bastante visível.

Estes picos de baixa intensidade também podem ser associados à $T_{g}$ do $\mathrm{PHB}$, bastante deslocada em relação à $T_{g}$ do homopolímero, que é de $5 \stackrel{\circ}{\circ}$. Esta idéia é 
reforçada pelo fato da amostra contendo PEO apresentar um pico nesta mesma região do $\mathrm{DSC}$, próximo a $1,9{ }^{\circ} \mathrm{C}$, que não pode ser relacionada com a $\mathrm{T}_{\mathrm{m}}$ do $\mathrm{PEO}$, uma vez que esta é de aproximadamente $65^{\circ} \mathrm{C}$.

Uma análise de DSC dos homopolímeros PEG e PEO podem ser feitas para obter-se uma análise mais assertiva acerca das transições associadas à estes.

A ausência da $T_{m}$ do PEG/PEO no primeiro aquecimento juntamente com 0 decréscimo da $T_{g}$ e da $T_{m}$ do PHB são indicativos da forte interação entre os dois homopolímeros. O decréscimo da $\mathrm{T}_{\mathrm{m}}$ leva a um possível aumento da janela de processabilidade do polímero, permitindo que este seja processado à uma temperatura menor e cada vez mais distante da sua temperatura de degradação.

As curvas de DSC do primeiro aquecimento são caracterizadas pelos múltiplos picos de fusão da fase cristalina do PHB na blenda. Estes múltiplos picos são em geral observados por DSC em polímeros semi-cristalinos e também foram observados no PHB por Marchessault e Pearce ${ }^{58}$. Os picos podem ser explicados pela presença de mais de um grupo de cristais com diferentes parâmetros de rede ou cristalitos de espessuras lamelares variadas, ou ainda por um processo de recristalização ocorrido durante o ensaio de DSC, aonde um cristalito lamelar mais fino funde-se a uma temperatura menor, recristaliza-se em uma lamela mais espessa e funde-se uma segunda vez.

Este processo de recristalização prejudica os cálculos de cristalinidade, uma vez que a mesma porção de PHB funde-se mais de uma vez, elevando o valor da entalpia de fusão observada no DSC e levando a leituras de cristalinidade maiores do que a realidade.

Marchessault e Pearce ${ }^{58}$ também observam que estes múltiplos picos se apresentam mais distintos em amostras de PHB preparadas por dissolução em clorofórmio se comparados a amostras misturadas no fundido, o que explica o fato destes picos de recristalização aparecerem com uma menor intensidade na segunda etapa de aquecimento do DSC. 


\subsection{Ensaio dinâmico-mecânico (DMTA)}

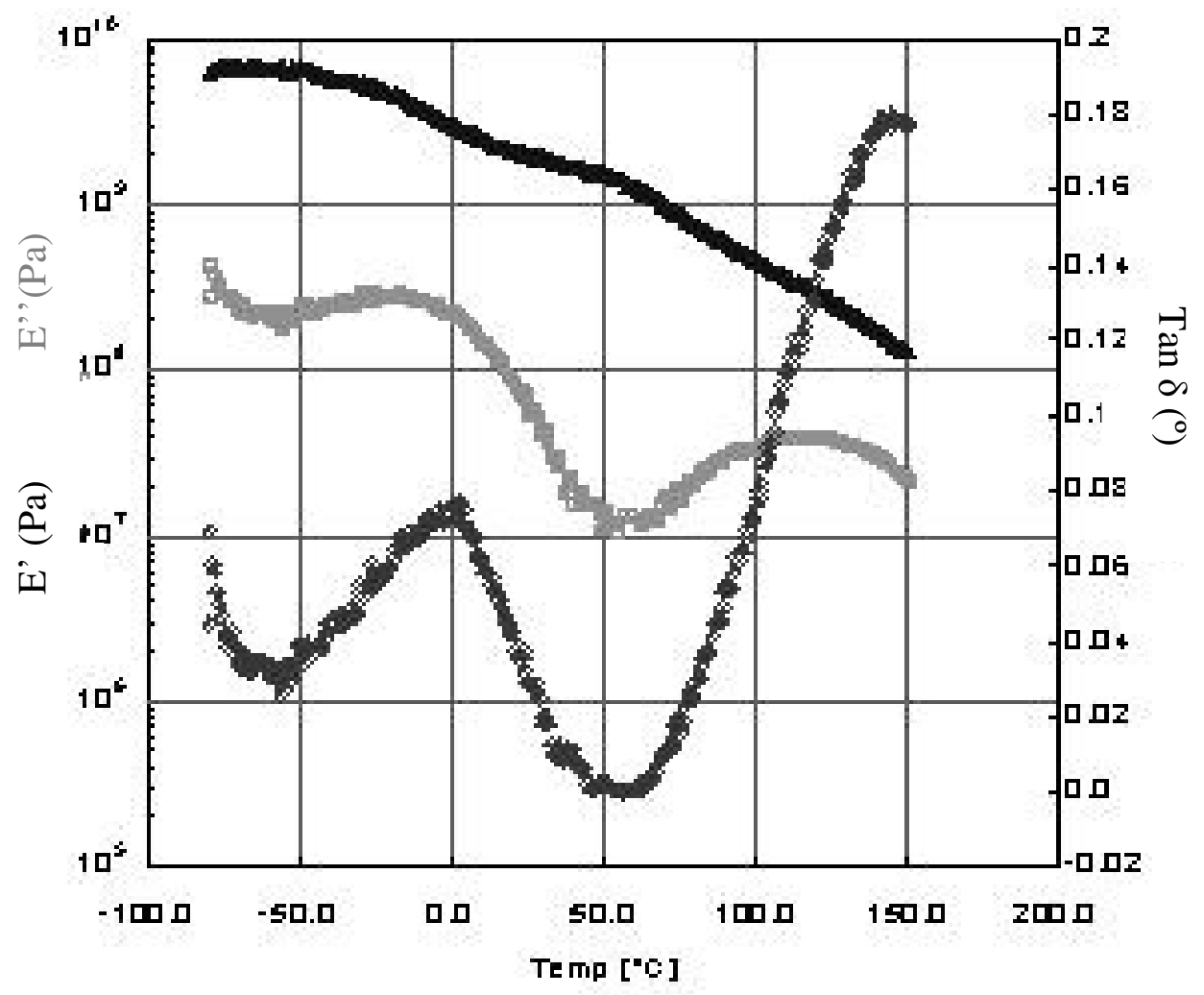

Figura 63: DMTA da blenda PHB/PEG de composição 95/05

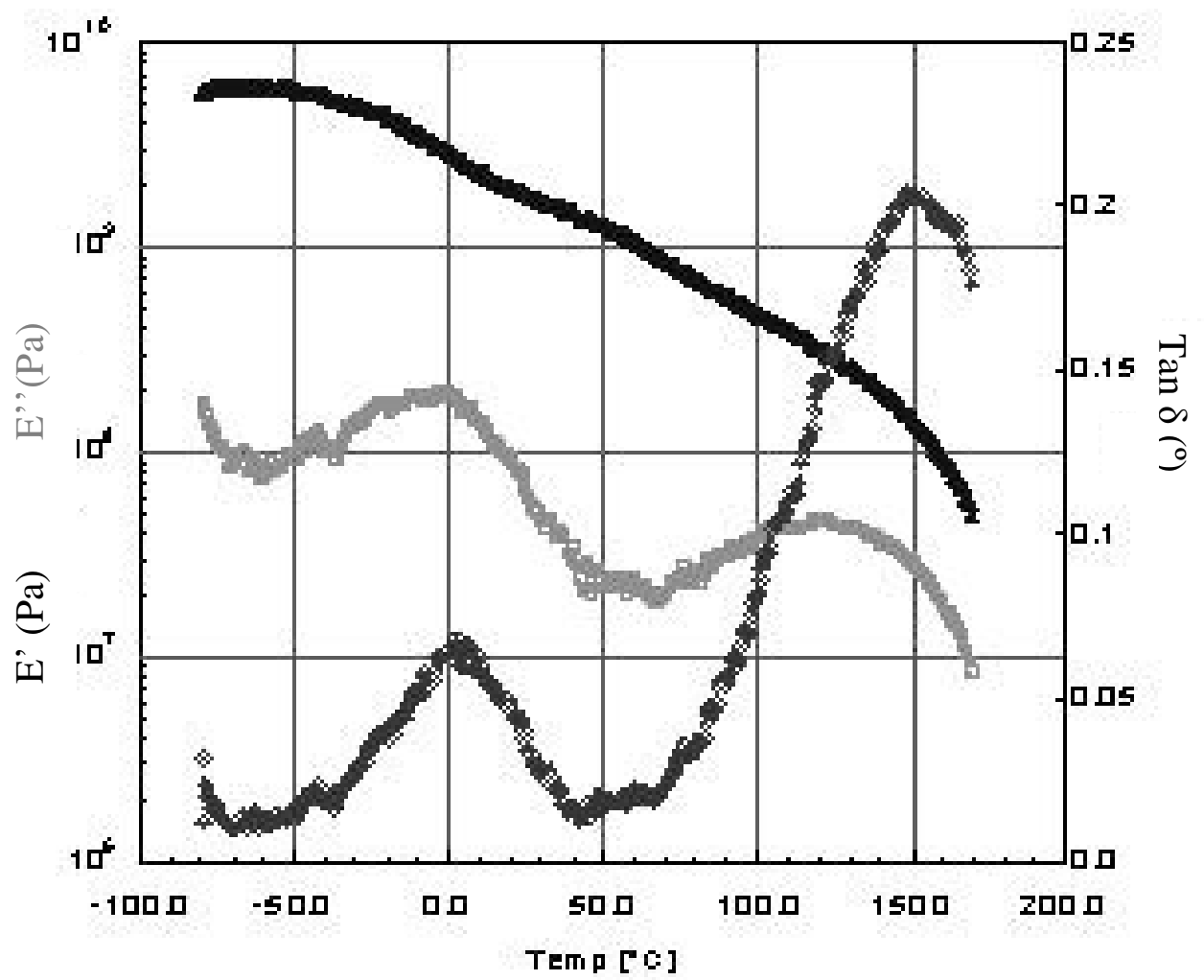

Figura 64: DMTA da blenda PHB/PEO de composição 95/05 


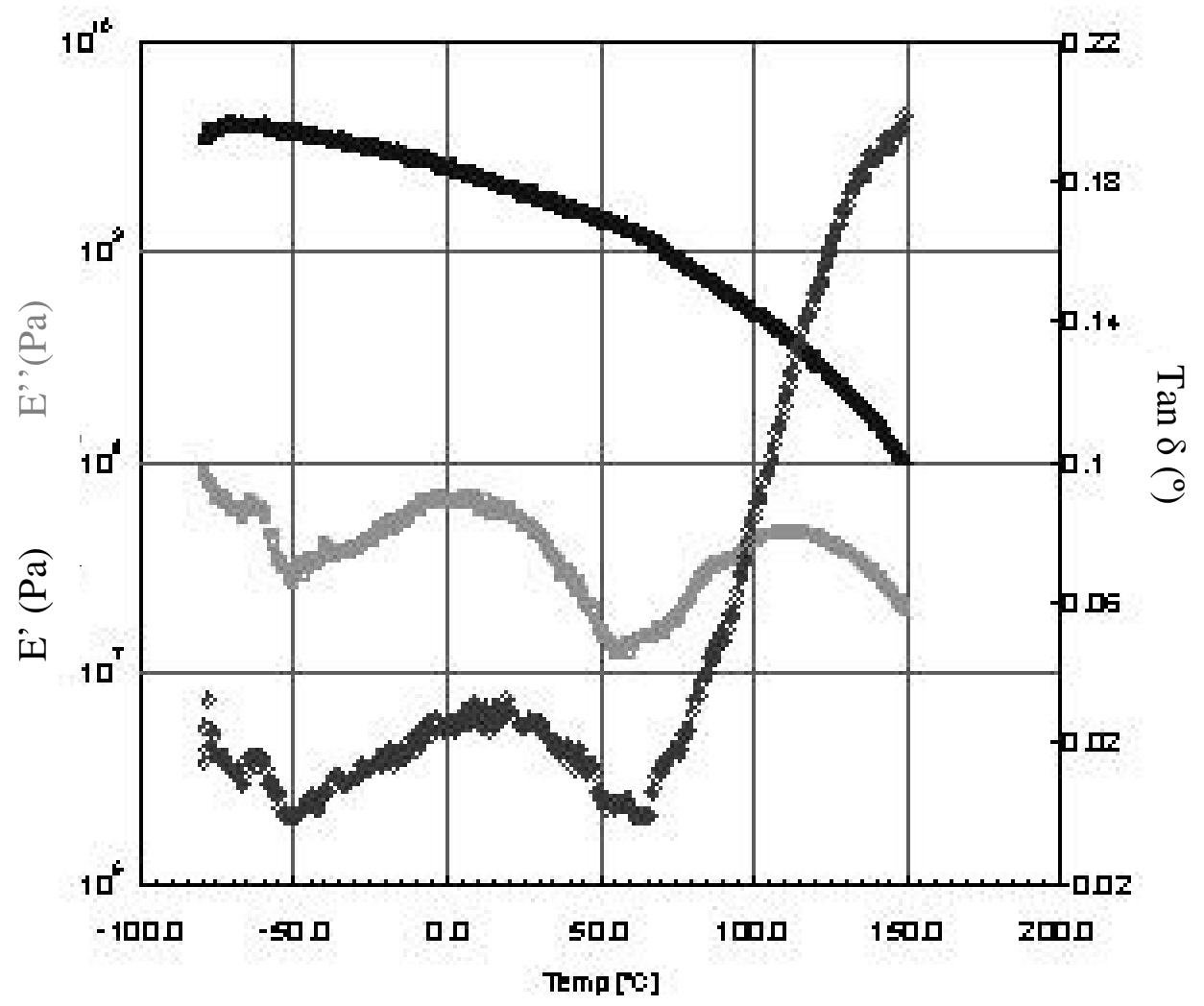

Figura 65: DMTA da blenda PHB/PEG de composição 80/20

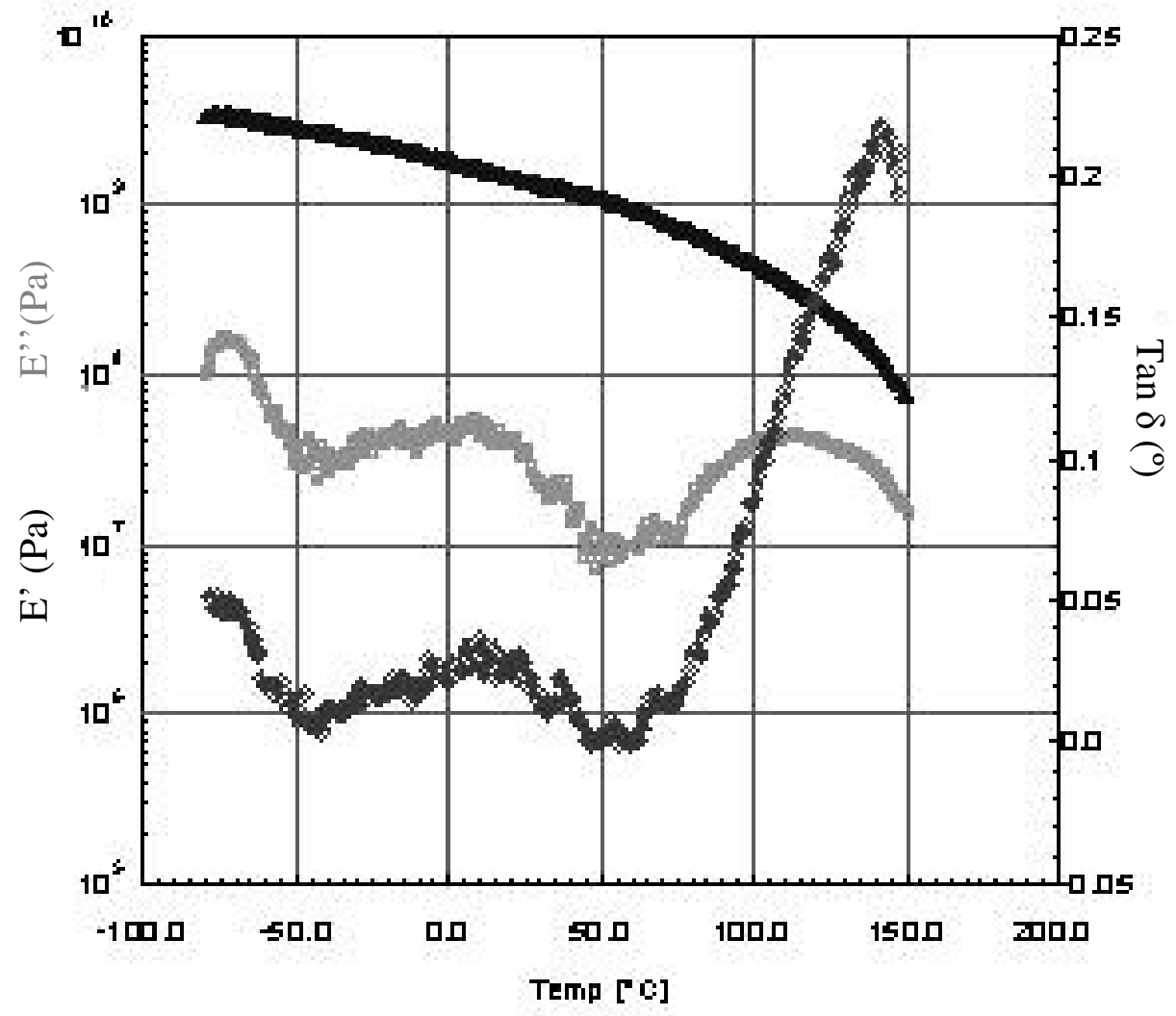

Figura 66: DMTA da blenda PHB/PEG de composição 70/30 
Tabela 10 - Características das blendas

\begin{tabular}{|c|c|c|c|}
\hline Blenda & \multicolumn{2}{|c|}{$\begin{array}{c}\text { composição } \\
\text { (massa \%) }\end{array}$} & $\begin{array}{c}\operatorname{tg} \delta^{(\mathbf{c})} \\
-\mathrm{T}_{\mathrm{g}}-\end{array}$ \\
\hline & PHB & PEG/PEO & $\left({ }^{\circ} \mathrm{C}\right)$ \\
\hline PHB/PEG-30 $^{(\text {a) }}$ & 70 & 30 & 14,9 \\
\hline PHB/PEG-20 $^{(\mathbf{a})}$ & 80 & 20 & 12,1 \\
\hline PHB/PEG-10 $^{(\mathbf{a})}$ & 90 & 10 & 11,4 \\
\hline PHB/PEG-05 $^{\text {(a) }}$ & 95 & 5 & $-0,5$ \\
\hline PHB/PEO-05 $^{(\mathbf{b})}$ & 95 & 5 & 2,1 \\
\hline
\end{tabular}

Aonde:

Massa molar do PEG $=(a) 300 \mathrm{~g} \cdot \mathrm{mol}^{-1}$, (b) $4 \times 10^{6} \mathrm{~g} \cdot \mathrm{mol}^{-1}$;

Massa molar do PHB: $2.63 \times 10^{5} \mathrm{~g} \cdot \mathrm{mol}^{-1}$.

Temperatura de transição:

(c) pico de tangente de $\delta$ obtido por DMTA.

A frequência utilizada na análise de DMTA provoca um deslocamento na temperatura de transição vítrea, fazendo com que esta apresente um valor ligeiramente maior do que a medida por meio do DSC (Tabela 10).

Para todas as blendas, a análise de DMTA (Figuras 63 à 66 e Tabela 10) revelou uma larga relaxação mecânica, associada à temperatura de transição vítrea na faixa de -50 a $50 \stackrel{\circ}{ }$ C (módulo de perda $E "$ e tg $\delta$ ), que se manteve na mesma faixa de temperaturas independentemente da composição e concentração da blenda.

Apesar disto o módulo de armazenamento E' decresceu com o aumento da concentração de PEG na blenda, e, comparativamente, blendas com PEO apresentavam maior rigidez do que as com PEG durante toda a faixa de temperaturas analisada. A $25 \stackrel{\circ}{\circ}$, o E' das blendas se encontrava na faixa de 1.5 GPa a $2 \mathrm{GPa}$, comparável a de termoplásticos flexíveis, como o polietileno e 0 polipropileno.

\section{Conclusões}


As curvas de DSC são caracterizadas pela redução da $T_{m}$ do $\mathrm{PHB}$ e pela ausência de picos de fusão para o PEG/PEO no primeiro ciclo de aquecimento. Estes fatores levam à conclusão de que existe uma forte interação entre o PHB e o PEG/PEO que leva a um possível aumento da janela de processabilidade do polímero.

Os cálculos feitos à partir das curvas de DSC mostram também que o material sujeito a um ciclo térmico apresenta maior grau de cristalinidade em comparação ao material testado sem exposição ao calor.

O dados obtidos pela análise termogravimétrica (TG) e sua diferencial (DTG) também levam à conclusão de que existe miscibilidade entre os polímeros, uma vez que a temperatura de degradação do PHB foi sensivelmente alterada e é observada apenas uma etapa principal de degradação, sendo que as duas etapas principais de perda de massa não correspondem às proporções mássicas dos constituintes da blenda.

Percebe-se que o PEG em concentrações maiores que $10 \%$ em massa reduz significativamente a temperatura de degradação do PHB, o que não é interessante. Para uma maior resistência térmica, uma boa composição seria entre 5 e $10 \%$ em massa de PEG.

Através das fotos de MEV conclui-se que, apesar da miscibilidade entre os polímeros ocorrer, existe também uma segregação de fases que aumenta sensivelmente com o tempo de estocagem do material, esta segregação de fases provoca a recristalização do $\mathrm{PHB}$, que é responsável pelo endurecimento e fragilização observados nas amostras envelhecidas.

A difração de raios-X nos mostra que a adição de PEG/PEO ao PHB traz uma redução considerável para a cristalinidade do sistema, e que o aumento de $5 \%$ para $30 \%$ no teor de PEG é responsável por apenas uma pequena redução na cristalinidade, mas uma considerável redução na recristalização sofrida pela blenda com o tempo de estocagem. A adição de 5 \% em massa de PEO traz por sua vez uma menor redução inicial na cristalinidade mas mantém esse efeito com o tempo.

As análises de DMTA demonstram que o módulo de armazenamento E' decresce com o aumento da concentração de PEG na blenda e que blendas com PEO apresentam maior rigidez do que as com PEG. O DMTA também demonstra que as amostras foram tenacificadas, uma vez que em temperatura ambiente, as 
blendas apresentam um E' comparável a de termoplásticos flexíveis, como o polietileno e o polipropileno.

Através dos resultados dos ensaios realizados, chega-se a conclusão de que a blenda entre PHB/PEG de composição 95 \% e 05 \% em massa, respectivamente, é uma composição ótima, relativamente às amostras estudadas, uma vez que esta apresenta uma boa redução da $\mathrm{T}_{\mathrm{m}}$ sem o comprometimento da temperatura de degradação, como a demonstrada em blendas com maiores teores de PEG, obtendo-se assim uma boa janela de processabilidade.

Esta composição também demonstrou uma certa resistência ao tempo de estocagem, além de apresentado uma boa redução grau de cristalinidade, e, portanto, uma provável melhora nas propriedades mecânicas, processabilidade e estabilidade em função do tempo em relação ao $\mathrm{PHB}$ e às blendas com concentrações maiores de PEG. 


\section{Referências Bibliográficas}

1. CABRAL, J.G. Processamento de poli(3-hidroxibutirato) através de moagem de alta energia, 2005, Dissertação de Mestrado, Universidade de São Paulo, SP, Brasil.

2. HARDY, J. Chemicals and fuels from Biomass. Department of Chemistry - The University of York, U.S.A., 2001.

3. LEE, S. Y.; CHOI, J.; Polym. Degrad. Stab. 1998, 59, 387.

4. RAGHAVAN, D.; Polym. Plast. Technol. Eng. 1995, 42, 41.

5. ROSA, D. S.; LOTTO, N. T.; GUEDES, C. G. F.; Polym. Test. 2004, 23, 3.

6. REDDY, C. S. K.; GHAI, R; RASHIMI; KALIA, V. C.; Bioresour. Technol. 2003, $87,137$.

7. KORNER, I.; REDEMANN, K.; STEGMANN, R.; Waste Manag. 2005, 25, 409.

8. CHANDRA, R.; RUSTGI, R.; Prog. Polym. Sci. 1998, 23, 1273.

9. NONATO, R. V.; MANTELATtO, P. E.; ROSSELL, C. E. V.; Appl. Microbiol. Biotechnol. 2001, 57, 1.

10. BERTRAND, J. L.; PhD Thesis, Université de Montreal, Canadá, 1992.

11. GOMES, J. G. C.; BUENO NETTO, C. L.; Rev. Bras. Eng. Quim. 1997, 17, 24.

12. AMASS, W.; AMASS, A.; TIGHE, B.; Polym. Int. 1998, 47, 89.

13. VENDRUSCOLO, C. W.; ANDREAZZA, I. F.; GANTER, J. L. M. S.; FERRERO, C.; BRESOLIN, T. M. B.; Int. J. Pharm. 2005, 296, 1.

14. SANTOS, H.; VEIGA, F.; PINA, M. E.; SOUZA, J. J.; Int. J. Pharm. 2005, 295, 15.

15. KHANNA, S.; SRIVASTAVA, A. K.; Process Biochem. 2005, 40, 607. 
16. ARVANITOYANNIS, I.; BILIADERIS, C. G.; OGAWA, H.; KAWASAKI, N.; Carbohydr. Polym. 1998, 36, 89.

17. TUdORACHI, N.; CASCAVAL, C. N.; RUSU, N.; PRUTEANU, M.; Polym. Test. 2000, 19, 785.

18. LEHNINGER, A. L.; NELSON, D. L.; Cox, M. M.; Principles of Biochemistry, 2nd ed., Worth Publisher, Inc.: New York, 1993.

19. KOIZUMI, F.; ABE, H.; DOI, Y.; J. Mat. Sci.- Pure Appl. Chem. 1995, A 32, 759.

20. DU, G. C.; CHEN, J.; YU, J.; LUN, S.; Biochem. Eng. J. 2001, 8, 103.

21. KONING, G.; WITHOLT, B.; Mater. Sci Eng., C 1996, 4, 121.

22. GRACIDA, J.; ALBA, J.; CARDOSO, J.; PEREZ-GUEVARA, F.; Polym. Degrad. Stab.2004, 83, 247.

23. LIGGAT, J. Editorial PHB and Hydroxyalkanoate Polymers. Polymer International, v.39, 1996.

24. CHEN, L.J.; WANG, M. Production and Evaluation of Biodegradable Composites based on PHB-PHV Copolymer. Biomaterials, v.23, 2002.

25. GALEGO, N.; ROZSA, C.; SANCHEZ, R.; FUNG, J.; VÁZQUEZ, A.; TOMAS, J.S. Characterization and Application of Poly(b-hydroxybutyrate) family as composite biomaterials. Polymer Testing, v.19, 2000.

26. WANG, Y.; AMEER. G.A.; SHEPPARD, B.J.; LANGER, R. A tough biodegradable elastomer. Nature Biotechnology, v.20, june 2002.

27. PATEL, M.; BASTIOLI,C.; MARINI, L. Environmental Assessment of Biobased Polymers and Natural Fibers. Utrecht University, Utrecht, Netherland,2003.

28. WEBER, C. J. Biobased Packaging Materials for the Food Industry - Status and Perspectives. The Royal Veterinary and Agricultural University, Denmark, 2000. 
29. INOUE,Y.; YOSHIE, N. "Structure and physical properties of bacterially synthesized polyesters", Progress in Polymer Science, 17, 571-610, 1992.

30. www.biocycle.com.br, visualização do dia 25/07/2011.

31. GHAFFAR. A.M.E.H.A. Development of a Biodegradable Material Based on Poly(3-hydroxybutyrate) PHB. 2002. Tese de Doutorado - University of HalleWittenberg, Halle, Germany.

32. AN, Y.; LI, L.; DONG, L.; MO, Z.; FENG, Z. Nonisothermal Crystallization and Melting Behaviour of Poly(b-hydroxybutyrate)-Poly(vinil-acetate) blends. Journal of Polymer Science: Part B - Polymer Phisics, v.37, 1999.

33. ROSA, D.S.; PENTEADO, D.F.; CALIL, M.R. Avaliação das Propriedades Térmicas, Morfológicas e a Relação com a Biodegradabilidade em Fungos e Bactérias de PCL e PHB. Grupo de Polímeros Biodegradáveis, CCET/USF-Itatiba SP, 2003.

34. http://www.aeaarp.org.br/uploads/SMA2009/BIOCYCLE-III\%20-\%20030609.pdf, visualização do dia 24/07/2011.

35. http://www.mercadodeplasticos.com/modules/popnupblog/index.php?postid=13

36. WU, C.; GAN, Z.; Polymer 1998, 18, 4429.

37. SCOTT, G.; Polym. Degrad. Stab. 2000, 68, 1.

38. ABOU-ZEID, D. M.; MULLER, R. J.; DECKWER, W. D.; J. Biotechnol. 2001, 86, 113.

39. ZUCHOWSKA, D.; HLAVATÁ, D.; STELLER, R.; ADAMIAK, W.; MEISSNER, W.; Polym. Degrad. Stab. 1999, 64, 339.

40. FLEMMING, H. C.; Polym. Degrad, Stab. 1998, 59, 309.

41. DI LORENZO, M. L.; "Spherulite growth rates in binary polymer blends", Progress in Polymer Science 28 (2003) 663-689 
42. EL-HADI, A., SCHNABEL, R., STRAUBE, E. et al, "Correlation between Degree of Crystallinity, Morphology, Glass Temperature, Mechanical Properties and Biodegradation of Poly (3-hydroxyalkanoate) PHAs and their Blends", Polymer Testing, v. 21, pp. 665-674, 2002.

43. DE KONING, G.J.M.; SCHEEREN, A.H.C; LEMSTRA, P.J., "Crystallization phenomena in bacterial poly[(R)-3-hydroxybutyrate]: 3. Toughening via texture changes", Eindhoven University of Technology, Eindhoven, Holanda.

44. CHIU, H.J.; YOU, J.W.; DON, T.M., "Spherulitic morphology and crystallization kinetics of melt-miscible blends of poly(3-hydroxybutyrate) with low molecular weight poly(ethylene oxide)", Polymer 44 (2003) 4355-4362.

45. DE KONIG, G.J.M., LAMSTRA, P.J., Polymer 34 (1993) 4089.

46. HOLMES, P.A., Phys. Technol. 16 (1985) 32.

47. EL-HADI, A., Ph.D. thesis, Martin-Luther University of Halle, Germany, 2001.

48. ZWEIFEL, H., MAIER, R.D., SCHILLER, Plastics Additives Handbook, 6 ed.,Cincinnati, Ohio, Hanser, 2009.

49. MACEDO, J. S.; "Desenvolvimento de biocompósitos a base de polihidróxibutirato e resíduos do processamento de fibras de casca de coco", Tese de Doutorado, Universidade Federal do Rio de Janeiro, Rio de Janeiro, 2010.

50. ROA, J. P. B., SOUZA N. J., LAGO, R. M., PATRÍCIO, P. S. O.; Estudos das propredades térmicas e morfológicas das blendas PHB/PEG, 10ํㅡㄹ Congresso Brasileiro de Polímeros - Foz do Iguaçu, PR - Outubro/2009.

51. CHAN, R. T. H., MARÇAL, H., RUSSEL, R. A., HOLDEN P. J., FOSTER L. J. R.; Application of Polyethylene Glycol to Promote Cellular Biocompatibility of Polyhydroxybutyrate Films, International Journal of Polymer Science, 2011.

52. SPERLING, L. H.; Introduction to Physical Polymer Science, Wiley-Interscience, 2001, p 136-143 e 580-585. 
53. ANDERSEN, Bistra; Investigations on Environmental Stress Cracking Resistance of LDPE/EVA Blends, 2004, Tese de doutorado, Universidade Martin-Luther, Halle-Wittenberg, Alemanha.

54. ANDRADE, M. L. Estudo fotofísico em blendas parcialmente miscíveis de poli(metacrilato de alquila-co-estireno)/poliestireno, Tese Doutorado, Universidade Estadual de Campinas, Instituto de Química, 2003.

55. PARRA, D.F.; RODRIGUES, J.A.F.R; LUGÃO, A.B., Crystallization on films of PHB/PEG blends. Evaluation by DSC. Journal of Thermal Analysis and Calorimetry, Vol. 79 (2005) 379-381.

56. DRUMOND, W.S.; MOTHÉ, C.; WANG, S.H., Quantitative analysis of biodegradable amphiphilic poly(I-lactide)-block-poly(ethylene glycol)-block-poly(Ilactide) by using TGA, FTIR and NMR. Journal of Thermal Analysis and Calorimetry, Vol. 85 (2006) 1, 173-177.

57. AVELLA, M.; MARTUSCELLI, E., Poly-D-(3-hydroxybutyrate)/poly(ethyleneoxide) blends: phase diagram, thermal and crystallization behaviour. Polymer 1988, 29,1731-1737.

58. MARCHESSAULT, R.H.; PEARCE, R., "Multiple melting in blends of isotactic and atactic poly(fl-hydroxybutyrate)", McGill University, Montreal Quebec, Canada, 1994 